\title{
Laser Induced Neuro-Stimulation Analysis For \\ Potential Treatment Of Post-Traumatic Stress Disorder \\ by
}

Kavleen Aulakh

\begin{abstract}
A thesis submitted to the
Faculty of Graduate and Postdoctoral Affairs

in partial fulfillment of the requirements for the degree of

Master of Applied Science

in
\end{abstract}

\section{Electrical and Computer Engineering}

Carleton University

Ottawa, Ontario

(C) 2016, Kavleen Aulakh 


\begin{abstract}
Patients suffering from Post-Traumatic Stress Disorder (PTSD), often experience reduced adenosine triphosphate (ATP) production which leads to decreased neurotransmission ability. The focus of this dissertation is to establish the correlation between the photosensitivity of ATP release and (PTSD).

The aim is to exploit the effectiveness of neuro-stimulation to yield higher ATP levels in cells and tissues when induced with a near infrared laser $(808 \mathrm{~nm})$. This is addressed by examining the transmittance of light through a variety of transcranial samples obtained from animal models. The study also highlights the comparative analysis of the efficacy of high power laser light on the viability and ATP productivity in neuroblastoma cells (SH-SY5Y) versus cortical neurons (M-CX-400).
\end{abstract}

The outcome of the light tissue interactions with skin, bone, fat and neuro-muscular tissues revealed an inverse and logarithmic relationship between penetration depth and the intensity of light. The most effective dosage, irradiated time and the power for light stimulation was observed to be $50 \mathrm{~J} / \mathrm{m}^{2}, 10$ secs to $3 \mathrm{~min}, 500 \mathrm{~mW}$ respectively. The cell viability analysis proved the robustness nature of SH-SY5Y cells compared to cortical neurons. On light stimulation, the ATP levels of cortical neurons increased by a factor of 4.5, when irradiated at $500 \mathrm{~mW}$ of power.

The findings shed light on the fundamental optical parameters for photo-bio stimulation and their relevance to the post cellular responses of photosensitive compounds. Thereby, providing guidelines for prototyping low cost and highly effective bio-photonic medical devices, for the potential treatment of PTSD. 


\section{ACKNOWLEDGEMENT}

I would like to express my deep gratitude towards my co-supervisor Dr. William Willmore, my supervisor Dr. Winnie Ye and their respective teams for their timely guidance, support and motivation for the successful completion of my dissertation.

I am also indebted towards Mr. Nagui Mikhail (the hidden hero, department of electronics) for his efforts in helping me setup my test lab. This project would have been incomplete without the expert advice and technologies contributed by Allied Scientific Pro, Ottawa Heart Institute and the University of Ottawa.

It would have been impossible for me to finish this endeavor without your support, constructive criticism and guidance. I am indeed grateful and warmly appreciate all your efforts.

Finally, I would like to dedicate my work to my parents. 


\section{TABLE OF CONTENTS}

ABSTRACT ............................................................................................................................ i

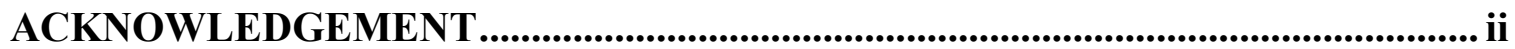

TABLE OF CONTENTS ......................................................................................... iii

LIST OF TABLES .............................................................................................................. v

LIST OF FIGURES ......................................................................................................... v

LIST OF ABBREVIATIONS ................................................................................................ vi

CHAPTER 1: INTRODUCTION.............................................................................. 1

1.1 THESIS OBJECTIVE ............................................................................................... 11

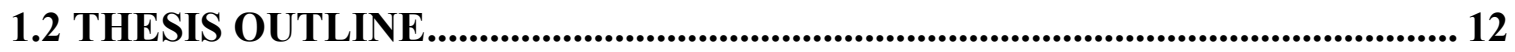

CHAPTER 2 :LITERATURE REVIEW ................................................................. 14

CHAPTER 3 :EXPERIMENTAL METHODOLOGY ................................................. 24

$3.1 \quad$ MATERIAL BACKGROUND ........................................................................... 24

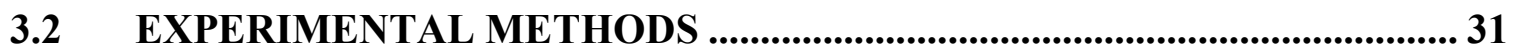

CHAPTER 4: EXPERIMENTAL RESULTS................................................................ 35

4.1 ABSORPTION SPECTRUM VERSUS PENETRATION DEPTH IN

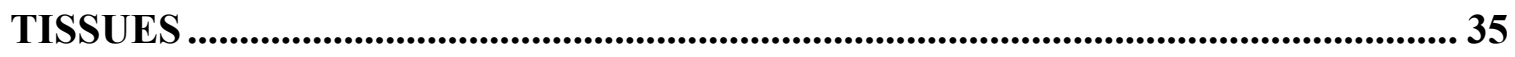

4.2 CELL VIABILITY (3-(4,5-DIMETHYLTHIAZOL-2-YL)-2,5-

DIPHENYLTETRAZOLIUM BROMIDE (MTT) ASSAY ......................................... 43 


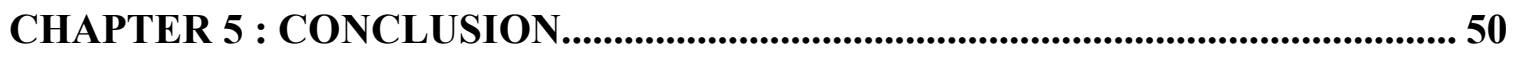

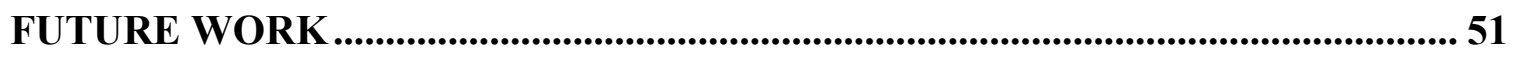

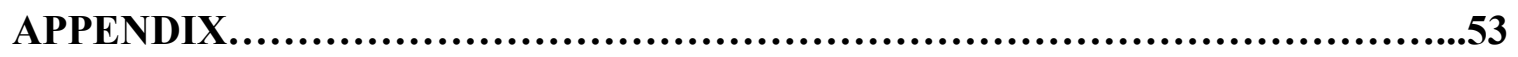

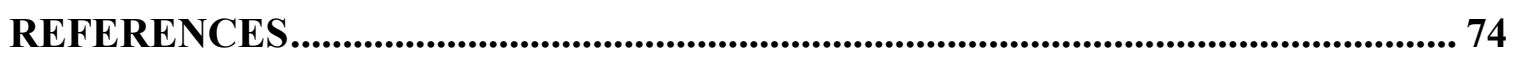




\section{LIST OF TABLES}

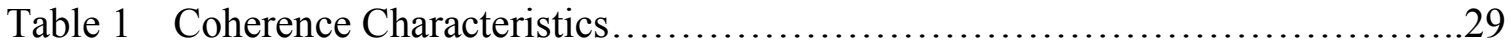

Table 2 Data for delivering dose corresponding to $50 \mathrm{~J} / \mathrm{m}^{2}$ at $500 \mathrm{~mW}$ of power ......... 41

\section{LIST OF FIGURES}

Figure 1 Mitochondria and its inner structure ............................................................. 7

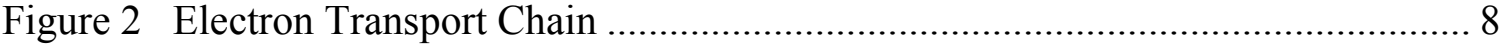

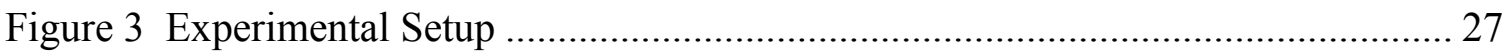

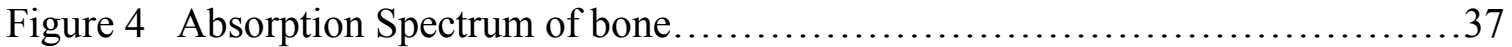

Figure 5 Absorption spectrum of neuromuscular tissues.............................................. 38

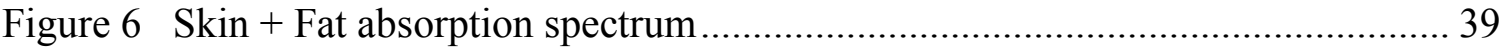

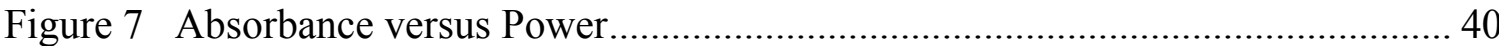

Figure 8 Modeling of irradiation time and pig's brain penetration depth...................... 42

Figure 9 MTT analysis for SH-SY5Y at low power treatments .................................... 44

Figure 10 MTT analysis for SH-SY5Y at high power treatments ....................44

Figure 11 MTT analysis for Neurons at low power treatments ..................................... 46

Figure 12 Luciferase-luciferin analysis for SH-SY5Y at low power treatments..........47

Figure 13 Luciferase- luciferin analysis for neurons at low- high power treatments ......48 


\section{LIST OF ABBREVIATIONS}

\begin{tabular}{|l|l|}
\hline ADP & Adenosine diphosphate \\
\hline APA & American Psychiatric Association \\
\hline ATCC & American Type Culture Collection \\
\hline ATP & Adenosine triphosphate \\
\hline CAF & Canadian Armed Forces \\
\hline DMSO & Dimethyl Sulfoxide \\
\hline DSM & Diagnostic and Statistical Manual of Mental Disorders \\
\hline DTT & Dithiothreitol \\
\hline EGTA & Ethylene Glycol Tetra-acetic Acid \\
\hline EMDR & Eye Movement Desensitization and Reprocessing \\
\hline FALS & Familial Amyotrophic Lateral Sclerosis \\
\hline FDA & Food and Drug Administration \\
\hline Fe-S & Iron sulfide \\
\hline $5-$ HIAA & 5 -Hydroxyindoleacetic Acid \\
\hline HPA & Hypothalamic-Pituitary-Adrenal \\
\hline LED & Light Emitting Diode \\
\hline
\end{tabular}




\begin{tabular}{|l|l|}
\hline$m$-TBI & mild Traumatic Brain Injury \\
\hline NADH & Nicotinamide Adenine Dinucleotide \\
\hline NCS & National Comorbidity Survey \\
\hline NHNP & Normal Human Neural Progenitors \\
\hline NIHSS & National Institute of Health Stroke Scale \\
\hline NIR & Near Infrared \\
\hline PKC & Protein Kinase C \\
\hline PRGC & Photosensitive Retinal Ganglion Cells \\
\hline PTSD & Post-Traumatic Stress Disorder \\
\hline RBC & Red Blood Cells \\
\hline RSCEM & Rabbit Small Clot Embolic Stroke Model \\
\hline TBS & Theta Burst Stimulation \\
\hline TCA & Tricarboxylic Acid \\
\hline TDC & Transcranial Direct Current Stimulation \\
\hline TLCT & Transcranial Light Emitting Diode Therapy \\
\hline TMS & Transcranial Magnetic Stimulation \\
\hline
\end{tabular}




\section{CHAPTER 1}

\section{INTRODUCTION}

"Don't become a mere recorder of facts, but try to penetrate the mystery of their origin"

-Ivan Pavlov

Eighty years ago, the Russian physiologist stated the exact purpose of my research towards PTSD. This disorder is evident in individuals, who have either witnessed or experienced any traumatic event such as sexual violence, war, natural disaster or any other kind of event, which leads to a mental imbalance.

The study highlights the significance of photosensitive biological compounds (ATP) for treating PTSD. Thereby, introducing a novel methodology for the treatment of symptoms of PTSD, which are specifically observed in war veterans, military officials and the general population.

Recently, Brunet et al [1] studied the lifetime prevalence rate of PTSD in the Canadian Armed Forces (CAF). It was found that $85.6 \%$ of military officials have been exposed to trauma. Moreover, Erickson et al [2] analyzed the gender based statistical data for major depressive disorders and compared the CAF with the general population, indicating $89 \%$ of officers (male/female), suffering from the discouraging attitude towards life.

In addition, the 2015 Fall Reports of the Minister of Veteran Affairs [3] reveals that 1 amongst 10 of Canadian military officials involved in the Afghanistan mission was 
being treated for PTSD (i.e. 3,578 clients and 14,732 clients). Likewise, the National Comorbidity Survey (NCS) report [4] addressed the lifetime prevailing symptoms of PTSD among adult Americans, which ranged from $7.8 \%$ to $10.4 \%$. However, it varied from $26.9 \%$ to $30.9 \%$ in war veterans [5]. Above all, Canada witnessed 8 official deaths by 4 February 2016, due to PTSD [6]. This has led to a global concern and the need of the hour is to develop strict measures for reducing the effects of PTSD.

Initially in 1980, American Psychiatric Association (APA) included PTSD into Third Degree of the Diagnostic and Statistical Manual of Mental disorders (DSM-III) [7], stating the traumatic events as catastrophic stressed events. However, with the increase in lifespan, clinical trials and literature reviews, PTSD has been categorized as DSM-V [8], implied as Trauma and Stressor Related Disorders. This resulted in upgraded diagnostic criteria which include the mechanistic explanations of the behavioral symptoms. Moreover, it incorporates 4 distinct diagnostic factors which include re-experiencing the traumatic event, avoidance pertaining to stressful memories, negative moods and arousal of aggression or self-destructive attitude. Although, facts from DSM-IV [9], like the significant functional criterion, exclusion criterion referring to non-medicinal side effects and the duration criterion of at least 1 month before being diagnosed with PTSD are included in DSM-V [8]. It has also been categorized based on age group, which considers children aged below 6 years having the prominent symptoms of disassociation with the rest of the world.

Developing a more effective and efficient treatment requires a detailed understanding of both the root cause of the problem and the study of their treatments. On current investigation, it was found that PTSD diagnosis was based on psychological 
analysis followed by antidepressant medications for regulation of the biological responses. However, none of these deliver a quick recovery of PTSD.

Psychotherapies are based on the exposure of incident, majorly focusing on cognitive behavioral treatments which include anxiety management, cognitive exposure and restructuring $[10,11,13]$. In addition, eye movement desensitization and reprocessing (EMDR) $[10,12,13]$, psychodynamic therapy [10,13], hypnotherapy [13] and trauma desensitization [10] have been considered as methods of effective treatment. Lifestyle changes, peer support associations, mind coaching techniques, recovery animals, and mobile applications like a PTSD coach are several accessible self-help options [14].

The malfunctioning of the Hypothalamic-Pituitary-Adrenal (HPA) axis, an imbalance in the neurotransmission circuitry and the fluctuations in adrenergic mechanisms are the major reasons contributing towards the biological disturbance in PTSD patients $[15,16]$. This leads to the weakness in the prefrontal cortex, resulting in the inability of patients to decide on and execute daily tasks $[16,17]$. Thereby, patients get triggered by the response called "flight or fight" [16]. In contrast, the physical shrinkage of the hippocampus [18] is also witnessed in such patients, which induces a feedback loop of cortisol in their adrenal system, leading to suicidal attempts and anxiety attacks.

Based on the psychological analysis, the neurotransmission activities have been regulated through medication. The main neurotransmitters [19] that have been targeted for PTSD are Serotonin, Dopamine and Norepinephrine. These neurotransmitters each have unique functionalities, however, when combined, they control cognitive functions and mood. Moreover, neurotransmitter synthesis has an indirect relationship with ATP 
productivity. For example, ATP and Tyrosine combine in chromaffin cells to produce Dopamine. Similarly, Dopamine catalytic reaction with dopamine $\beta$ - hydroxylase produces Norepinephrine [20]. However, Serotonin synthesis is initiated using amino acid tryptophan, which further gets destroyed by 5-HIAA (which is produced by serotonergic neuron mitochondria) [21]. Thus, its association with the mitochondrial respiration minimizes the probability for direct photo-stimulation. Hence, the photosensitive nature of dopamine and norepinephrine increases their probability for boosting the reactions through direct stimulation.

The stimulation of biological specimens or the light therapy has been explored since ancient times. The Greek Mythology, reveals the existence of Heliopolis (city of sun). This city was known for the healing temples, which used polychromatic polarized light [22]. Further in 1876, blue light was used to stimulate the nervous system [23] and the secretory glands [23]. It was also responsible for the successful treatment of Solar Elixirs [24]. However, light therapy gained recognition in 1900's, when Dr. N. R Finsen used continuous wave of red and UV part of sunlight for successful treatments of smallpox, lupus and skin tuberculosis. The main focus of wavelength ranged from $400-750 \mathrm{~nm}$. This light based therapy was termed as Contemporary phototherapy $[25,26]$, which led to the evolution of various health treatments.

Sooner, in 1920's Dr. Spitler H. R. contemplated the principles of modern ocular phototherapy (Syntonic) [27], which represents the balancing of parasympathetic and sympathetic nervous system. This was followed by practicing all kinds of experiments with sun lamps to treat circulatory diseases [28] and many other degenerative disorders such as peritonitis [29]. 
However, the entire phenomenon of treatments gained a whole new perspective with the use of a laser for stimulating biological specimens to cure diseases. It began in 1960's with the use of ruby laser [30], followed by Helium-Neon laser [31] and eventually advancing to semiconductor medical laser and Light-emitting diodes [32]. These lasers targeted the wavelengths ranging from $630-950 \mathrm{~nm}$. And were used to study the noninvasive techniques for wound repair [33], treatments for inflammatory conditions [34], ulcers [35], autoimmune diseases [36] and many more. It has been accomplished to such an extent that today we have Food and Drug Administration (FDA) approved blue light therapy [37] for curing acne. Earlier the treatments used a short spectrum of light, but now it involves the entire therapeutic window from $650-1350 \mathrm{~nm}$. The shift of focus to this window is termed as Low Level Laser Therapy (LLLT) [38]. And, my research also plays a key role in exploring the benefits of LLLT.

LLLT, an emerging technology, is used for stimulating or inhibiting cellular functions [39]. It has been widely used to monitor the production of growth factor, matrix deposition, cell motility and proliferation. Thereby used for tissue repair, prevention, death and ultimately wound healing [40]. It is used to reduce chronic musculoskeletal pains like rheumatoid arthritis [41], lower back pains [42], frozen shoulders [43] etc. It has not only gained its importance for tissue healing but has also done remarkable improvement in dentistry. Dentists are using lasers to cure chronic periodontitis [44], dental implant infections, hypersensitivity and many more dental issues [45]. These lasers are also used by dermatologists to cure skin disorders like pigmentation [46,47], hair loss and hair 
removal [47]. It has also proved its worth, for acupuncture's [48] and minor neurological problems [49].

LLLT utilizes both visible spectrum or near infrared light and the electromagnetic radiation constitutes of both wave and particle-like properties of light. It basically converts the light energy to metabolic energy, which subsequently modulates cell functioning. Hence coined as photo-bio-modulation [50]. The electromagnetic spectrum for LLLT is nontoxic as it only stimulates light- sensitive compounds and hence, no induction of tissue heating takes place when compared to aesthetic lasers. Moreover, it enhances tissue regeneration [50].

The NIR spectrum of LLLT tends to be more powerful when compared to the visible spectrum. The few speculations of the overpowering nature of near infrared are due to its non-ionizing electromagnetic energy. This basically refers to the insufficient quantum energy to produce ionization in molecules. This electromagnetic radiation is just sufficient to excite the bio- molecule to its excited state and cannot completely isolate the electron from within its molecular structure. Also, it has miniscule thermal energy which helps in deep penetration.

Until now, PTSD and LLLT have been briefly discussed. However, the correlation between the two is still missing. When researched, it was found that the pathology of several psychiatric disorders leads to dysfunction of mitochondria and hence reduced genes of mitochondria molecules and lower ATP levels [51,52]. Thereby, it is crucial to understand the mechanism involved in ATP production.

The small rod-shaped organelles in a cell are called Mitochondria. They are the powerhouse of a cell, responsible for oxidative chemical reactions which, produce energy 
in the form of ATP. It is the only organelle, which contains the enzymes for proper regulation of Krebs cycle and respiratory pathway, thus leading to the breakdown of ATP for providing energy to perform various cellular activities.

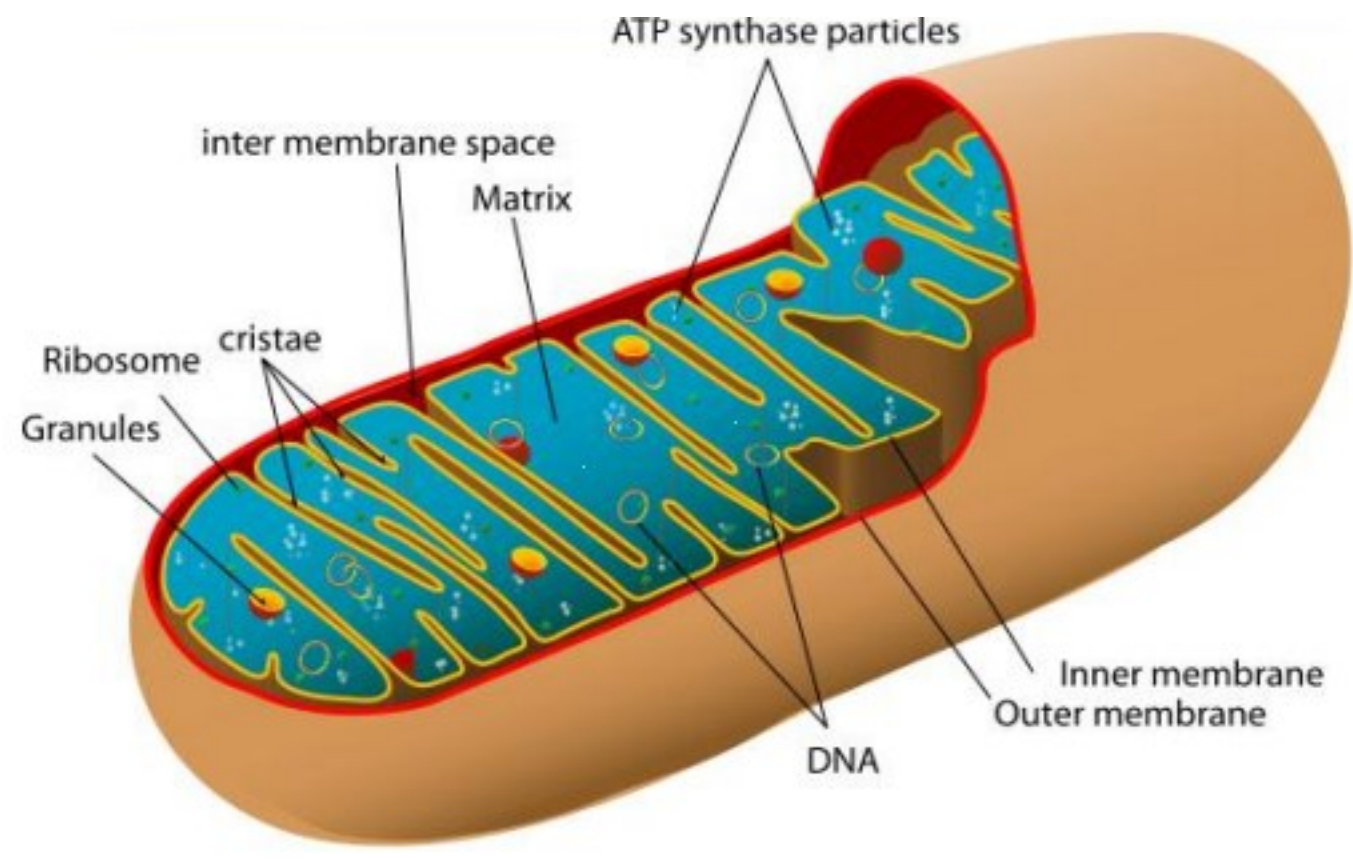

Figure 1: Mitochondria and its inner structure [53]

Krebs cycle or the Tricarboxylic acid (TCA) cycle plays the most important role in the deposition of energy in reduced coenzymes such as Nicotinamide adenine dinucleotide (NADH), which then circulate the energy using electron transport chain [54]. The energy received by the electrons of NADH and the ester formation by the succinic acid in the TCA cycle is transferred to the mitochondrion by undergoing a chain reaction of 5 complex proteins referred as oxidative phosphorylation. This causes a membrane potential which is utilized by complex protein ATP synthase to attain then phosphorylation of adenosine diphosphate (ADP) to ATP. This electron transport chain mainly comprises of 
5 complex proteins. The Figure 2, below provides a detailed description of the electron transport chain.

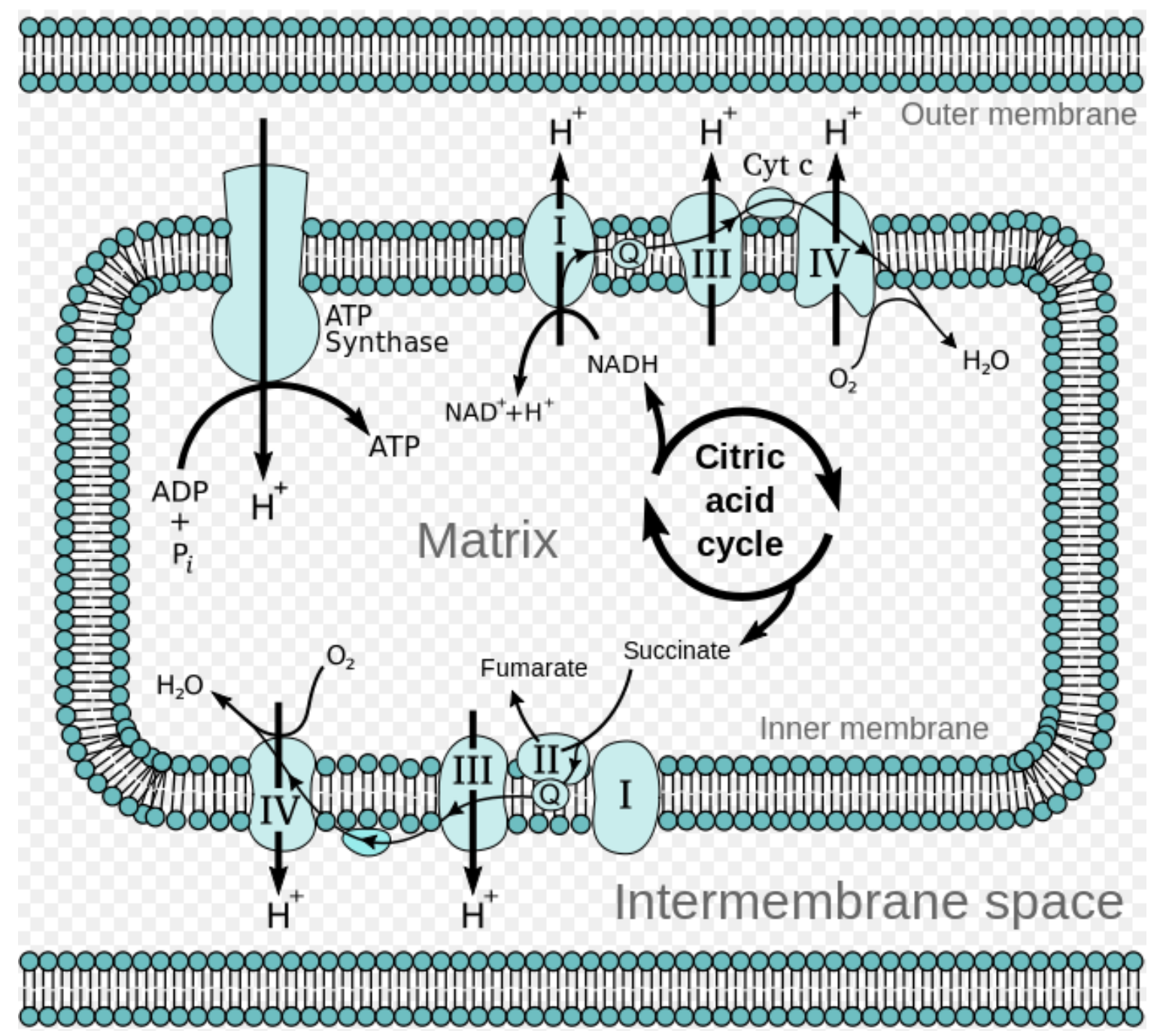

Figure 2: Electron Transport Chain [55]

Initially, NADH reduced coenzyme is attached to complex I, which leads to reduction of coenzyme Q-10. The electrons readily get transferred by complex I using a series of clusters of Fe-S which helps in promoting 4 protons across the intermembrane space of mitochondria. Complex II is the next entry point for electron transfer. It utilizes the product of succinate and converts it into Fumarate. These electrons then undergo 
formation of Complex III, which results in ubiquinol oxidation and 2 molecular reductions of cytochrome C. The Complex IV (Cytochrome C oxidase) is the ultimate complex reaction in this transport chain of electrons. However, this is the most important compound in relation with photo bio-modulation, as this is the only photosensitive compound which can help in increased ATP production within any mitochondrion. Thereby, transporting 10 protons in total for a single NADH. This is followed by ATP synthase for phosphorylation of ADP into the energy articulated molecules (ATP) [54].

Since the commencement of research on light and development of LLLT, researchers concluded that the cytochrome $\mathrm{c}$ oxidase is the complex compound which can undergo full oxidation and reduction. And by comparing the action spectrum with the spectroscopic data, Karu et al [56] suggest that this complex compound is a primary photo acceptor, which is responsible for biological cellular changes when activated by light. However, it is believed that it works best when it is an intermediate stage and is neither fully oxidized nor fully reduced for witnessing any cellular responses. Thus helping in increasing the content of ATP in a cell. She also explains the possible mechanisms which undergo in the photo-sensitive biological specimens [57,123]

Until the beginning of $21^{\text {st }}$ century, it was believed that the best way for neurophotonic simulation was through the eyes [58]. Moreover, the Retinohypothalamic tract plays a crucial role by connecting the parts of the retina to the nervous system which further help to maintain the circadian rhythm. Thus promoting the regulation of hormonal levels and neurotransmitters in various parts of the brain [58]. In addition, the photosensitive ganglion cells also play a major role in sending the signals to the brain, which further affect the neurological functions. It helps in regulating the sleep/wake cycle, neurotransmitter 
levels in the hypothalamus, executive functional responses and ocular physiology. As observed, the wavelength of light which stimulate the functioning of ganglion cells (pRGCs) is approximately $475 \mathrm{~nm}[59,60]$.

However, there have been multiple attempts to reduce the effects of cognitive disorders and hence, improve memory by either using transcranial LED therapy [61] or transcranial magnetic simulations [62]. Clinical trials have been conducted, but it is still not clear if any of the above therapies will be the ultimate solution for the reduction of mental disabilities caused due to any traumatic injuries or hormonal imbalances.

After complete reconsideration of all the facts related to the biological cycle, neurotransmission analysis and the development of LLLT techniques, it was found that entire literature considered continuous wave and only a few, considered the effects of using a pulsed wave. However, for any laser treatments, there are various light attributes (such as coherence), which needs to be taken into consideration. After, evaluating the light attributes, Karu et al demonstrated that the highest stimulating growth of E-coli (in vitro) was observed at dose of $50 \mathrm{~J} / \mathrm{m}^{2}$ [64]. Similarly, erythema reflected the maximum intensity at the same dose [65]. However, Hashmi et al clarifies the importance of pulsed light at LLLT [66]. Duty cycle also plays an important role in enhancing the effect of light therapy. Mantineo et al reflected the importance of selecting $80 \%$ as duty cycle for the reduced inflammation (in vivo) [67,68]. Moreover, Boras et al treated traumatic trigeminal neuropathy, using LLLT with $80 \%$ duty cycle. Hence, in this research, after various trials I preferred using $80 \%$ duty cycle with $50 \mathrm{~J} / \mathrm{m}^{2}$ of dosage. The frequency of $200 \mathrm{~Hz}$ and 700 $\mathrm{Hz}$ were selected after analyzing the effectiveness of LLLT literature $[66,67,123]$. 
However, these parameters may or may not be true for in vivo and clinical trials. The detailed description of these attributes has been discussed in Chapter 3 .

Hence, this dissertation focuses on the use of infrared spectrum range (pulsed) laser, for investigating the effects of laser light, into the excitation of cytochrome c oxidase and eventually analyzing the high yield of ATP molecules in vitro. The main objective was to overcome the mitochondrial dysfunctionality, which leads to PTSD. However, cytochrome c oxidase being the only known photo acceptor and the involvement of cytochrome c oxidase in the Krebs cycle for production of the energy molecules ATP, led us to the hypothesis to study the modulation of this complex compound with respect to PTSD. As seen in depressed clients, ATP levels tend to decrease [51,52]. So, our motive is to harmlessly excite the ATP molecules which might result in positive feedback of HPA axis, resulting in controlled release of neurotransmitters. Hence, leading to the reduced symptoms of PTSD.

\subsection{THESIS OBJECTIVE}

The main objective of this study is to discuss the photo-sensitive nature of all the neurological components such as skin, neuromuscular tissues, brain and neurocranium skull. Hence, understanding the most effective parameters for any transcranial laser treatments. These laser parameters were then explored to analyze the viability and the ATP production when compared to in vitro primary cell line versus the robust neuroblastoma cell line (SH-SY5Y). 
This is a fundamental research which may provide a novel methodology for reducing the symptoms of PTSD. Moreover, it outlines the basic guidelines to guide the designing of an effective medical device for mental disorders.

\subsection{THESIS OUTLINE}

Chapter 1 is the introductory chapter, outlining PTSD, LLLT and the biological mechanisms involved in LLLT. It also correlates ATP productivity with LLLT and PTSD.

Chapter 2 outlines the literature review which was beneficial to formulate the current in vitro research hypothesis. Thereby, formulating the proof of concept.

Chapter 3 describes in detail, the experimental methodology involved in selecting the right parameters for penetration testing thus analyzing the absorbance of biological samples when compared to the high power and large irradiation time. It also assessed the viability analysis by MTT assay on SH-SY5Y and primary cortex cell line. In addition, the methods to determine the concentration of ATP have also been discussed, for the 2 different cell lines.

Chapter 4 provides the experimental results of the respective methods which are involved in proving the hypothesis of the correlation between ATP and PTSD. It outlines the success of proof of concept, thus providing a new concept to consider while targeting issues of mental disorders.

Finally, Chapter 5 concludes the findings and highlights some important facts when comparing 2 different cell lines that originate in the nervous system. When compared, huge 
difference lies due to their existing levels of sensitivity. It also focuses on the future work to fully consolidate the proof of concept and thus hopefully outlining the guidelines for more advanced, effective and efficient medical devices. 


\section{CHAPTER 2}

\section{LITERATURE REVIEW}

The photo-bio-modulation or LLLT has been around since 1967. However, it entered limelight in recent years, for therapeutic applications in neurorehabilitation, ophthalmology, pathology and physical medicine. Primarily, it was used for wound healing and chronic pain relief. With the extensive research, the medical applications using LLLT expanded to treatment of diseases such as myocardial infarction, peritonitis, ulcers, strokes and traumas.

The use of lasers for the medical applications was witnessed within a short time span of 7 years, after the discovery of Ruby laser, 1960 and He-Ne laser in 1961. Mester E et al (1967) recognized the potential of He-Ne laser to boost the growth of hair [69] and to provoke recovery of the wound when tried on animals like mice [70], and these treatments expanded shortly to treat skin ulcers in humans [71]. Since then, LLLT has been widely used in diverse areas of medical industries like regenerative medicine, inflammatory reduction, pain relief, chronic diseases, psychological problems and many more. However, the first accomplishment took place in 2002, when FDA approved the first Microlight 830 $\mathrm{nm}$ laser for noninvasive treatment of Carpal Tunnel Syndrome, a condition that causes hindrance in hand movements $[72,73]$. Since then, all the major organs from head to toe have been targeted for treatments of several disorders with LLLT.

Firstly, the LLLT based neurological treatments, have been discussed. The acute ischemic stroke has witnessed immense improvement with pooled Neuro-Thera Efficacy 
and Safety Trial (algorithm), which involved manageable blind placebo treatments [74]. This involved successful noninvasive treatments with low energy, near infrared laser on animal trials as well as humans. And nearly $70 \%$ patients achieved positive National Institutes of Health Stroke Scale (NIHSS) results [75]. Thus, the results when compared with intravenous tissue plasminogen activator (TPA), the transcranial laser therapy showed no adverse effects towards hemorrhage symptoms [76].

Initially, LLLT was applied on animal models for treatment of mild traumatic brain injuries (mTBI) [77]. In 2009, Moreira et al described the consequences of LLLT on systemic and localized immunomodulation, particularly with tumor necrosis factor (TNFa) and interleukin levels in blood circulation and brain of mice, followed by an injured brain [78]. Wu et al also demonstrated similar study on mice but with a different approach using appropriate weights and thus highlighting the improved neurological score when compared to the controls [79].

Similarly, Schiffer et al disclosed the cognitive benefits of LLLT on depressed patients with anxiety disorders and revealed the increase in regional cerebral blood flow, when treated with near infrared device [80]. Moreover, Naeser et al investigated a pilot study involving several patients suffering from mTBI and thus analyzed post transcranial treatments leading to the enhanced cognitive functions such as executive functionality, memory and learning capabilities [81]. He also experimented on intranasal treatments, displaying reduced post concussions and increased sleep, in addition to the boost in cognitive functionalities [82]. Likewise, Salgado et al evaluated the benefits of transcranial Light-emitting diode therapy (TLCT) on neural disorders like Alzheimer and dementia [83]. Researchers have also conducted successful NIR treatments to ease the implications 
of degenerative brain diseases. Moges et al determined the efficacy of LLLT on Familial Amyotrophic Lateral sclerosis (FALS), a disorder due to degenerative loss of neurons. The effect was tested on animal models to determine the effective synergy [84].

Trimmer et al approved his hypothesis of truncated transportation of axons in patients, addressing issues of sporadic Parkinson's disease and illustrated the improved response when treated with LLLT [85]. Similarly, Ying et al established the phenomenon to reduce apoptosis of dopaminergic neurons when inhibited with mitochondrial inhibitors like rotenone, while using near infrared treatments. The loss of dopaminergic neurons is considered to be one of the major factors for patients suffering from Parkinson's disease, which reduces with LLLT [86]. Likewise, relevant experiments were conducted by Zhang et al for the treatment of Alzheimer disease to understand the possible mechanisms to activate protein kinase C's (PKC) signaling and thus reducing apoptosis and determine the anti- apoptotic effects of low power laser irradiation (LPLI) [87].

Until now, we only determined the efficacy of LLLT on the central nervous systems via physical treatments on humans or animal models. However, the benefits of light therapy are not only limited to brain and is widely spread to cure all the major body ailments. Now, we will discuss some of the treatments related to pain.

Byrnes et al highlighted the effect of light in alteration of immunity response and regenerating speedy recovery of patients suffering from spinal injury [88]. Gigo-Benato et al examined the consequences on recovery mechanism of nerve regeneration specifically neurorrhaphy after operating animal models by laser therapy. Moreover, he concluded that pulsed and continuous wave lasers, when combined, produce more effective and quick recovery [89]. Somewhat, a similar conclusion was inferred by Barbosa et al, when 
examining the regeneration of damage of peripheral nerves, when irradiated with light of various wavelengths [90].

The pain and tenderness in the skeletal muscles may lead to a chronic disorder termed as Fibromyalgia. Despite medication, Gur et al reported that LLLT help reduces the symptoms of this musculoskeletal disorder [91]. He also reported the efficacy of lasers in the management of chronic pain in the lower back [92]. Moreover, he also conducted the study on Osteoarthritis and found similar and better results while treating the patients with lasers with different dose and timings for the treatment [93]. And, when compared with the laser acupuncture Yurtkuran et al noticed that the placebo light treatments were less effective than acupuncture performed with lasers while treating knee osteoarthritis [94]. Roberta et al reported the immediate and prolonged effectiveness of LLLT on triggered points on neck [95]. The ancient technique of acupuncture has been known to be one of the best options in medical history to treat chronic pains. However, with the advancing technology, this technique has been incorporated with lasers and has been transformed to be much more effective and efficient, as reported by Baxter et al [96].

The benefits of medical practices with light have been clearly indicated above. However, the scope of light therapy does not end here. It has expanded its applications towards dentistry, lipolysis and many more. Carlos et al explain the benefits of the laser in endodontic treatments in pain reduction, root canal resorptions and enlargements, decrement in bacterial infections and apical surgeries. However, these treatments are not only limited to low intensity [97]. Laser liposuction was first revealed by Apfelberg et al in 1992 [98], but since then, it has undergone many scientific and medical improvements. Sandra et al have reviewed and compared the effectiveness of laser liposuction to the 
conventional practices of liposuction, a technique to remove additional fat. The author concluded the laser liposuction treatments to be safe therapeutic treatments [99]. These are few implications of lasers in medical industry. However, the applications are streamlining and hopefully, it will revolutionize the future.

Until now, we discussed the involvement of LLLT in medical history at the macroscopic scale. Now, we will investigate the mechanism at the microscopic level. Biomolecules which are mainly responsible for converting photo-chemicals into energy, when targeted by low intensity light ranging in the therapeutic window are divided into 2 namely non-specialized or photoacceptors and specialized or photoreceptors.

Rojas et al explained the photoreceptors to be the biological molecules which have been specially designed to convert the photo-chemicals into energy such as chlorophyll in plants which is responsible for photosynthesis, cone and rod receptors in eyes which help us to perform visual functions and Melanopsin responsible for circadian rhythm. However, photoacceptors are photosensitive merely in their metabolic system like cytochrome c oxidase and chromophores [100]. Moreover, Karu et al prioritize the mechanisms involved in LLLT. She described the possibility of the changed redox properties of molecules in the respiratory chain, due to electronic excitation, resulted through stimulation with low intensity light. Also, the transient heating in light sensitive chromophores might be the reason for photosensitization in micro biomolecules. However, the production of native singlet oxygen and auto-oxidation with a singlet electron are the possible mechanisms resulting in therapeutic applications with light. In addition, she has also outlined the secondary mechanisms of transduction in biological cells, after a long period of time after irradiation such as mitochondrial photoacceptors and amplification in components of a 
respiratory chain like nicotinamide adenine dinucleotide dehydrogenases, cytochrome $\mathrm{c}$ oxidase, etc. [101]. Karu et al also compiled the diverse roles of ATP and the enrollment of different mechanisms for mitochondrial functionality, thus providing enough facts to consider the low level laser therapy to be streamlined in therapeutic applications [101]. Furthermore, the findings below shed light on ATP growth (secondary mechanism) and LLLT, thus solidifying the proof of concept.

Passarella et al conducted in vitro testing on rat liver, by irradiating it with HeliumNeon laser operating at the infrared range. These were the earliest findings based on the increased electrochemical potential and ATP growth, which was recorded by performing luciferase-luciferin assay [102]. In addition, Karu et al recorded the growth of ATP molecules after irradiating HeLa cells (immortal cancer line) with Helium-Neon laser, irradiating in the visible region of electromagnetic spectrum. It was found that the increase was dependent on the cultured phase of HeLa cells [103]. Likewise, Noriko MochizukiOda et al analyzed the effect of low level infrared laser on rat cortex tissue, witnessing 19\% increased the content of ATP when compared with the untreated controls. However, the Adenosine diphosphate content remained unaltered in comparison with the laser targeted sights [104].

Similarly, Amat et al analyzed the absorption spectrum of ATP in the luciferaseluciferin reaction, when irradiated with red light of visible spectrum and NIR lasers, witnessing changed biochemical behavior and increased participation of irradiated ATP samples when compared to un-irradiated samples [105]. Benedicenti et al also reported the 
efficacy of infrared pulsed laser in the production of $22 \%$ more intracellular ATP, when targeting human lymphocytes and comparing it with controls [106].

Similar experiments were also conducted in vivo to confirm the photo signaling mechanism of ATP such as Paul A. Lapchak et al performed transcranial experiments on a rabbit small clot embolic stroke model (RSCEM) using near infrared laser treatments (NILT). 41\% raise of cortical ATP was recorded when compared with sham-treated and naive models [107]. Moreover, Oron et al evaluated the effect of NIR light on cultured NHNP (normal human neuronal progenitor) cell line. It was discovered that the ATP levels, increased at least by a factor of 2 when compared with the controls [108].

Kujawa et al investigated ATPase activities of red blood cells (RBC) when being targeted by a NIR laser. The RBC structure was also analyzed. It was found that membrane ions were influenced by dosage and fluence of the light parameters, with most effective at dosage of $12-15 \mathrm{~J} / \mathrm{cm}^{2}[109]$. Moreover, Peplow et al reviewed the experiments involving growth factors, cytokines and genes. The studies in both animals and humans, when irradiated with laser light, were discussed and it was concluded that wavelength of light along with its dosage plays a crucial role in altering expressions of gene and also release growth factors [110].

In contrast, the modulation in genes transcription of the electron chain involved in Krebs cycle, including the increase in cytochrome c oxidase have been noticed on the fibroblast cell models by Masha et al, when irradiated with the laser operating at visible light [111]. Similarly, Wagner et al concentrated on evaluating angiogenesis and cytokines release with the modulating light on rats, for the treatment of oral healing. It was discovered that tumor necrosis factor showed an upward regulation on all stages of the experiment and 
$4 \mathrm{~J} / \mathrm{cm}^{2}$ was the optimum dosage to record the modulation in cytokine release [112]. He also studied the role of energy densities in phototherapy while analyzing healing of oral wounds. It was found that the time of healing increase exponentially when treated at 4 $\mathrm{J} / \mathrm{cm}^{2}$, on comparison to $20 \mathrm{~J} / \mathrm{cm}^{2}[113]$.

Some of the biochemical compounds related to nitric oxide and cytochrome oxidase, which are either mutated or inhibited by phototherapy have been discussed in detail by Poyton et al. The behavior is anomalous corresponding to hypoxic and normal oxygen level concentrations [114]. Moreover, Gagliardi et al discussed the sensitivity of (visible light) continuous wave Helium-Neon laser on adenine nucleotides in the functionality of the powerhouse of a cell. And discovered that the rate of ATP depends on the carrier of ADP/ATP while including the undergoing catalytic activity [115]. Similarly, Karu et al discussed the sensitive nature of ATP corresponding to pulsed infrared laser irradiation on cultured HeLa cells [116].

The involvement of laser in stimulating the biological cellular responses have been discussed. But in order to precisely understand the mechanism, it is important to be aware about the optical properties of tissues including skin, bone, water, fat and all different composition materials of humans or animals. Jacques et al reassessed the absorption and scattering phenomenon of biological tissues, compiling the importance based on chromophore content and the dependency of the wavelength of light. However, he concluded that all the parameters vary from individual to individual [117].

Until now, the effect of light therapy on the biological tissues and cellular responses has been discussed. But, the real question is about the appropriate timing to analyze the irradiated samples to receive optimum results? Hawkins et al clarifies the doubt about 
timing and concluded that microcellular responses are best analyzed 1-3 hours after irradiation. However, the indirect effects like proliferation are best recorded after 24 hours of post-irradiation. These parameters were concluded by performing wound healing experiments on fibroblast cells and then recording the cellular migration and responses through different biological assays [118].

So far, the entire discussion was based on the effectiveness of LLLT to cure diseases, the mechanism involved in treatments and the sources which supported the events like ATP production. But, the link correlating ATP and PTSD is still missing. And that is exactly what $\mathrm{Su}$ et al describe in his research paper. Post-mortem analysis of patients suffering from PTSD was diagnosed with irregular genetics and networking of mitochondria, concluding that it can become one of the biomarkers to analyze the patients suffering from depressive disorders [119]. And till date, the only existing photoreceptors in mitochondria are found to be cytochrome c oxidase and ATP. Researchers like Hayworth et al have proved the efficacy of lasers, to stimulate and upregulate the functionality of cytochrome c oxidase, in vivo [120]. Rojas et al also explained the increased cytochrome oxidase in rats, in vivo. However, it was also found that rotenone was prevented from decreasing cell respiration, when irradiated with NIR light [100]. The best and effective treatment for PTSD can only be created, if positives of different simulation techniques have been discovered and incorporated into an efficient therapy.

Lastly, we elaborate the various techniques which stimulate transcranial therapy. Huang et al discuss a fairly new concept called Theta Burst Stimulation (TBS) which includes, the continuous and the intermittent stimulation. He also compares the efficacy of his technique with the pre-existing Transcranial Magnetic Stimulation (TMS) and 
Transcranial Direct Current stimulation (TDCs) [121]. In addition, McKinley et al focus on changing the ideology of researchers to mix and match the noninvasive TMS techniques with neurological and physiological mechanisms [122]. Moreover, recently Paolo et al have commenced the utilization of NIR light to reduce major depressive disorders as a proof of concept, thus confirming the preliminary data [123]. Similarly, the findings from my research will also add some important concepts which require consideration, for effective treatment of stress disorders. 


\section{CHAPTER 3}

\section{EXPERIMENTAL METHODOLOGY}

To strengthen the belief of a direct correlation with the growth of ATP to PTSD, all the possible in vitro experiments were performed. These involved the samples of brain composition, neuroblastoma cells and primary neurons.

The experiment was conducted in the following 3 stages:

1. Laser Light Penetration Analysis (Based on Power and Time)

2. Cell Viability (3-(4,5-dimethylthiazol-2-yl)-2,5-diphenyltetrazolium bromide (MTT) Assay

3. Luciferase and Luciferin reaction (determines ATP Levels)

\subsection{MATERIAL BACKGROUND}

\section{Laser Light Penetration Analysis (Based on Power and Time)}

Freshly deceased pig's head was obtained from a butcher's market, in the local area. The samples of fats, tissues, skin, bones and brains were dissected from the pig's head. They were kept on ice, which led to the avoidance of post-death tissue breakdown. In addition, freshly deceased mice samples were obtained from the Neurosciences Department at Carleton University. 
In terms of physical structure, pigs head has the best resemblance to human's head $[124,125]$ and mice have comparable neurochemistry and neurobiology when compared with Homo sapiens [126,127], for in vivo treatments.

\section{Cell Viability (3-(4,5-dimethylthiazol-2-yl)-2,5-diphenyltetrazolium bromide (MTT) Assay}

The human neuroblastoma cell line, SH-SY5Y, and mouse cortical neurons were originally obtained from Institute of Biochemistry and Neurosciences Department at Carleton University respectively. MTT (3-(4,5-dimethylthiazol-2-yl)-2,5-diphenyl tetrazolium bromide; thiazolyl blue tetrazolium bromide) was obtained from Sigma (M2128; Oakville, Ontario, Canada). The solvent dimethyl sulfoxide (DMSO) was obtained from Caledon Laboratory Chemicals (Georgetown, Ontario, Canada).

The comparable neurophysiology and neurochemistry of mouse cortical neurons with that of humans [126,127], was the reason behind the selection of the 2 different cell lines. And the MTT Assay, determines the cell viability, by reducing a yellow tetrazole substrate to a purple formazan product using mitochondrial NADPH oxidoreductases in living cells. This assay, essentially, measures the mitochondrial activity and is subject to treatments, which may alter the content of mitochondria within the cell (mitochondrial biogenesis). In most cells, however, any fluctuation in the quantities of viable cells is linearly correlated to the number of their mitochondria. It is the most commonly used assay for viability analysis and is often utilized for cytotoxic analysis of drugs. 


\section{Luciferase and Luciferin reaction (determines ATP levels)}

The mouse primary cortical neurons were obtained from QBM Cell Science (Ottawa, Ontario, Canada). The SH-SY5Y cells were obtained from the American Type Culture Collection (ATCC; Manassas, Virginia). Luciferase Cell Lysis Buffer (25mM glycylglycine (pH 7.8), $1 \%$ Triton $\mathrm{X}-100,15 \mathrm{mM}$ potassium phosphate $\left(\mathrm{KH}_{2} \mathrm{PO}_{4}\right), 15 \mathrm{mM}$ magnesium sulfate $\left(\mathrm{MgSO}_{4}\right), 4 \mathrm{mM}$ EGTA, 1mM Dithiothreitol (DTT - added just prior to use)). Luciferase Assay Buffer ((25mM glycylglycine (pH 7.8), $15 \mathrm{mM} \mathrm{KH}_{2} \mathrm{PO}_{4}, 15 \mathrm{mM}$ $\mathrm{MgSO}_{4}, 4 \mathrm{mM}$ EGTA, and 1mM DTT (added just prior to use)) and Luciferin solution (25mM glycylglycine ( $\mathrm{pH} 7.8)$ and $1 \mathrm{mM}$ D-luciferin synthetic crystalline) were prepared prior to use.

Luciferin, the substrate for the enzyme luciferase (from fireflies), is converted to oxyluciferin by the enzyme, emitting light in the process, by the reaction below [128]:

$$
\begin{aligned}
& \text { Luciferase + luciferin }+\mathrm{ATP} \stackrel{\mathrm{Mg}^{2+}}{\longleftrightarrow} \text { Luciferase }- \text { luciferyl }-\mathrm{AMP}+\mathrm{PP}_{\mathrm{i}} \\
& \text { Luciferase - luciferyl }-\mathrm{AMP}+\mathrm{O}_{2} \rightarrow \text { Luciferase }+ \text { oxyluciferin } \\
&+\mathrm{AMP}+\mathrm{CO}_{2}+h v
\end{aligned}
$$

The high sensitivity of the above reaction makes it ideal to measure the intracellular concentration of ATP.

\section{Experimental setup}

An $808 \mathrm{~nm}, 8 \mathrm{~W}$ peak power CNI Model (with PSU-H-LED) laser, highly sensitive thermal sensor (up to $12 \mathrm{~W}$ ) and a handheld Nova I optical power meter was obtained from 
Allied Scientific Pro (Gatineau, Quebec). An SMA 905 optical fiber was connected to the laser output jack. The treatments for all samples varied from 10 seconds to the maximum of 5 min for viability analysis. The pulsed laser was collimated with the longitudinal coherence of $2.45 \mathrm{~nm}^{-1}$ and the tests were performed from $10 \mathrm{~mW}$ to $1.5 \mathrm{~W}$.

Mouse primary cortical neurons were treated with a laser from a confocal microscope (Nikon alrsimp Confocal Workstation) at the University of Ottawa. Primary neurons were highly sensitive and could only survive $2 \mathrm{~min}$ out of the tissue culture incubator (maintained at $37^{\circ} \mathrm{C}$ with $5 \% \mathrm{CO}_{2}$ and $95 \%$ relative humidity $(\mathrm{RH})$ ). The treatments were done in black 96-well tissue culture plates (Brand plates- Model: Bio Lite, Wertheim, Germany) with 1 second of laser penetration per well. The Fig. 3 below depicts the experimental setup.

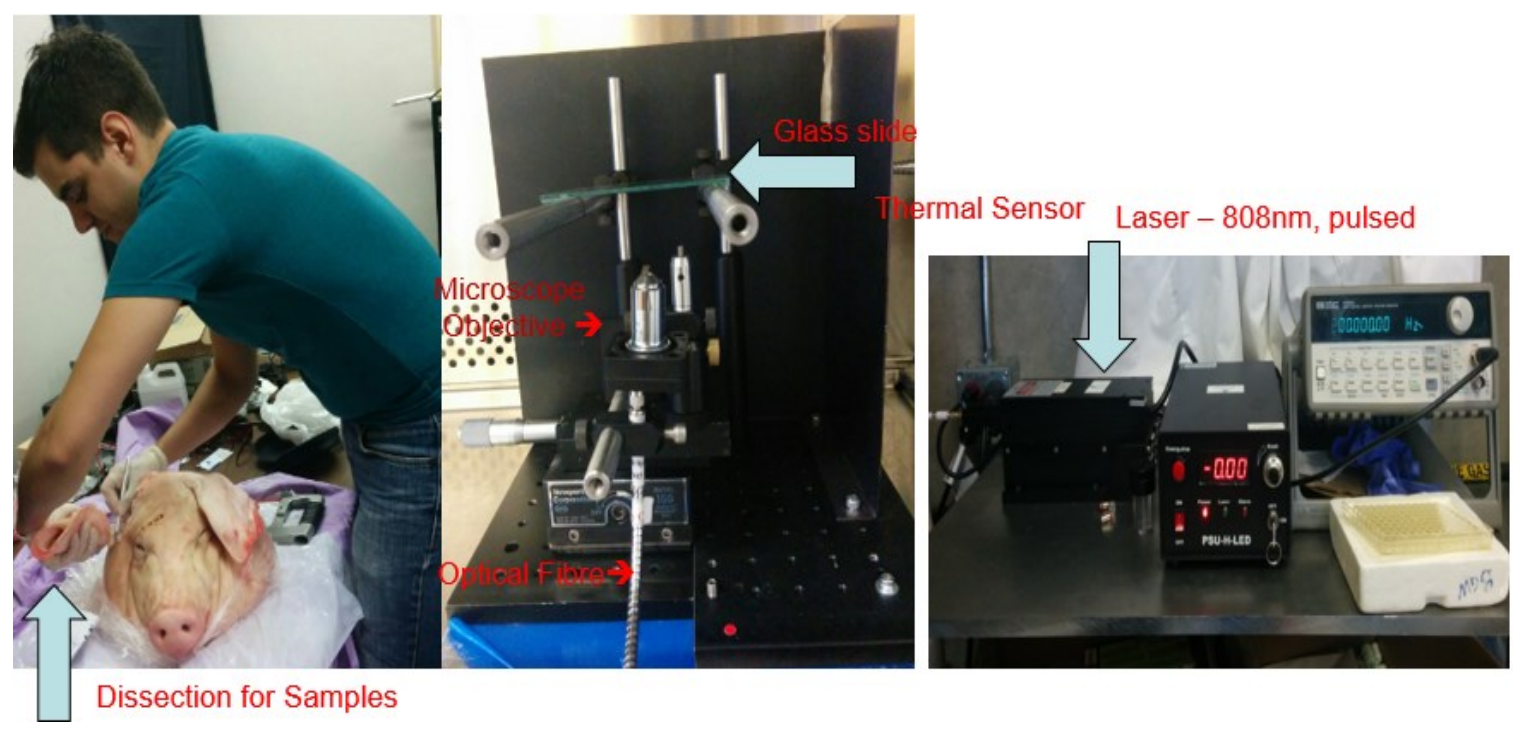

Figure 3: Experimental Setup

Before performing any biological experiments, the following laser light attributes should be taken into consideration: 
- Output power: It may vary depending on the continuous wave mode and the pulsed wave mode laser. However, it is generally provided by the laser manufacturer or could be determined manually.

- Intensity: It is the amount of power irradiated per unit area, Units- (Watts $\left./ \mathrm{m}^{2}\right)$.

- Fluence/ Dosage: It refers to the intensity at which the light oscillates in a periodic manner. The optimal dosage for the in vitro testing is found to be $50 \mathrm{~J} / \mathrm{m}^{2}$ [129], but it might vary with in vivo testing.

- Duty cycle: This parameter determines the active operational duration of laser for which it is periodic in nature. It is an important factor for modulation.

- Dark period of Coherence time - It refers to the time at which the light wave is not operating but is oscillating in a periodic fashion.

- Pulse period of Coherence time - This refers to the period for which the pulse is active and is oscillating periodically for a given period of time.

- Temporal/ Longitudinal Coherence - This parameter characterizes the ability of the electromagnetic wave, to interact with itself at any random time. Thereby, deciding the mode of operation (single frequency or multiple frequencies).

Longitudinal coherence $=\frac{1}{\text { Spectral width }}$

- Spatial Coherence - This attributes towards the correlation between the lateral direction of the wave to the phase at which it is traveling. It depends on the divergence of the beam, which is determined by the ratio of the wavelength of light to the beam diameter.

Lateral coherence $=\frac{\text { Wavelength }}{\text { Beam Divergence }}$ 
Low intensity light, when bombarded on any biological matter, in general, suffers relative low excitation rate of photons causing the non-coherent nature of light propagation, leading to excessive losses such as scattering.

Moreover, Karu et al [129] simplified the correlation between coherence lengths of lasers, when compared with conventional light sources such as LED or lamp. Table 1 below clearly describes the characteristics:

\begin{tabular}{|l|l|l|l|}
\hline Source of Light & Temporal Coherence & Coherence Length & Spatial Coherence \\
\hline LASER & Extremely HIGH & Extremely LONG & Extremely HIGH \\
\hline LED & LOW & SHORT & HIGH \\
\hline LAMP (spectral filter) & LOW & SHORT & Very LOW \\
\hline LAMP (without spectral filter) & Very LOW & Very SHORT & Very LOW \\
\hline
\end{tabular}

Table 1: Coherence Characteristics [129]

\section{Cell Culture Procedure}

The SH-SY5Y human neuroblastoma cell line (ATCC CRL-2266) and the M-Cx400 mouse brain primary neurons from the cortex were cultured with two different protocols. The difference in their protocols, was due to the highly sensitive nature of primary neurons, compared to the highly robust nature of the neuroblastoma cells. The neuroblastoma cells have the tendency to sustain high degree of aerobic glycolysis whereas primary neurons are highly sensitive to a slight change in their environmental conditions.

The SH-SY5Y cells were cultured by rapid thawing of frozen cell stocks in T75 flasks (Thermo Fisher Scientific, Rochester, New York, U.S.A). They were directly added to 20 ml of media (a 1:1 mixture of Eagle's Minimum Essential Medium and F12 Medium, 
containing $10 \%$ fetal bovine serum and antibiotics (penicillin, streptomycin, antimycotic)), such that the $10 \%$ DMSO in the freezing medium was automatically diluted to less than $0.1 \%$. After the cells settled and adhered, the media was changed and the cells incubated in a tissue culture incubator until further use (generally 24 hours later). After thawing, mouse primary cortical neurons required a minimum of 1 week for proper growth with the dendrites and axons, completely visible and contamination free.

Initially, the frozen stock of primary neurons was removed from liquid nitrogen and placed in preheated water bath at $37^{\circ} \mathrm{C}$. The time taken from removal of the vial from liquid nitrogen tank to preheating the cells in water bath was kept as short as possible (less than 30 seconds), ensuring rapid thawing of the cells. The vial was then removed from the water bath after $2 \mathrm{~min} 30 \mathrm{sec}$ and the outside of vial was disinfected by wiping it with $70 \%$ ethanol. It was then placed in a laminar flow hood and the cells were gently thawed. Thawing was followed by gentle transfer of $1 \mathrm{~mL}$ of cells into a $15 \mathrm{~mL}$ centrifuge tube. Pre-warmed medium (Neurobasal medium + B27; Thermo Fisher Scientific), was added onto the cells dropwise over 2 min while slowly rotating the centrifuge tube to avoid osmotic shock. Cells were plated into 96 -well plates with $200 \mu \mathrm{L} /$ well at a density of approximately 80,000 cells/well.

Seeding was followed by incubating the cells for $2 \mathrm{hr}$ at $5 \% \mathrm{CO}_{2}$ and $37^{\circ} \mathrm{C}$. After the incubation period, the media was partially removed so that cells were not dehydrated and the freshly warmed medium was added. Cells were incubated for 7 days at $37^{\circ} \mathrm{C}$ and $5 \% \mathrm{CO}_{2}$. The medium was changed after every 3 days. In addition to the temperature conditions, HEPES buffer was utilized to maintain the $\mathrm{pH}$ of the mouse primary cortical neurons. 


\subsection{EXPERIMENTAL METHODS}

\section{Laser Light Penetration Analysis (Based on Power and Time)}

The human skull comprises of 44 bones and their width varies from $6.5-18 \mathrm{~mm}$, depending on the gender and age. Mahinda et al [130], confirmed the variation in thickness of human skull by performing autopsies of 6.6 male versus 1 female. Moreover, cerebrospinal fluid and neurocranium of the skull protects the human brain, which comprises of $40 \%$ grey matter, $60 \%$ white matter, (neurons and glial cells) [131]. The major outline of this experiment was to expose the in vitro components of the brain and thereby investigating, the boundary parameters of laser which impose the least harm for in vivo treatments.

Initially, we experimented on a pig's head, as it resembles the physical anatomy and composition of human's head $[124,125]$. Then the pigs head was dissected to obtain samples of fat, tissues, skin, brain and neurocranium part of the skull. The width of the samples was measured by a digital Vernier caliper.

The samples were placed onto a glass slide inside a biosafety cabinet. They were irradiated in a bottom-up approach with the $808 \mathrm{~nm}$ pulse laser. The top-down laser treatment was also attempted, but it was found that the bottom-up approach was more accurate as it precisely targeted the samples with the laser. The duty cycle of the laser was fixed at $80 \%$ as it was found to be optimum from prior trial runs. The thermal sensor was placed vertically on top of the samples and the absorbance of light was measured with the optical power meter attached to the thermal sensor head. The absorbance of light through 
various samples and the penetration depth of the laser light was measured. The penetration depth was measured in millimeter and the absorbance was measured in milliwatt.

The penetration depth analysis was conducted while keeping human skull and brain anatomy in mind. Since humans could not be used as a test sample, we considered the closest approximation in terms of pig's head. In contrast to this, viability analysis of laser treatment was also performed on mice samples. Thus, ensuring the correct parameters of two-photon absorption through laser in mice/rodents. Proper animal protocols were followed and zero contamination of samples were ensured.

\section{Cell Viability (3-(4,5-dimethylthiazol-2-yl)-2,5-diphenyltetrazolium bromide (MTT) Assay}

The SH-SY5Y cultured cells were plated into 96 well plates, with phosphate-buffered saline (PBS) placed in the outer wells, to prevent the dehydration of cells. Cells were incubated with $10 \mu \mathrm{L}$ of MTT stock solution $\left(5 \mathrm{mg} / \mathrm{mL}\right.$ in PBS) for 1 hour at $37^{\circ} \mathrm{C}, 5 \% \mathrm{CO}_{2}$ and $95 \%$ RH. After incubation, the medium was carefully removed from the 96-well plate, and $100 \mu \mathrm{L}$ of DMSO was added to cells, lysing the cells and solubilizing the purple formazan product. The absorbance of cells was measured using a Biotek Epoch microplate reader with Gen5 software (version 2; Biotek Instruments Inc., Winooski, Vermont), working at $570 \mathrm{~nm}$ wavelength with a background subtraction of $630 \mathrm{~nm}$.

This entire procedure was replicated for primary cortex mouse neurons. The only difference was the culturing of cells. The SH-SY5Y cells were highly robust in comparison to the highly sensitive primary neurons. The neuroblastoma cells could be scraped, 
vortexed and lysed when required. However, primary neurons were incapable to undergo the above procedures, as it resulted in cell death.

The treatments for the SH-SY5Y and neuronal cells were done in a broad range of time and power, varying from 10 secs to $5 \mathrm{~min}$ and $30 \mathrm{~mW}$ to $1000 \mathrm{~mW}$ respectively. All treatments were performed with at least 3 replications, which was followed by statistical comparison with their respective controls i.e. the untreated cells.

\section{Luciferase-luciferin reaction (determines ATP levels)}

This bioluminescent approach relies on the enzyme luciferase, and its substrate luciferin, to detect both intracellular and extracellular ATP in vitro. This mechanism is relatively rapid and sensitive and is therefore used widely for ATP measurements. The luminescence signal is directly correlated to the concentration of ATP in the sample.

This luciferin and luciferase assay was performed for both the neuroblastoma cells (SHSY5Y) and mouse primary cortical neurons ( $\mathrm{M}-\mathrm{Cx}-400)$, cultured in the same way as they were cultured for the cell viability assays. The cells were plated in 96 well plates and were initially irradiated with an $808 \mathrm{~nm}$ laser, for the time duration ranging from 10 secs to 3 min $30 \mathrm{sec}$. The individual wells were irradiated using a bottom-up approach. Reduced meniscus effect, was observed in the bottom-up approach when compared with the topbottom approach.

After irradiation, the transfected cells were lysed in $35 \mu \mathrm{L}(\mathrm{pH}$ 7.8) of Luciferase Cell lysis buffer and the resulting lysate was centrifuged using Thermo IC- Model: IEC Multi RF (Needham Heights, MA, USA) at $4^{\circ} \mathrm{C}$ for 5 minutes. This was then followed by the addition of $12 \mu \mathrm{L}$ of lysate and subsequent addition of $76 \mu \mathrm{L}$ of Luciferase Assay Buffer to 
the wells. After mixing, $50 \mu \mathrm{L}$ of Luciferin Solution was added to the wells, to initiate the reaction. After ensuring complete mixing of the wells, the concentration of ATP was measured by luminescence using a BMG Labtech FLUOstar OPTIMA filter-based multimode microplate reader with OPTIMA software (version 2.10 R2) with luminescent settings.

The luciferase/luciferin assay was performed multiple times for both the cell lines, ensuring the untreated controls in the same set of the experiment. Results are presented as the means of 3 repetitions with standard error of means (SEM).

\section{Statistics}

The results are represented, after evaluation of statistical analysis using Sigma plot version 12.3, for each of the 3 replicates. One-way ANOVA followed by non-parametric tests (such as Dunnett's Test) were used to compare the treatments with their respective controls. 


\section{CHAPTER 4}

\section{EXPERIMENTAL RESULTS}

The following experiments were carried out to test the effectiveness of LLLT on biological samples:

1. Absorption spectrum vs penetration depth for various tissues

2. Cell Viability analysis

3. Release of ATP

The experiments tested the effects of NIR laser on biological samples and the upregulation of ATP within cells, which will further help in designing an effective device for utilization of LLLT, and to treat stress-related disorders (mainly PTSD).

\subsection{ABSORPTION SPECTRUM VERSUS PENETRATION DEPTH IN TISSUES}

In order to perform any transcranial stimulation, it is pertinent to understand the optical properties of the samples being irradiated by the low level laser. The objective of these experiments was to examine the depth of penetrance of laser light through a variety of cranial tissues, to determine the efficacy of neurostimulation, using a transcranial laser. The understanding of laser depth penetration is crucial for designing medical devices for therapeutic applications. The optical therapeutic window $(650-1350 \mathrm{~nm})$ [132] is said to be the best to analyze the maximum ability of light to penetrate into tissues. This refers 
to maximal penetration depth corresponding to the near infrared window used for medical NIR spectroscopy.

The focus of this section is to investigate the role of $808 \mathrm{~nm}$ (near infrared wavelength) laser light in stimulating different transcranial samples and thus modeling the absorption range, corresponding to the irradiated samples. Hence, the ultimate goal of this study is to modulate the cellular responses of the brain by LLLT in order to reduce the symptoms of stress disorders.

The study presents the absorption spectrum of skin, neuromuscular tissue, fats and bones, corresponding to the penetration depth of irradiation. However, the in vitro absorption spectrum varies from individual to individual depending upon numerous factors such as the type of tissues, the sites of exposure, the timing of exposure and sterile environmental conditions. The in vitro analysis may or may not imply to the in vivo conditions.

Due to the difficulty of obtaining human samples for experimentation, it was decided to use a freshly deceased pig's head as a model system as it provides the closest approximation to the composition of a human head in terms of tissue composition and thickness.

The animal, laser and biohazard protocols were in accordance with the standards set by Carleton University and the Animals for Research Act of Ontario, the Guidelines of the Canadian Council on Animal Care (CCAC), the Canadian Food Inspection Agency and the Public Health Agency of Canada (Health Canada). The sterility and complexity of the testing were closely monitored to avoid any kind of contamination. The skin, bone, fat and tissue samples were dissected with precision and measured to find a relatively accurate 
correlation between tissue thickness and power loss. The relevant data was collected and the data was extrapolated to model the irradiation time versus penetration depth, for varied power levels. For different tissues, the dose of photonic energy required for stimulating the target, the power and the duty cycle was measured.

The hardest part is the adequate penetration of light passing through the cranial structure. The absorption spectrum of bone, compared with the penetration depth of light corresponding to different powers of the laser, operating at near infrared spectrum (808 nm) was measured.

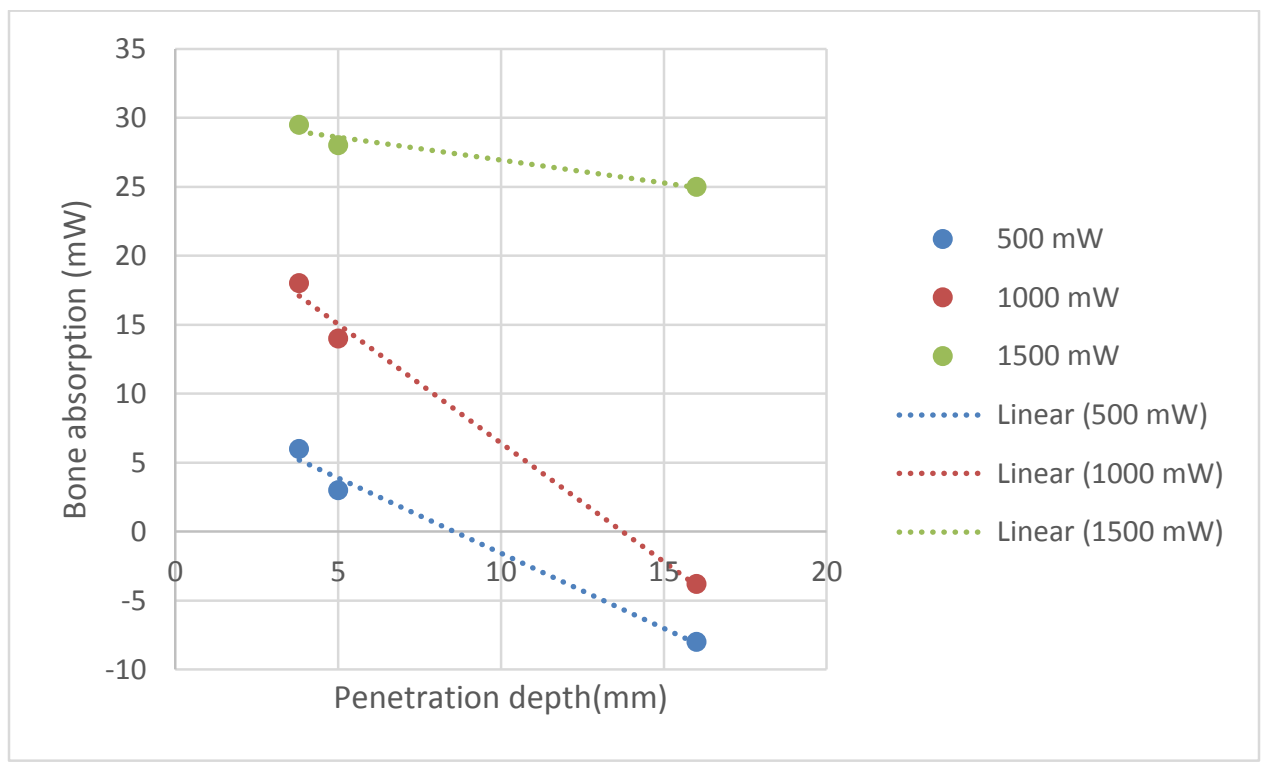

Figure 4: Absorption spectrum of Bone, measured at $700 \mathrm{~Hz}, 80 \%$ duty cycle and the peak output power of $500 \mathrm{~mW}, 1000 \mathrm{~mW}$ and $1500 \mathrm{~mW}$ respectively.

The above graph [133] depicts the variation of increased penetration depth corresponding to the increased power of the laser. The increase in the power leads to the increased penetration depth. It was observed that $1000 \mathrm{~mW}$ of power was not enough to 
penetrate through highly dense bone. The negative absorption might be due to the fluorescence in bones, or it might be due to the baseline shift. Ugryumova et al [134] clearly depicts the bone density and the absorption coefficients, which provides an insight of the expected pattern, with the laser. However, the absorbance of light was highly dependent on individual bone density and incident light intensity.

Similarly, the absorption spectrum of the neuromuscular tissue (such as gray matter, white matter) was observed. It was noticed that the penetration depth rises with the increased power, however, the absorbance tends to reduce. And the absorption spectrum for tissues varied corresponding to the different protein and water content. Fig. 5 below demonstrate the above findings.

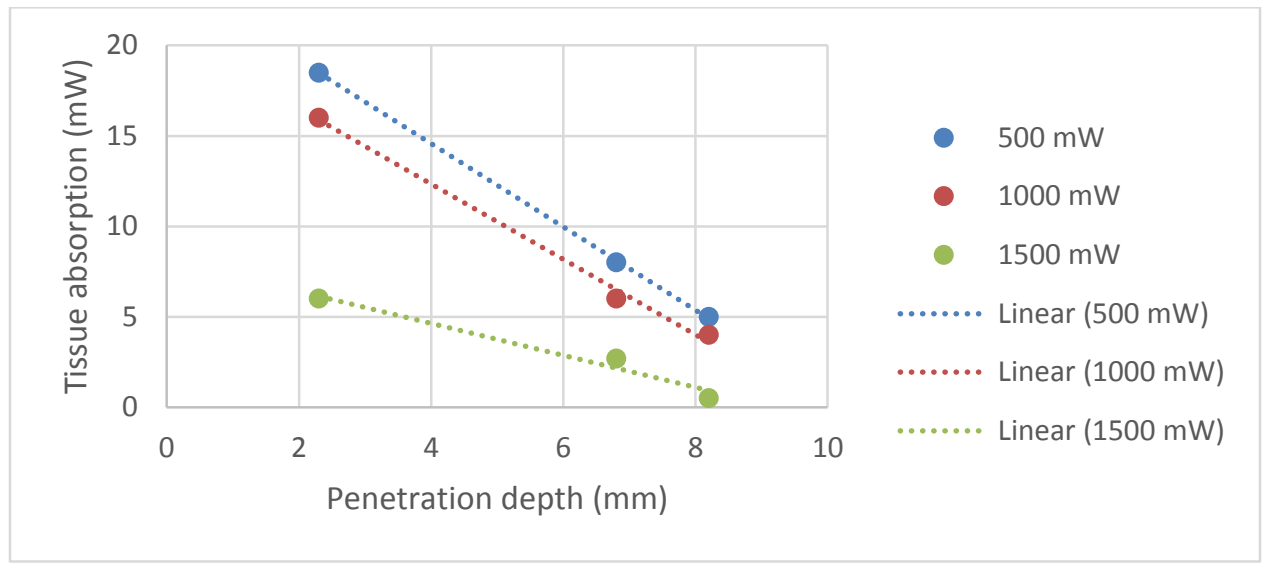

Figure 5: Absorption spectrum of Neuromuscular Tissues, measured at $700 \mathrm{~Hz}, 80 \%$ duty cycle and the peak output power of $500 \mathrm{~mW}, 1000 \mathrm{~mW}$ and $1500 \mathrm{~mW}$ respectively.

The depth of penetration and absorbance of laser light of skin and fat were also assessed. The readings of absorption vary with the density of lipid membranes, such as 
observed at $1500 \mathrm{~mW}$ of power. The increasing power led to the increased penetration depth in fats. However, the absorbance rate reduced in comparison to bones and tissues. Scattering losses might be the reason behind the reduced rate of light absorption. Salomatina et al [135] report similar patterns corresponding to changing wavelength of laser light versus absorption in subcutaneous fats. The skin is a mix of tissues such as subcutaneous fat, muscles, blood vessels. Hence, understanding the absorption spectrum for the amalgamation of skin and fat is equally important. The graph below [133], depicts the trends followed.

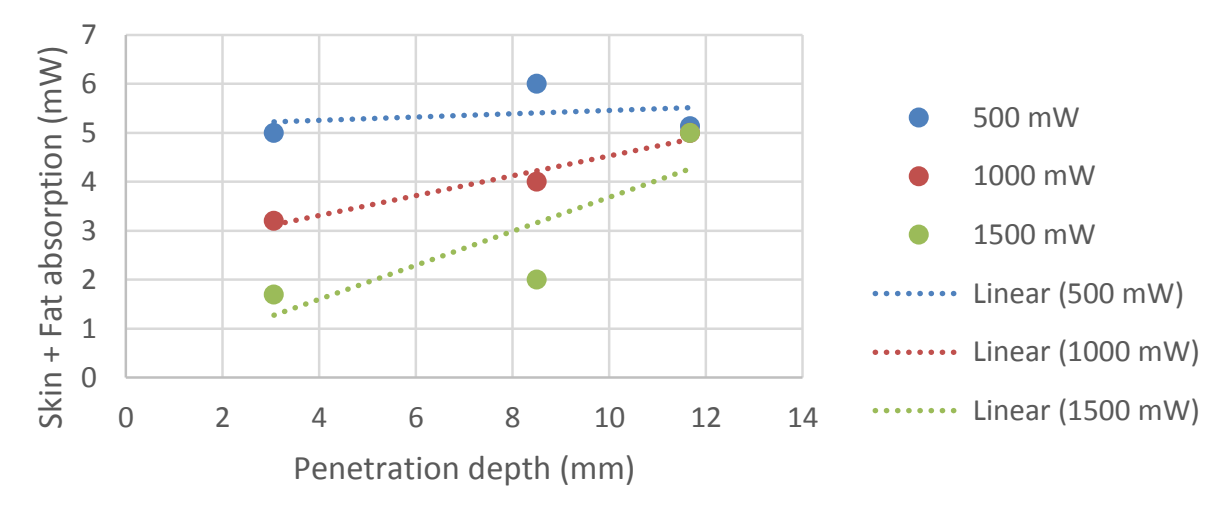

Figure 6: Skin + Fat Absorption spectrum measured at $700 \mathrm{~Hz}, 80 \%$ duty cycle and the peak output power of $500 \mathrm{~mW}, 1000 \mathrm{~mW}$ and $1500 \mathrm{~mW}$ respectively

The absorption spectrum depends on a) the depth of cutaneous layer, b) the levels of skin pigmentation and c) the density of lipid content. It was seen that irrespective of the intensity or power of the laser, the light absorbance by a mix of fats and tissues converged at $11 \mathrm{~mm}$ of penetration depth. The reason behind the convergence may be the emulsification of adipose tissues occurred due to the light interaction. Neira et al [136] support the reasoning by presenting the effect of LLLT on fats. Similarly, Anderson et al 
[137] represent the scattering coefficients for skin, which easily helps in understanding the above figure.

The findings of absorption spectrum versus penetration depth in various tissues in pig's head were then compared to similar tissues in mouse. We tried to determine whether laser power, depth of penetration and absorption in various tissues were a general principle across species, so we then tested the same parameters on similar mice biological samples. Results in mouse tissues were similar to that found in pig tissues. However, the parameters (such as the laser operating frequency) for irradiating mouse samples were altered, merely because of its timid size and the risk of damaging the samples.

The figure below demonstrates the absorption spectrum for mouse samples.

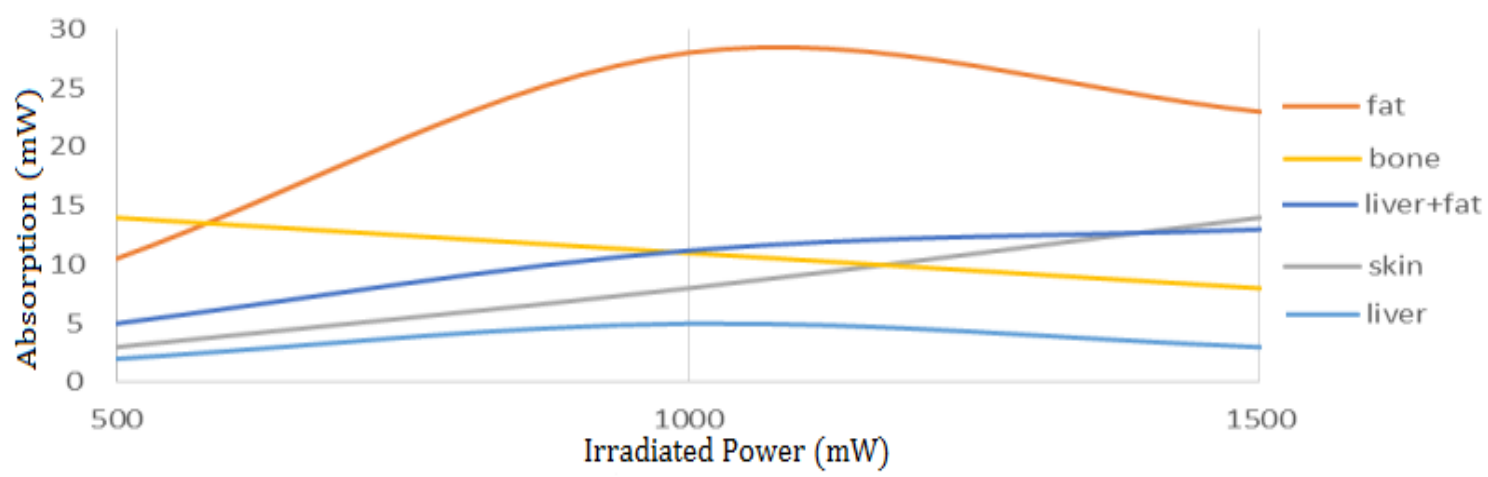

Figure 7: Absorbance versus Power (Mice), measured at $200 \mathrm{~Hz}, 80 \%$ duty cycle and the peak output power of $500 \mathrm{~mW}, 1000 \mathrm{~mW}$ and $1500 \mathrm{~mW}$ respectively [133]

The fat samples of mice showed stress response towards the light at $1000 \mathrm{~mW}$. The stress response was related to the emulsification of fats. It was also observed, that the irradiation with high powers damaged tissue samples. 
After evaluating the absorbance curves, we extrapolated the data to model the relationship between penetration depth and irradiation time, for different peak powers. The table below provides the mean of the measurements of samples.

\begin{tabular}{|l|l|l|l|l|l|}
\hline Interference & $\begin{array}{l}\text { Average Power } \\
(\mathrm{mW})\end{array}$ & $\begin{array}{l}\text { Power Density } \\
\left(\mathrm{W} / \mathrm{m}^{2}\right)\end{array}$ & $\begin{array}{l}\text { Depth } \\
(\mathrm{cm})\end{array}$ & $\begin{array}{l}\text { Power Lost } \\
(\mathrm{mW})\end{array}$ & $\begin{array}{l}\text { Power Loss } \\
(\%)\end{array}$ \\
\hline None & 93.0 & 23250 & 0 & 0 & 0 \\
\hline Skin & 10.4 & 2588 & 0.2 & 83.5 & 82.7 \\
\hline Skull & $1.0^{*}$ & 250 & 0.9 & 92.0 & 98.9 \\
\hline Brain & 2.7 & 663 & 0.5 & 91.2 & 90.7 \\
\hline
\end{tabular}

Table 2: Data for delivering dose corresponding to $50 \mathrm{~J} / \mathrm{m}^{2}$ at $500 \mathrm{~mW}$ output power [133]

After penetrating skin and skull, an estimated $0.115 \pm 0.005 \%$ of the light intensity was residual as most of the light is absorbed. It was found that with each successive halfcentimeter of brain tissue penetrated, an additional $94.4 \pm 3.7 \%$ of the light intensity was absorbed. The numerical model depicts the time, which was required to deliver a dose of $50 \mathrm{~J} / \mathrm{m} 2$. In order to develop a realistic clinical model for neurological treatment of mental health disorders, irradiation time should be a matter of seconds or minutes. In order to understand the required laser power, the graph below (Fig. 8) uses data extrapolated (Table 
2) from these findings to show how much irradiation time each laser $(500 \mathrm{~mW}, 5 \mathrm{~W}$, and $15 \mathrm{~W}$ ) require delivering $50 \mathrm{~J} / \mathrm{m}^{2}$ at a given depth.

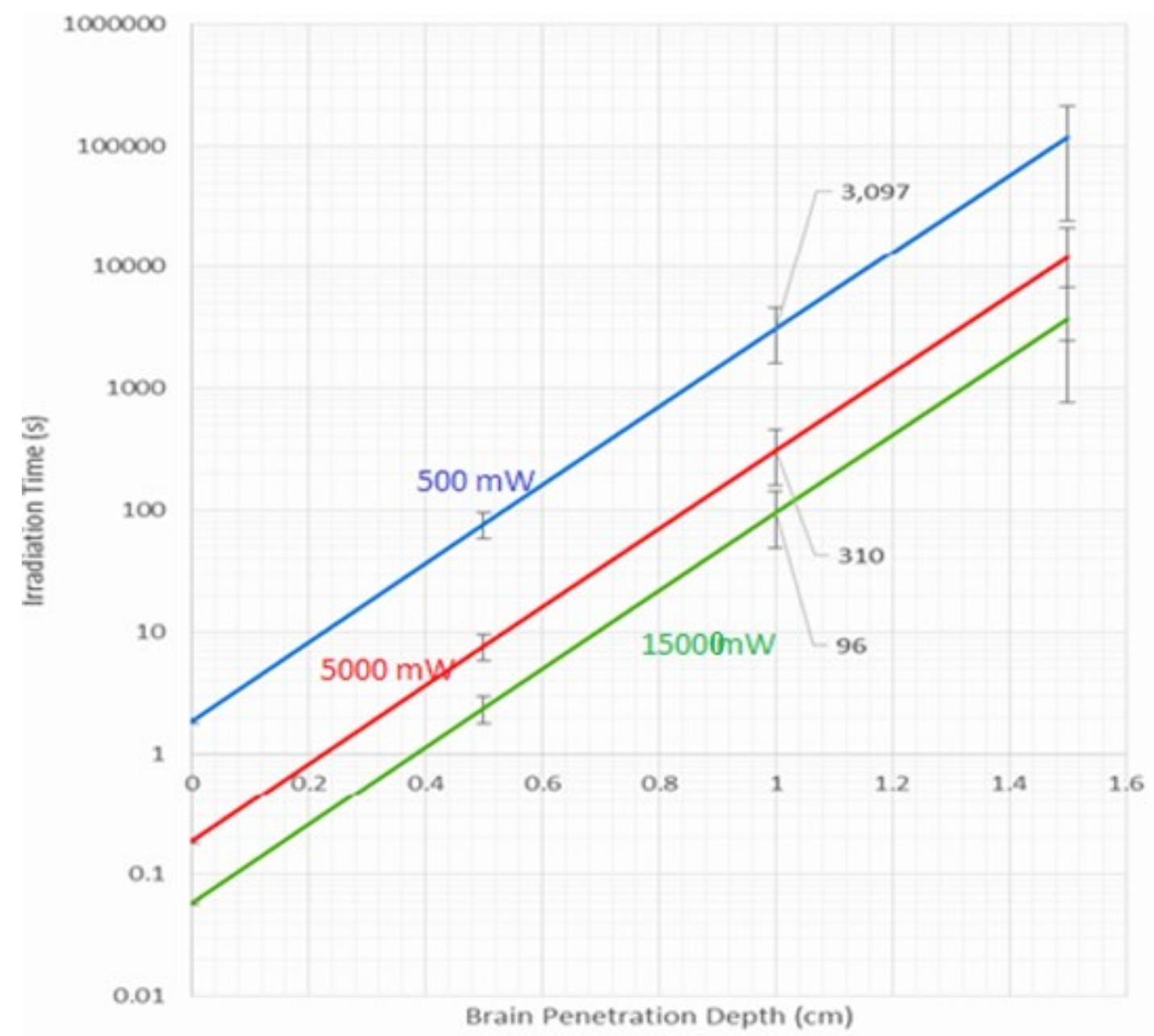

Figure 8: Modeling of irradiation time and pig's brain penetration depth [133]

Hence, from the above model, the estimated time to deliver $50 \mathrm{~J} / \mathrm{m}^{2}$ of dose for penetrating a depth of $1 \mathrm{~cm}$ in the brain was found out to be $51 \mathrm{~min}, 5.2 \mathrm{~min}$ and $1.6 \mathrm{~min}$ for $500 \mathrm{~mW}, 5000 \mathrm{~mW}$ and $15000 \mathrm{~mW}$ of power respectively.

Thus, the findings were adequate to correlate the relationship between the absorption spectrum, penetration depth and the irradiation power. Thus, it was concluded 
that the penetration depth is directly proportional to irradiation time. However, the power is inversely proportional towards the depth of penetration.

\subsection{CELL VIABILITY (3-(4,5-DIMETHYLTHIAZOL-2-YL)-2,5- DIPHENYLTETRAZOLIUM BROMIDE (MTT) ASSAY}

The MTT (3-(4,5-dimethylthiazol-2-yl)-2,5-diphenyltetrazolium bromide) analysis is a cell viability test to perceive the changes in the cultured cells, after being irradiated with pulsed laser. This is a foremost step to realize the effects of the light parameter that are just enough to stimulate cellular responses without cell death.

The yellow MTT enters cells and is cleaved by active (i.e. in living cells) mitochondrial NADPH-dependent dehydrogenases to a purple tetrazolium formazan product. Neurons are highly sensitive in nature, so the laser parameters were first tested on neuroblastoma cells, SH-SY5Y (human neuroblastoma) cells.

Initially, the viability of cells, treated with low power laser light, ranging from 30 $\mathrm{mW}$ to $300 \mathrm{~mW}$, was tested. The results showed no changes in cell viability treated with various powers of low power laser light. The graph below depicts the viability trend towards low power measurements (Fig. 9). 


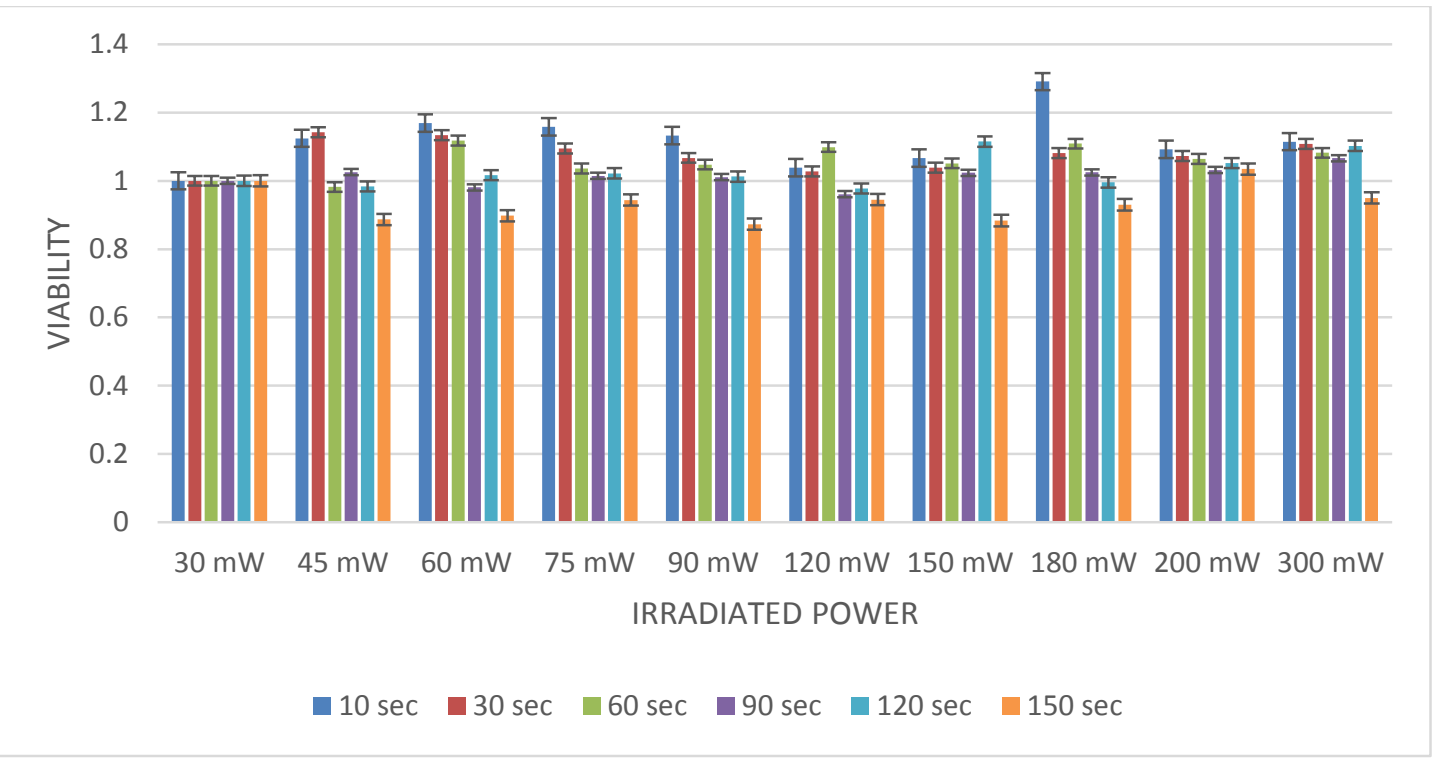

Figure 9: MTT analysis for SH-SY5Y at low power treatments

We then determine cell viability at high laser powers (200 to $1,000 \mathrm{~mW})$. The figure below demonstrates the viability response at high power of in vitro irradiation.

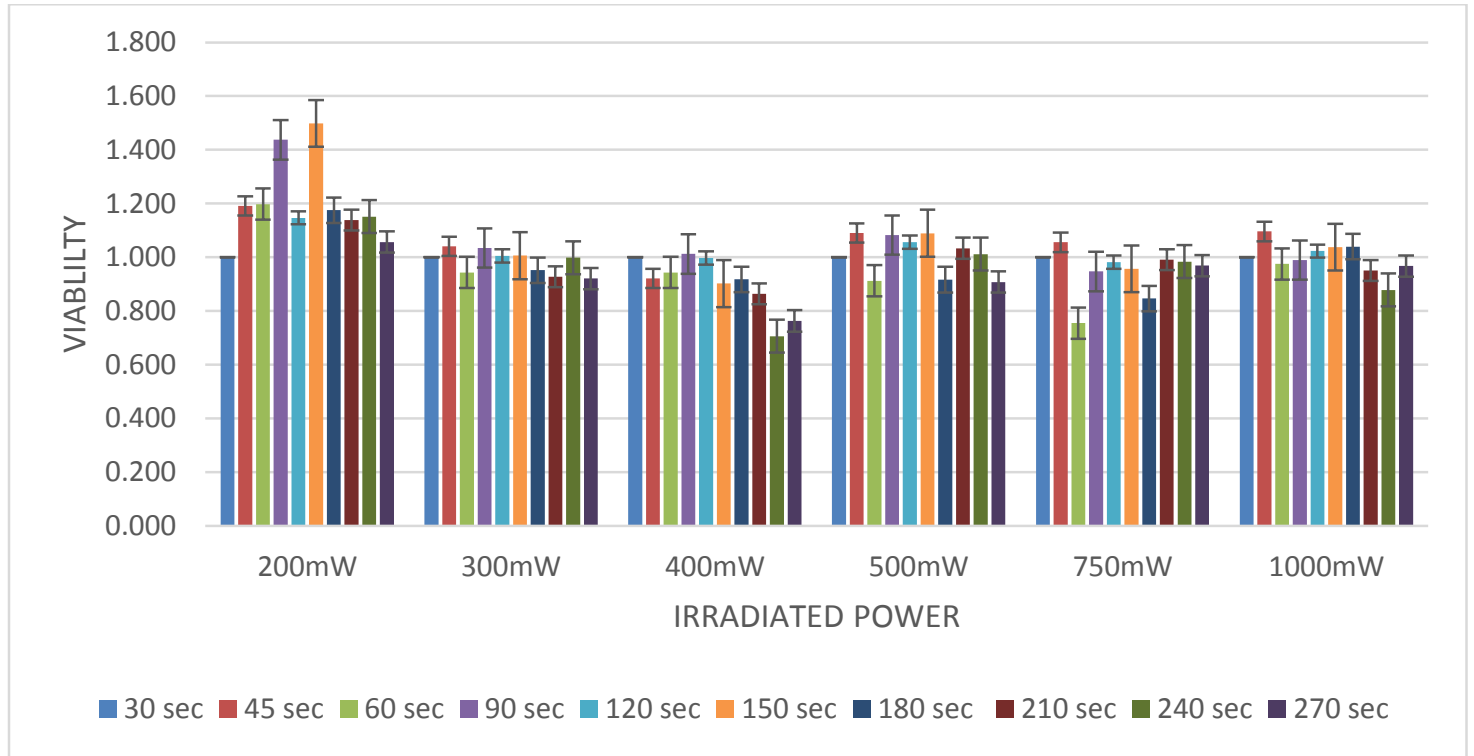

Figure 10: MTT analysis for SH-SY5Y at high power treatments 
At $1000 \mathrm{~mW}$ laser treatments, SH-SY5Y changed their morphology, indicating that they were sick. It was essential to determine the powers and times of laser light treatments of cells that would not result in cell death. Cell death was not observed either at the highest powers or the longest times (Figure 9 and 10). Cells observed under the microscope, after treatment, showed no signs of cell death either by apoptosis or necrosis.

The robustness of the SH-SY5Y cells could be due to the fact that they are a cancer cell. Cancer cells are known to survive highly stressful, extreme conditions such as lack of oxygen and nutrient supplies. Cells were treated with a top-down approach, with the laser treatment from above, and a bottom-up approach with the laser treatments from below the cells. It was found that the bottom-up approach avoided problems of light scattering due to the meniscus effect, and therefore this approach was taken for all subsequent experiments.

After determining the treatment parameters for SH-SY5Y cells, the experiments were repeated with mouse cortical neurons. The timings and the power of treatments had to be altered from the SH-SY5Y experiments as the primary neurons were more sensitive to the treatments.

The timing of the treatments was kept to less than 3 minutes as primary neurons would perish if kept for longer outside of the incubator. Primary neurons tend to undergo necrosis under high-powered laser treatments (such as those above $600 \mathrm{~mW}$ ). The Fig. 11 below elaborates the viability analysis for neurons at low power treatments for different period of timings. 


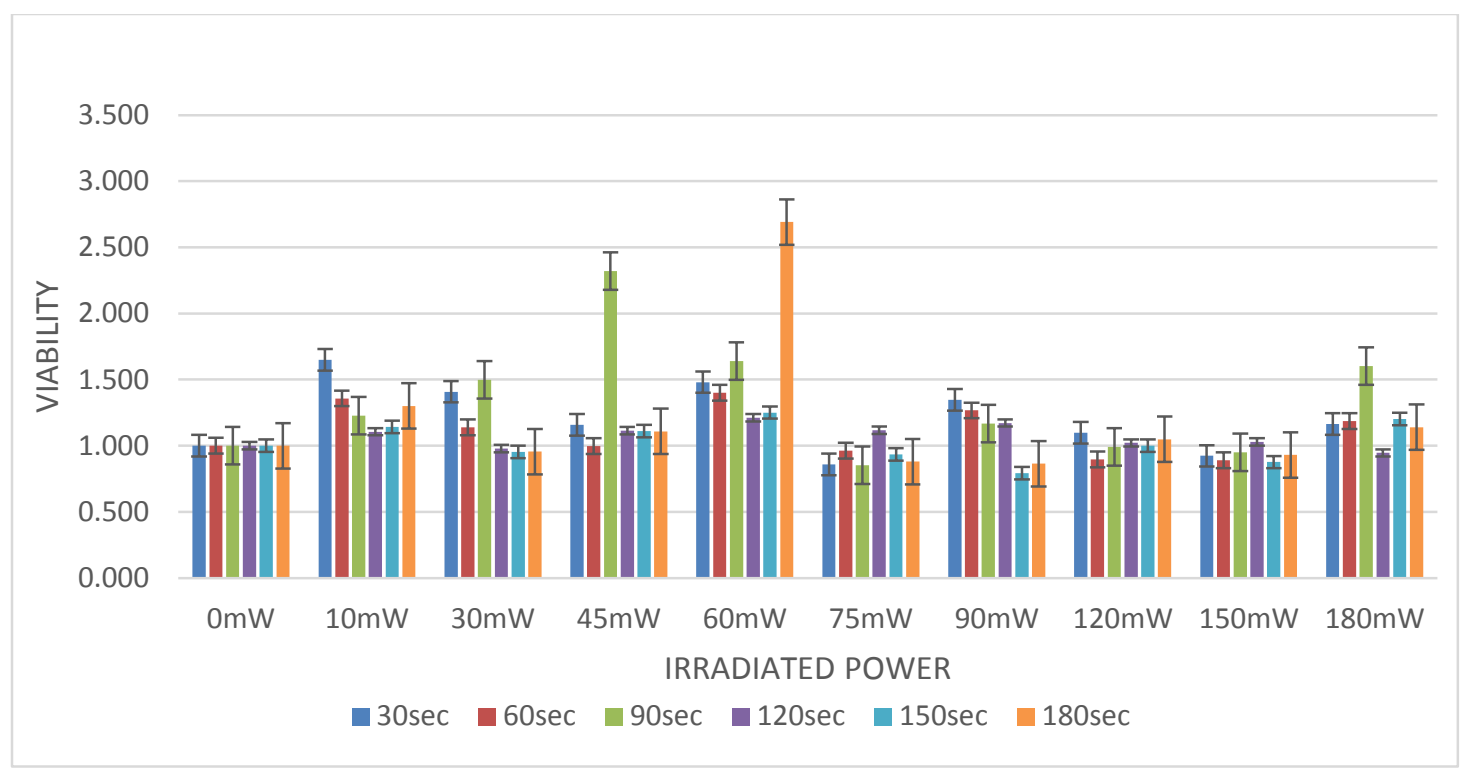

Figure 11: MTT analysis for Neurons at low power treatments

Cell viability increased at $30(10$ and $30 \mathrm{~mW}), 90(45 \mathrm{~mW})$ and $180 \operatorname{secs}(60 \mathrm{~mW})$ of treatment timings. This means that 90 second is crucial for both the neuron and its neuroblastoma cell type, resulting in higher viability between 30 and $60 \mathrm{~mW}$ of laser power. Higher viability, as measured by the MTT assay, may be the result of stress response in cells triggered by LLLT treatment. The stress response may result in mitochondrial biogenesis [138] which would appear as an increase in viable cells via this assay with LLLT treatment. However, these results may be misleading as treatments may not lead to an increased number of cells, but rather an increased number of mitochondria per cell, via a stress response. 


\subsection{LUCIFERASE AND LUCIFERIN ANALYSIS}

ATP was measured via a luciferase-luciferin assay. This assay utilizes the enzymatic activity of luciferase, which converts luciferin to oxyluciferin in an ATP-dependent manner (see Scheme 3). ATP was left out of the assay as it was provided by the sample. The higher the amounts of ATP in the sample, the more luminescent product is produced by the enzyme. The figure below depicts the production of ATP in the SH-SY5Y human neuroblastoma cells.

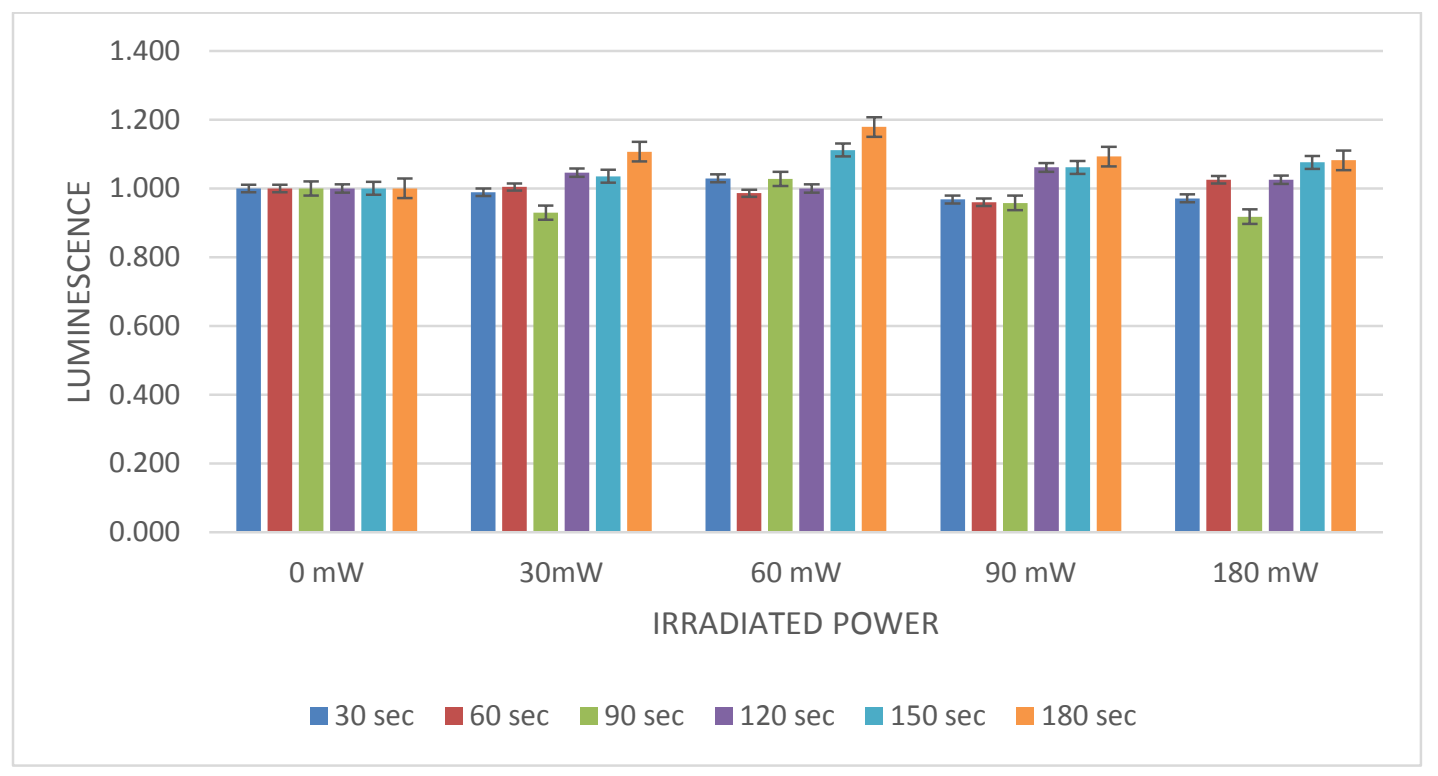

Figure 12: Luciferase-luciferin analysis for SH-SY5Y at low power treatments

ATP production did not change in the cancer cells with treatments of up to $180 \mathrm{~mW}$ of laser power for up to 180 seconds. This may reflect the robust nature of the cancer cell and its resistance to various types of treatments. In contrast, primary neurons showed a 4.5- 
fold increase in ATP production with treatment of $500 \mathrm{~mW}$ of laser power for 1 second (Fig. 13)

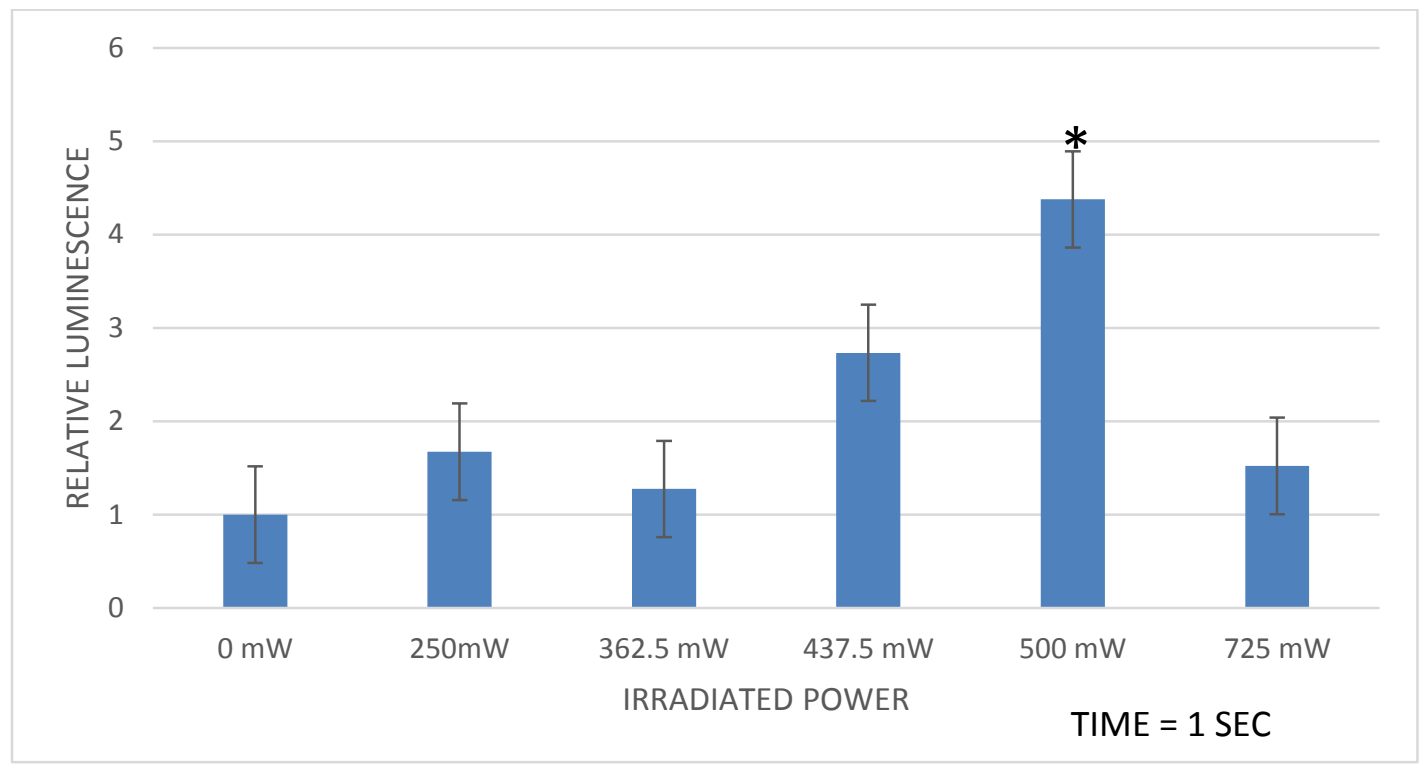

Figure 13: Luciferase- luciferin analysis for neurons at low- high power treatments, where * denotes the highest significant change in luminescence measured in the experiments

Treatment times for primary neurons had to be kept under 3 seconds, due to their sensitive (humidity, $\mathrm{CO}_{2}$ ) nature. ATP measurements revealed that biochemical changes can occur in cells with laser treatment even in the absence of any changes in cell viability (death via apoptosis or necrosis). Thus, laser treatment can cause biochemical changes at the target site of the brain, given the correct powers and times. It could be easily speculated that the in vivo penetration of laser light into the brain (treatments of up to 10 seconds at one site) can result in the many fold increase in the production of ATP within neuronal cells. It has been found that the levels of adenosine in a healthy human brain ranges from 30 to $300 \mathrm{nM}$ [139]. The target site for neurotransmitter release in the brain is the 
hippocampus, which is buried in the deepest part of the brain. Thus, LLLT must target the hippocampus through the weakest link of the skull or through nostrils.

Cell lines are useful for testing the parameter of laser power and time of treatment. However, these parameters must be retested for use in vivo in complex organisms with complex tissues, if they are to be used for LLLT. This thesis provides evidence for the powers and times required for such treatments and tests the limits of such treatments to remain below the levels that would result in cell death and tissue damage. 


\section{CHAPTER 5}

\section{CONCLUSION}

The combination of the varied power and time of laser irradiation clearly demonstrated the effectiveness of Low Level Laser Therapy (LLLT). The absorption spectrum predicts the expected trend line for the neuro-transcranial bio samples when irradiated with $808 \mathrm{~nm}$ of NIR laser light.

The increase in irradiation time tends to increase the penetration depth in the bio samples. And the irradiation time is inversely related to the power. Greater irradiation power requires less time of exposure and vice versa. In addition, the depth of penetration increases as irradiation time and output power increase. However, the absorption rate differs depending on the various factors like wavelength, water content, skin pigmentation, lipid content and the tissue composition, altered by the individual cellular responses. The absorption spectrum trends for the bones, neuromuscular tissues, skin and fat samples provide us a fundamental understanding of the photosensitive response of biological specimens under exposure of a coherent laser. Regardless of how coherent the laser is the light penetration behaves in a non-coherent fashion, stimulating all the particles on its way and leading to almost $90 \%$ of scattering. The pig's head was chosen as it best resembles human samples for corresponding tissues, fats, skin and bone. And similarly, mice were chosen to represent the neurotransmission network system of humans.

The cell viability analysis for SH-SY5Y cells, when compared with the mouse cortical neurons, demonstrated their sensitiveness towards light. The data shows the 
robustness of SH-SY5Y when compared with highly sensitive neurons, thus reflecting their capability to withstand extreme temperatures, oxygen-less conditions and any kind of manual tampering like scraping. On the contrary, neurons would undergo apoptosis in those conditions and when irradiated with light, they undergo necrosis under 4 seconds.

The light treatments on both the cell lines enhanced the productivity of ATP levels. The light stimulation on SH-SY5Y did not produce any significant enhancement in the ATP levels. On contrast, $500 \mathrm{~mW}$ of power treatments on mouse cortical neurons increased the productivity of ATP levels by 4.5 times. This power is sufficient enough to provide the dosage of $50 \mathrm{~J} / \mathrm{m}^{2}$. The most effective irradiation time may vary from $1 \mathrm{sec}$ to $3 \mathrm{~min}$. Thus, successfully initiated non-ionizing excitation of biological compounds (ATP).

The photosensitivity of ATP could potentially mutate the neurotransmission system, resulting in reduced symptoms of psychological disorders such as PTSD.

In summary, this research will provide optimal values on fundamental parameters using laser irradiation on biologically photosensitive compounds for potential treatment of PTSD. It also provides basic guidelines for designing low cost, effective and efficient medical devices for therapeutic applications such as PTSD.

\section{FUTURE WORK}

The research limits to the in vitro testing of effects of LLLT on skin, bone, fat and neuromuscular tissue. The absorption and scattering coefficients for all the above biological samples, both in vitro and in vivo, need to be comprehended. The in vitro analysis for the most effective dose, time and power, will provide the guidelines for in vivo testing, based on blood sample analysis for neuro transmission circulation after laser 
treatments in animal models. However, they might need to be altered, depending on the experimental setup. Thus achieving the ultimate goal to design and fabricate a medical device, which suppresses PTSD symptoms. 


\section{APPENDIX}

Raw Data for Bone absorption

\begin{tabular}{|l|l|l|l|}
\hline & & bone & \\
\hline & $500 \mathrm{~mW}$ & $1000 \mathrm{~mW}$ & $1500 \mathrm{~mW}$ \\
\hline $3.8 \mathrm{~mm}$ & $(6.21,5.96,6.1)$ & $(18.3,18.16,17.78)$ & $(29.54,28.7,30.3)$ \\
\hline $5 \mathrm{~mm}$ & $(3.12,3.01,2.94)$ & $(13.79,14.27,13.96)$ & $(28,27.26,28.93)$ \\
\hline $16 \mathrm{~mm}$ & $(-8.26,-8.03,-7.09)$ & $(-3.32,-4.17,-3.84)$ & $(25.18,24.6,25)$ \\
\hline
\end{tabular}

\begin{tabular}{|c|c|c|c|}
\hline & & bone & \\
\hline & $500 \mathrm{~mW}$ & $1000 \mathrm{~mW}$ & $1500 \mathrm{~mW}$ \\
\hline $3.8 \mathrm{~mm}$ & 6 & 18 & 29.5 \\
\hline $5 \mathrm{~mm}$ & 3 & 14 & 28 \\
\hline $16 \mathrm{~mm}$ & -8 & -3.8 & 25 \\
\hline
\end{tabular}

The reason for the -ve absorption was due to baseline shift. The error might also be due to the occurrence of fluorescence inside the bones, on emission of light. However, this data will be repeated again to eliminate the wrong -ve readings.

Raw Data for Tissue absorption

\begin{tabular}{|l|l|l|l|l|}
\hline & \multicolumn{3}{|l|}{ Tissue } & \\
\hline & $500 \mathrm{~mW}$ & $1000 \mathrm{~mW}$ & $1500 \mathrm{~mW}$ \\
\hline $2.3 \mathrm{~mm}$ & $(18.66,18.58,18.39)$ & $(16.26,16.02,15.96)$ & $(6.15,6.05,5.98)$ \\
\hline $6.8 \mathrm{~mm}$ & $(7.86,8.2,7.95)$ & $(6.21,5.9,6.07)$ & $(2.47,2.9,2.61)$ \\
\hline $8.2 \mathrm{~mm}$ & $(5.07,5.13,4.97)$ & $(4.08,4.12,3.96)$ & $(0.65,0.51,0.45)$ \\
\hline \multicolumn{5}{|r|}{} \\
\hline & \multicolumn{3}{|c|}{ tissue } \\
\hline $2.3 \mathrm{~mm}$ & 18.5 & 16 & 6 \\
\hline $6.8 \mathrm{~mm}$ & 8 & 6 & 2.7 & \\
\hline $8.2 \mathrm{~mm}$ & 5 & 4 & 0.5 & \\
\hline
\end{tabular}


Skin + Fat absorption

\begin{tabular}{|l|l|l|l|}
\hline & \multicolumn{3}{|c|}{ Skin+Fat } \\
\hline & $500 \mathrm{~mW}$ & $1000 \mathrm{~mW}$ & $1500 \mathrm{~mW}$ \\
\hline $3.06 \mathrm{~mm}$ & $(4.96,5.04,5)$ & $(3,3.4,3.27)$ & $(1.74,1.63,1.67)$ \\
\hline $8.5 \mathrm{~mm}$ & $(5.83,6,6.27)$ & $(4.23,4,3.8)$ & $(2.13,2.06,2)$ \\
\hline $11.67 \mathrm{~mm}$ & $(4.9,5.2,5.27)$ & $(5.17,5.03,4.85$ & $(5.2,5.05,5)$ \\
\hline
\end{tabular}

\begin{tabular}{|l|r|r|r|}
\hline & Skin+Fat & & \\
\hline & $500 \mathrm{~mW}$ & $1000 \mathrm{~mW}$ & $1500 \mathrm{~mW}$ \\
\hline $3.06 \mathrm{~mm}$ & 5 & 3.2 & 1.7 \\
\hline $8.5 \mathrm{~mm}$ & 6 & 4 & 2 \\
\hline $11.67 \mathrm{~mm}$ & 5.1 & 5 & 5 \\
\hline
\end{tabular}

$>$ Raw Data for low power treatments of SH-SY-5Y cells (MTT Analysis)

Note: Dark blue regions correspond to the treated wells.

A)

\begin{tabular}{|c|c|c|c|c|c|c|c|c|c|c|c|c|c|}
\hline & 1 & 2 & 3 & 4 & 5 & 6 & 7 & 8 & 9 & 10 & 11 & 12 & \\
\hline \multirow{2}{*}{$A$} & 0.04 & 0.038 & 0.041 & 0.039 & 0.038 & 0.038 & 0.039 & 0.04 & 0.038 & 0.038 & 0.04 & 0.041 & 570 \\
\hline & 0.039 & 0.037 & 0.039 & 0.037 & 0.037 & 0.038 & 0.039 & 0.039 & 0.038 & 0.038 & 0.04 & 0.039 & 630 \\
\hline \multirow{2}{*}{ B } & 0.039 & 0.278 & 0.286 & 0.27 & 0.301 & 0.292 & 0.271 & 0.258 & 0.359 & 0.283 & 0.303 & 0.039 & 570 \\
\hline & 0.038 & 0.084 & 0.087 & 0.084 & 0.09 & 0.087 & 0.083 & 0.081 & 0.099 & 0.083 & 0.09 & 0.039 & 630 \\
\hline \multirow{2}{*}{ C } & 0.048 & 0.257 & 0.308 & 0.272 & 0.294 & 0.292 & 0.288 & 0.309 & 0.292 & 0.281 & 0.306 & 0.038 & 570 \\
\hline & 0.047 & 0.08 & 0.088 & 0.084 & 0.092 & 0.087 & 0.087 & 0.091 & 0.086 & 0.084 & 0.09 & 0.038 & 630 \\
\hline \multirow{2}{*}{ D } & 0.084 & 0.268 & 0.272 & 0.295 & 0.276 & 0.29 & 0.312 & 0.295 & 0.306 & 0.291 & 0.324 & 0.041 & 570 \\
\hline & 0.082 & 0.081 & 0.085 & 0.086 & 0.084 & 0.087 & 0.091 & 0.089 & 0.089 & 0.085 & 0.108 & 0.041 & 630 \\
\hline \multirow{2}{*}{$E$} & 0.041 & 0.294 & 0.311 & 0.288 & 0.319 & 0.311 & 0.316 & 0.321 & 0.31 & 0.305 & 0.313 & 0.04 & 570 \\
\hline & 0.04 & 0.087 & 0.091 & 0.085 & 0.104 & 0.088 & 0.091 & 0.094 & 0.09 & 0.085 & 0.091 & 0.04 & 630 \\
\hline \multirow{2}{*}{$F$} & 0.048 & 0.273 & 0.295 & 0.295 & 0.305 & 0.298 & 0.298 & 0.346 & 0.297 & 0.316 & 0.311 & 0.039 & 570 \\
\hline & 0.048 & 0.085 & 0.087 & 0.088 & 0.09 & 0.088 & 0.092 & 0.096 & 0.088 & 0.09 & 0.091 & 0.038 & 630 \\
\hline \multirow{2}{*}{ G } & 0.042 & 0.327 & 0.325 & 0.32 & 0.35 & 0.307 & 0.341 & 0.324 & 0.312 & 0.379 & 0.302 & 0.052 & 570 \\
\hline & 0.041 & 0.097 & 0.092 & 0.092 & 0.097 & 0.09 & 0.096 & 0.094 & 0.09 & 0.109 & 0.094 & 0.051 & 630 \\
\hline \multirow{2}{*}{$\mathrm{H}$} & 0.061 & 0.039 & 0.042 & 0.066 & 0.038 & 0.037 & 0.04 & 0.04 & 0.041 & 0.042 & 0.037 & 0.038 & 570 \\
\hline & 0.059 & 0.038 & 0.041 & 0.064 & 0.038 & 0.037 & 0.039 & 0.039 & 0.04 & 0.041 & 0.037 & 0.037 & 630 \\
\hline
\end{tabular}


B)

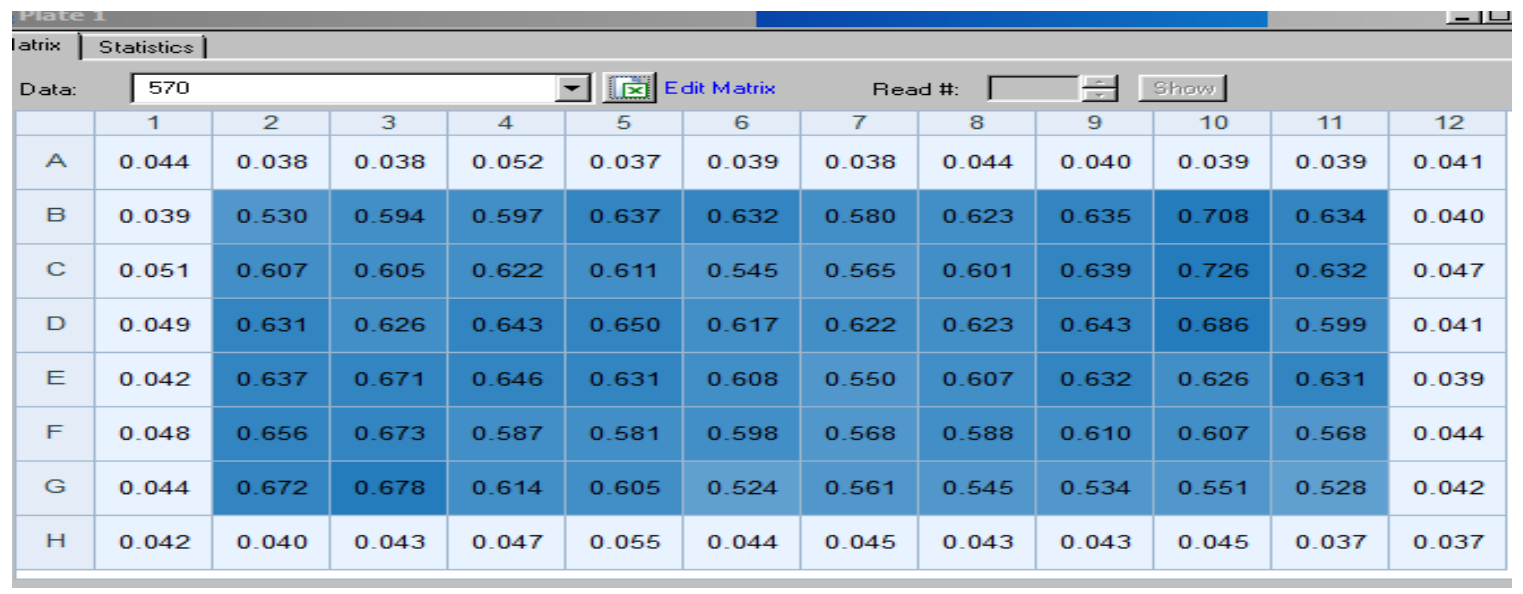

\begin{tabular}{|c|c|c|c|c|c|c|c|c|c|c|c|c|}
\hline \multirow{3}{*}{$\begin{array}{l}\text { itrix } \\
\text { Jata: }\end{array}$} & \multicolumn{12}{|c|}{ Statistics | } \\
\hline & \multicolumn{4}{|l|}{1630} & \multicolumn{2}{|c|}{ [x] Edit Matrix } & \multicolumn{4}{|c|}{ Read \#: $\square=-$ Show } & & \\
\hline & 1 & 2 & 3 & 4 & 5 & 6 & 7 & 8 & 9 & 10 & 11 & 12 \\
\hline$A$ & 0.043 & 0.037 & 0.037 & 0.045 & 0.036 & 0.038 & 0.038 & 0.043 & 0.039 & 0.039 & 0.038 & 0.042 \\
\hline в & 0.039 & 0.140 & 0.153 & 0.147 & 0.153 & 0.156 & 0.148 & 0.152 & 0.156 & 0.170 & 0.157 & 0.039 \\
\hline c & 0.050 & 0.150 & 0.150 & 0.150 & 0.155 & 0.159 & 0.145 & 0.155 & 0.160 & 0.175 & 0.156 & 0.046 \\
\hline D & 0.048 & 0.163 & 0.154 & 0.156 & 0.159 & 0.150 & 0.155 & 0.154 & 0.155 & 0.163 & 0.148 & 0.041 \\
\hline$E$ & 0.042 & 0.154 & 0.159 & 0.163 & 0.155 & 0.149 & 0.147 & 0.151 & 0.154 & 0.152 & 0.154 & 0.039 \\
\hline$F$ & 0.047 & 0.168 & 0.168 & 0.147 & 0.152 & 0.159 & 0.149 & 0.145 & 0.171 & 0.152 & 0.148 & 0.043 \\
\hline$G$ & 0.044 & 0.169 & 0.177 & 0.164 & 0.155 & 0.138 & 0.146 & 0.141 & 0.138 & 0.146 & 0.145 & 0.042 \\
\hline $\mathrm{H}$ & 0.042 & 0.039 & 0.042 & 0.045 & 0.055 & 0.043 & 0.044 & 0.042 & 0.042 & 0.043 & 0.037 & 0.036 \\
\hline
\end{tabular}

C)

\begin{tabular}{|c|c|c|c|c|c|c|c|c|c|c|c|c|}
\hline & 1 & 2 & 3 & 4 & 5 & 6 & 7 & 8 & 9 & 10 & 11 & 12 \\
\hline \multirow{2}{*}{ A } & 0.289 & 0.216 & 0.253 & 0.262 & 0.246 & 0.254 & 0.218 & 0.233 & 0.243 & 0.231 & 0.164 & 0.15 \\
\hline & 0.087 & 0.072 & 0.078 & 0.08 & 0.077 & 0.08 & 0.073 & 0.077 & 0.08 & 0.076 & 0.063 & 0.061 \\
\hline \multirow{2}{*}{ B } & 0.05 & 0.045 & 0.045 & 0.044 & 0.052 & 0.043 & 0.044 & 0.045 & 0.043 & 0.24 & 0.213 & 0.203 \\
\hline & 0.048 & 0.043 & 0.043 & 0.042 & 0.051 & 0.041 & 0.042 & 0.043 & 0.041 & 0.078 & 0.072 & 0.072 \\
\hline \multirow{2}{*}{ C } & 0.047 & 0.044 & 0.047 & 0.056 & 0.043 & 0.043 & 0.044 & 0.044 & 0.043 & 0.253 & 0.188 & 0.163 \\
\hline & 0.046 & 0.043 & 0.045 & 0.056 & 0.041 & 0.041 & 0.043 & 0.043 & 0.041 & 0.08 & 0.068 & 0.064 \\
\hline \multirow{2}{*}{$\mathrm{D}$} & 0.047 & 0.047 & 0.048 & 0.047 & 0.045 & 0.043 & 0.043 & 0.071 & 0.045 & 0.257 & 0.224 & 0.215 \\
\hline & 0.045 & 0.046 & 0.046 & 0.045 & 0.044 & 0.042 & 0.041 & 0.068 & 0.043 & 0.082 & 0.079 & 0.077 \\
\hline \multirow{2}{*}{$E$} & 0.046 & 0.044 & 0.043 & 0.043 & 0.044 & 0.043 & 0.044 & 0.041 & 0.044 & 0.273 & 0.213 & 0.183 \\
\hline & 0.044 & 0.043 & 0.042 & 0.042 & 0.043 & 0.042 & 0.043 & 0.04 & 0.042 & 0.087 & 0.074 & 0.069 \\
\hline \multirow{2}{*}{$\mathrm{F}$} & 0.054 & 0.043 & 0.044 & 0.045 & 0.048 & 0.045 & 0.045 & 0.044 & 0.044 & 0.287 & 0.25 & 0.228 \\
\hline & 0.052 & 0.042 & 0.042 & 0.042 & 0.045 & 0.043 & 0.043 & 0.042 & 0.042 & 0.091 & 0.08 & 0.075 \\
\hline \multirow{2}{*}{ G } & 0.05 & 0.046 & 0.046 & 0.049 & 0.049 & 0.044 & 0.058 & 0.046 & 0.044 & 0.299 & 0.258 & 0.192 \\
\hline & 0.048 & 0.045 & 0.044 & 0.046 & 0.047 & 0.042 & 0.055 & 0.045 & 0.043 & 0.088 & 0.081 & 0.069 \\
\hline \multirow{2}{*}{$\mathrm{H}$} & 0.044 & 0.044 & 0.045 & 0.044 & 0.044 & 0.045 & 0.101 & 0.045 & 0.046 & 0.326 & 0.234 & 0.294 \\
\hline & 0.043 & 0.042 & 0.043 & 0.042 & 0.043 & 0.043 & 0.092 & 0.043 & 0.044 & 0.101 & 0.075 & 0.086 \\
\hline
\end{tabular}

Data showed no significant response towards the laser treatments. 
Raw Data for MTT analysis for SH-SY5Y at high power treatments

A)

\begin{tabular}{|c|c|c|c|c|c|c|c|c|c|c|c|c|c|}
\hline & 1 & 2 & 3 & 4 & 5 & 6 & 7 & 8 & 9 & 10 & 11 & 12 & \\
\hline \multirow{2}{*}{ A } & 0.039 & 0.041 & 0.039 & 0.044 & 0.037 & 0.041 & 0.041 & 0.039 & 0.04 & 0.039 & 0.039 & 0.038 & 570 \\
\hline & 0.038 & 0.041 & 0.038 & 0.041 & 0.036 & 0.04 & 0.04 & 0.039 & 0.039 & 0.038 & 0.039 & 0.038 & 630 \\
\hline \multirow{2}{*}{ B } & 0.04 & 0.314 & 0.451 & 0.383 & 0.577 & 0.418 & 0.617 & 0.412 & 0.381 & 0.336 & 0.318 & 0.038 & 570 \\
\hline & 0.039 & 0.096 & 0.115 & 0.103 & 0.136 & 0.108 & 0.144 & 0.108 & 0.105 & 0.095 & 0.093 & 0.037 & 630 \\
\hline \multirow{2}{*}{ C } & 0.048 & 0.564 & 0.576 & 0.379 & 0.544 & 0.504 & 0.524 & 0.454 & 0.42 & 0.473 & 0.367 & 0.039 & 570 \\
\hline & 0.048 & 0.166 & 0.149 & 0.105 & 0.132 & 0.132 & 0.131 & 0.115 & 0.108 & 0.119 & 0.099 & 0.039 & 630 \\
\hline \multirow{2}{*}{ D } & 0.038 & 0.604 & 0.487 & 0.353 & 0.577 & 0.517 & 0.406 & 0.388 & 0.401 & 0.267 & 0.349 & 0.039 & 570 \\
\hline & 0.038 & 0.164 & 0.129 & 0.098 & 0.155 & 0.133 & 0.107 & 0.105 & 0.106 & 0.082 & 0.097 & 0.039 & 630 \\
\hline \multirow[b]{2}{*}{$E$} & 0.04 & 0.526 & 0.544 & 0.382 & 0.567 & 0.518 & 0.606 & 0.38 & 0.503 & 0.461 & 0.418 & 0.039 & 570 \\
\hline & 0.039 & 0.167 & 0.138 & 0.107 & 0.136 & 0.126 & 0.14 & 0.106 & 0.126 & 0.116 & 0.109 & 0.043 & 630 \\
\hline \multirow{2}{*}{$\mathrm{F}$} & 0.041 & 0.452 & 0.579 & 0.255 & 0.434 & 0.538 & 0.482 & 0.336 & 0.546 & 0.569 & 0.515 & 0.073 & 570 \\
\hline & 0.04 & 0.116 & 0.137 & 0.079 & 0.106 & 0.151 & 0.126 & 0.094 & 0.155 & 0.136 & 0.126 & 0.07 & 630 \\
\hline \multirow{2}{*}{ G } & 0.04 & 0.438 & 0.565 & 0.432 & 0.422 & 0.43 & 0.528 & 0.46 & 0.418 & 0.331 & 0.466 & 0.042 & 570 \\
\hline & 0.039 & 0.152 & 0.135 & 0.113 & 0.114 & 0.136 & 0.168 & 0.121 & 0.132 & 0.094 & 0.118 & 0.041 & 630 \\
\hline \multirow{2}{*}{$\mathrm{H}$} & 0.04 & 0.039 & 0.041 & 0.051 & 0.064 & 0.037 & 0.039 & 0.046 & 0.04 & 0.042 & 0.038 & 0.037 & 570 \\
\hline & 0.039 & 0.038 & 0.041 & 0.05 & 0.058 & 0.036 & 0.038 & 0.046 & 0.039 & 0.042 & 0.037 & 0.037 & 630 \\
\hline
\end{tabular}

B)

\begin{tabular}{|c|c|c|c|c|c|c|c|c|c|c|c|c|c|}
\hline & 1 & 2 & 3 & 4 & 5 & 6 & 7 & 8 & 9 & 10 & 11 & 12 & \\
\hline \multirow{2}{*}{ A } & 0.039 & 0.045 & 0.038 & 0.041 & 0.037 & 0.039 & 0.038 & 0.039 & 0.039 & 0.039 & 0.039 & 0.044 & 570 \\
\hline & 0.038 & 0.045 & 0.037 & 0.04 & 0.036 & 0.038 & 0.037 & 0.038 & 0.039 & 0.039 & 0.038 & 0.044 & 630 \\
\hline \multirow{2}{*}{ B } & 0.039 & 0.543 & 0.459 & 0.564 & 0.551 & 0.52 & 0.618 & 0.481 & 0.523 & 0.588 & 0.487 & 0.041 & 570 \\
\hline & 0.039 & 0.143 & 0.119 & 0.142 & 0.135 & 0.137 & 0.147 & 0.122 & 0.138 & 0.142 & 0.123 & 0.04 & 630 \\
\hline \multirow{2}{*}{ C } & 0.039 & 0.547 & 0.531 & 0.544 & 0.451 & 0.546 & 0.538 & 0.503 & 0.554 & 0.53 & 0.533 & 0.039 & 570 \\
\hline & 0.038 & 0.147 & 0.134 & 0.136 & 0.118 & 0.135 & 0.133 & 0.128 & 0.143 & 0.131 & 0.131 & 0.039 & 630 \\
\hline \multirow{2}{*}{$D$} & 0.039 & 0.61 & 0.525 & 0.468 & 0.505 & 0.63 & 0.58 & 0.532 & 0.521 & 0.506 & 0.432 & 0.04 & 570 \\
\hline & 0.039 & 0.163 & 0.129 & 0.122 & 0.126 & 0.15 & 0.14 & 0.132 & 0.131 & 0.127 & 0.114 & 0.04 & 630 \\
\hline \multirow{2}{*}{$\mathrm{E}$} & 0.038 & 0.564 & 0.624 & 0.54 & 0.571 & 0.583 & 0.567 & 0.53 & 0.546 & 0.536 & 0.43 & 0.04 & 570 \\
\hline & 0.038 & 0.146 & 0.149 & 0.134 & 0.137 & 0.144 & 0.154 & 0.133 & 0.135 & 0.132 & 0.115 & 0.04 & 630 \\
\hline \multirow{2}{*}{$\mathrm{F}$} & 0.04 & 0.579 & 0.561 & 0.492 & 0.547 & 0.524 & 0.555 & 0.522 & 0.497 & 0.475 & 0.477 & 0.039 & 570 \\
\hline & 0.04 & 0.146 & 0.143 & 0.124 & 0.141 & 0.129 & 0.135 & 0.129 & 0.123 & 0.121 & 0.123 & 0.039 & 630 \\
\hline \multirow{2}{*}{ G } & 0.07 & 0.51 & 0.462 & 0.472 & 0.489 & 0.569 & 0.48 & 0.501 & 0.473 & 0.449 & 0.46 & 0.041 & 570 \\
\hline & 0.066 & 0.127 & 0.134 & 0.126 & 0.123 & 0.141 & 0.119 & 0.128 & 0.12 & 0.117 & 0.136 & 0.04 & 630 \\
\hline \multirow{2}{*}{$\mathrm{H}$} & 0.038 & 0.04 & 0.038 & 0.039 & 0.039 & 0.038 & 0.04 & 0.039 & 0.039 & 0.043 & 0.037 & 0.037 & 570 \\
\hline & 0.038 & 0.039 & 0.037 & 0.038 & 0.039 & 0.037 & 0.04 & 0.039 & 0.038 & 0.042 & 0.037 & 0.037 & 630 \\
\hline
\end{tabular}

C)

\begin{tabular}{|c|c|c|c|c|c|c|c|c|c|c|c|c|c|}
\hline & 1 & 2 & 3 & 4 & 5 & 6 & 7 & 8 & 9 & 10 & 11 & 12 & \\
\hline \multirow{2}{*}{ A } & 0.038 & 0.247 & 0.039 & 0.038 & 0.041 & 0.039 & 0.043 & 0.038 & 0.04 & 0.039 & 0.039 & 0.039 & 570 \\
\hline & 0.037 & 0.233 & 0.038 & 0.037 & 0.039 & 0.039 & 0.041 & 0.038 & 0.039 & 0.038 & 0.038 & 0.039 & 630 \\
\hline \multirow{2}{*}{ B } & 0.039 & 0.283 & 0.328 & 0.345 & 0.344 & 0.302 & 0.318 & 0.339 & 0.327 & 0.338 & 0.337 & 0.039 & 570 \\
\hline & 0.039 & 0.086 & 0.095 & 0.098 & 0.098 & 0.093 & 0.092 & 0.096 & 0.093 & 0.095 & 0.095 & 0.039 & 630 \\
\hline \multirow{2}{*}{ C } & 0.039 & 0.302 & 0.316 & 0.336 & 0.362 & 0.312 & 0.313 & 0.318 & 0.295 & 0.333 & 0.324 & 0.042 & 570 \\
\hline & 0.038 & 0.089 & 0.091 & 0.097 & 0.099 & 0.088 & 0.096 & 0.091 & 0.088 & 0.097 & 0.093 & 0.041 & 630 \\
\hline \multirow{2}{*}{ D } & 0.039 & 0.316 & 0.319 & 0.329 & 0.359 & 0.315 & 0.319 & 0.359 & 0.316 & 0.267 & 0.304 & 0.042 & 570 \\
\hline & 0.038 & 0.102 & 0.091 & 0.097 & 0.096 & 0.091 & 0.096 & 0.099 & 0.092 & 0.085 & 0.089 & 0.041 & 630 \\
\hline \multirow{2}{*}{$E$} & 0.041 & 0.322 & 0.319 & 0.312 & 0.317 & 0.319 & 0.327 & 0.324 & 0.344 & 0.372 & 0.342 & 0.039 & 570 \\
\hline & 0.04 & 0.1 & 0.096 & 0.09 & 0.093 & 0.091 & 0.109 & 0.094 & 0.107 & 0.126 & 0.096 & 0.038 & 630 \\
\hline \multirow{2}{*}{$\mathrm{F}$} & 0.043 & 0.343 & 0.314 & 0.309 & 0.319 & 0.306 & 0.303 & 0.315 & 0.326 & 0.296 & 0.322 & 0.039 & 570 \\
\hline & 0.042 & 0.097 & 0.096 & 0.09 & 0.091 & 0.089 & 0.096 & 0.091 & 0.093 & 0.088 & 0.093 & 0.038 & 630 \\
\hline \multirow{2}{*}{ G } & 0.039 & 0.346 & 0.321 & 0.317 & 0.323 & 0.321 & 0.319 & 0.334 & 0.329 & 0.328 & 0.296 & 0.04 & 570 \\
\hline & 0.038 & 0.098 & 0.091 & 0.092 & 0.091 & 0.092 & 0.093 & 0.096 & 0.098 & 0.095 & 0.088 & 0.039 & 630 \\
\hline \multirow[b]{2}{*}{$\mathrm{H}$} & 0.04 & 0.04 & 0.044 & 0.039 & 0.039 & 0.039 & 0.039 & 0.039 & 0.041 & 0.04 & 0.042 & 0.04 & 570 \\
\hline & 0.039 & 0.039 & 0.045 & 0.038 & 0.038 & 0.038 & 0.039 & 0.038 & 0.04 & 0.039 & 0.04 & 0.04 & 630 \\
\hline
\end{tabular}


Data Analysis for MTT analysis for SH-SY5Y at high power treatments

$200 \mathrm{~mW}$

One Way Analysis of Variance

Wednesday, April 13, 2016, 11:45:50 AM

Data source: Data 1 in Notebook1

Normality Test (Shapiro-Wilk) Passed $\quad(P=0.107)$

Equal Variance Test: $\quad$ Passed $\quad(P=0.715)$

\begin{tabular}{|c|c|c|c|c|c|c|}
\hline Group Name & $\mathbf{N}$ & Missing & Mean & Std Dev & SEM & \\
\hline Col 1 & 3 & 0 & 1.000 & 0.000 & 0.000 & \\
\hline Col 2 & 3 & 0 & 1.191 & 0.346 & 0.200 & \\
\hline Col 3 & 3 & 0 & 1.198 & 0.125 & 0.0719 & \\
\hline Col 4 & 3 & 0 & 1.437 & 0.518 & 0.299 & \\
\hline Col 5 & 3 & 0 & 1.147 & 0.244 & 0.141 & \\
\hline Col 6 & 3 & 0 & 1.498 & 0.582 & 0.336 & \\
\hline $\operatorname{Col} 7$ & 3 & 0 & 1.175 & 0.253 & 0.146 & \\
\hline Col 8 & 3 & 0 & 1.139 & 0.157 & 0.0908 & \\
\hline Col 9 & 3 & 0 & 1.152 & 0.0714 & 0.0412 & \\
\hline Col 10 & 3 & 0 & 1.057 & 0.160 & 0.0926 & \\
\hline \multicolumn{2}{|c|}{ Source of Variation } & DF & SS & MS & $\mathbf{F}$ & $\mathbf{P}$ \\
\hline \multicolumn{2}{|c|}{ Between Groups } & 9 & 0.646 & 0.0718 & 0.780 & 0.637 \\
\hline \multicolumn{2}{|l|}{ Residual } & 20 & 1.842 & 0.0921 & & \\
\hline \multicolumn{2}{|l|}{ Total } & 29 & 2.488 & & & \\
\hline
\end{tabular}

The differences in the mean values among the treatment groups are not great enough to exclude the possibility that the difference is due to random sampling variability; there is not a statistically significant difference $(\mathrm{P}=0.637)$.

Power of performed test with alpha $=0.050: 0.050$

The power of the performed test (0.050) is below the desired power of 0.800 .

Less than desired power indicates you are less likely to detect a difference when one actually exists.

Negative results should be interpreted cautiously.

$300 \mathrm{~mW}$

One Way Analysis of Variance

Wednesday, April 13, 2016, 11:48:17 AM

Data source: Data 1 in Notebook1

Normality Test (Shapiro-Wilk) Passed $\quad(\mathrm{P}=0.165)$

Equal Variance Test: $\quad$ Passed $\quad(P=0.310)$

\begin{tabular}{lccccc} 
Group Name & N & Missing & Mean & Std Dev & \multicolumn{1}{c}{ SEM } \\
Col 12 & 3 & 0 & 1.000 & 0.000 & 0.000 \\
Col 13 & 3 & 0 & 1.041 & 0.0421 & 0.0243 \\
Col 14 & 3 & 0 & 0.943 & 0.227 & 0.131 \\
Col 15 & 3 & 0 & 1.034 & 0.201 & 0.116
\end{tabular}




$\begin{array}{llllll}\text { Col 16 } & 3 & 0 & 1.005 & 0.0618 & 0.0357 \\ \text { Col 17 } & 3 & 0 & 1.006 & 0.0170 & 0.00982 \\ \text { Col 18 } & 3 & 0 & 0.952 & 0.108 & 0.0622 \\ \text { Col 19 } & 3 & 0 & 0.928 & 0.128 & 0.0738 \\ \text { Col 20 } & 3 & 0 & 0.998 & 0.110 & 0.0632 \\ \text { Col 21 } & 3 & 0 & 0.921 & 0.218 & 0.126\end{array}$

$\begin{array}{lrlccc}\text { Source of Variation } & \text { DF } & \text { SS } & \text { MS } & \text { F } & \text { P } \\ \text { Between Groups } & 9 & 0.0507 & 0.00564 & 0.304 & 0.965 \\ \text { Residual } & 20 & 0.371 & 0.0185 & & \\ \text { Total } & 29 & 0.422 & & & \end{array}$

The differences in the mean values among the treatment groups are not great enough to exclude the possibility that the difference is due to random sampling variability; there is not a statistically significant difference $(\mathrm{P}=0.965)$.

Power of performed test with alpha $=0.050: 0.050$

The power of the performed test $(0.050)$ is below the desired power of 0.800 .

Less than desired power indicates you are less likely to detect a difference when one actually exists.

Negative results should be interpreted cautiously.

$400 \mathrm{~mW}$

One Way Analysis of Variance

Wednesday, April 13, 2016, 11:49:53 AM

Data source: Data 1 in Notebook1

Normality Test (Shapiro-Wilk) Passed $\quad(\mathrm{P}=0.509)$

Equal Variance Test: $\quad$ Passed $\quad(\mathrm{P}=0.925)$

$\begin{array}{lccccl}\text { Group Name } & \text { N } & \text { Missing } & \text { Mean } & \text { Std Dev } & \text { SEM } \\ \text { Col 23 } & 3 & 0 & 1.000 & 0.000 & 0.000 \\ \text { Col 24 } & 3 & 0 & 0.922 & 0.129 & 0.0746 \\ \text { Col 25 } & 3 & 0 & 0.813 & 0.254 & 0.147 \\ \text { Col 26 } & 3 & 0 & 1.012 & 0.196 & 0.113 \\ \text { Col 27 } & 3 & 0 & 0.998 & 0.109 & 0.0630 \\ \text { Col 28 } & 3 & 0 & 0.902 & 0.194 & 0.112 \\ \text { Col 29 } & 3 & 0 & 0.918 & 0.287 & 0.166 \\ \text { Col 30 } & 3 & 0 & 0.863 & 0.189 & 0.109 \\ \text { Col 31 } & 3 & 0 & 0.706 & 0.248 & 0.143 \\ \text { Col 32 } & 3 & 0 & 0.763 & 0.221 & 0.127\end{array}$

$\begin{array}{lrcccc}\text { Source of Variation } & \text { DF } & \text { SS } & \text { MS } & \text { F } & \text { P } \\ \text { Between Groups } & 9 & 0.292 & 0.0324 & 0.816 & 0.608 \\ \text { Residual } & 20 & 0.794 & 0.0397 & & \\ \text { Total } & 29 & 1.086 & & & \end{array}$

The differences in the mean values among the treatment groups are not great enough to exclude the possibility that the difference is due to random sampling variability; there is not a statistically significant difference $(\mathrm{P}=0.608)$. 
Power of performed test with alpha $=0.050: 0.050$

The power of the performed test $(0.050)$ is below the desired power of 0.800 .

Less than desired power indicates you are less likely to detect a difference when one actually exists.

Negative results should be interpreted cautiously.

$500 \mathrm{~mW}$

One Way Analysis of Variance

Wednesday, April 13, 2016, 11:52:02 AM

Data source: Data 1 in Notebook1

Normality Test (Shapiro-Wilk) Passed $\quad(\mathrm{P}=0.536)$

Equal Variance Test: $\quad$ Passed $\quad(\mathrm{P}=0.863)$

$\begin{array}{lcccccc}\text { Group Name } & \text { N } & \text { Missing } & \text { Mean } & \text { Std Dev } & \text { SEM } & \\ \text { Col 34 } & 3 & 0 & 1.000 & 0.000 & 0.000 & \\ \text { Col 35 } & 3 & 0 & 1.091 & 0.0742 & 0.0429 & \\ \text { Col 36 } & 3 & 0 & 0.912 & 0.128 & 0.0736 & \\ \text { Col 37 } & 3 & 0 & 1.083 & 0.104 & 0.0598 & \\ \text { Col 38 } & 3 & 0 & 1.056 & 0.0330 & 0.0190 & \\ \text { Col 39 } & 3 & 0 & 1.089 & 0.181 & 0.104 & \\ \text { Col 40 } & 3 & 0 & 0.916 & 0.140 & 0.0806 & \\ \text { Col 41 } & 3 & 0 & 1.034 & 0.0448 & 0.0259 & \\ \text { Col 42 } & 3 & 0 & 1.012 & 0.0832 & 0.0480 & \\ \text { Col 43 } & 3 & 0 & 0.908 & 0.182 & 0.105 & \\ & & & & & & \\ \text { Source of Variation } & \text { DF } & \text { SS } & \text { MS } & \text { F } & \text { P } \\ \text { Between Groups } & 9 & 0.149 & 0.0166 & 1.298 & 0.298 \\ \text { Residual } & & 20 & 0.255 & 0.0128 & & \\ \text { Total } & 29 & 0.404 & & & \end{array}$

The differences in the mean values among the treatment groups are not great enough to exclude the possibility that the difference is due to random sampling variability; there is not a statistically significant difference $(\mathrm{P}=0.298)$.

Power of performed test with alpha $=0.050: 0.119$

The power of the performed test (0.119) is below the desired power of 0.800 .

Less than desired power indicates you are less likely to detect a difference when one actually exists.

Negative results should be interpreted cautiously.

$750 \mathrm{~mW}$

One Way Analysis of Variance

Wednesday, April 13, 2016, 11:53:16 AM

Data source: Data 1 in Notebook1

Normality Test (Shapiro-Wilk) Passed $\quad(\mathrm{P}=0.503)$

Equal Variance Test: $\quad$ Passed $\quad(P=0.926)$ 


$\begin{array}{lccccc}\text { Group Name } & \text { N } & \text { Missing } & \text { Mean } & \text { Std Dev } & \text { SEM } \\ \text { Col 45 } & 3 & 0 & 1.000 & 0.000 & 0.000 \\ \text { Col 46 } & 3 & 0 & 1.056 & 0.228 & 0.132 \\ \text { Col 47 } & 3 & 0 & 0.755 & 0.201 & 0.116 \\ \text { Col 48 } & 3 & 0 & 0.947 & 0.0259 & 0.0150 \\ \text { Col 49 } & 3 & 0 & 0.982 & 0.148 & 0.0853 \\ \text { Col 50 } & 3 & 0 & 0.957 & 0.110 & 0.0633 \\ \text { Col 51 } & 3 & 0 & 0.846 & 0.109 & 0.0630 \\ \text { Col 52 } & 3 & 0 & 0.992 & 0.155 & 0.0894 \\ \text { Col 53 } & 3 & 0 & 0.984 & 0.264 & 0.153 \\ \text { Col 54 } & 3 & 0 & 0.969 & 0.173 & 0.100 \\ & & & & & \\ \text { Source of Variation } & \text { DF } & \text { SS } & \text { MS } & \text { F } & \text { P } \\ \text { Between Groups } & 9 & 0.201 & 0.0223 & 0.849 & 0.583 \\ \text { Residual } & & 20 & 0.526 & 0.0263 & \end{array}$

The differences in the mean values among the treatment groups are not great enough to exclude the possibility that the difference is due to random sampling variability; there is not a statistically significant difference $(\mathrm{P}=0.583)$.

Power of performed test with alpha $=0.050: 0.050$

The power of the performed test $(0.050)$ is below the desired power of 0.800 .

Less than desired power indicates you are less likely to detect a difference when one actually exists.

Negative results should be interpreted cautiously.

$1000 \mathrm{~mW}$

One Way Analysis of Variance

Wednesday, April 13, 2016, 11:55:29 AM

Data source: Data 1 in Notebook1

Normality Test (Shapiro-Wilk) Failed $\quad(\mathrm{P}<0.050)$

Equal Variance Test: $\quad$ Passed $\quad(P=0.832)$

\begin{tabular}{lcccccc} 
Group Name & $\mathbf{N}$ & Missing & Mean & Std Dev & SEM \\
Col 56 & 3 & 0 & 1.000 & 0.000 & 0.000 \\
Col 57 & 3 & 0 & 1.096 & 0.355 & 0.205 \\
Col 58 & 3 & 0 & 0.975 & 0.121 & 0.0700 & \\
Col 59 & 3 & 0 & 0.989 & 0.0765 & 0.0442 \\
Col 60 & 3 & 0 & 1.023 & 0.0972 & 0.0561 \\
Col 61 & 3 & 0 & 1.038 & 0.192 & 0.111 \\
Col 62 & 3 & 0 & 1.040 & 0.126 & 0.0730 \\
Col 63 & 3 & 0 & 0.951 & 0.0427 & 0.0246 \\
Col 64 & 3 & 0 & 0.878 & 0.0563 & 0.0325 & \\
Col 65 & 3 & 0 & 0.967 & 0.216 & 0.125 & \\
\multicolumn{2}{l}{ Source of Variation } & DF & SS & MS & F & P \\
Between Groups & 9 & 0.0945 & 0.0105 & 0.403 & 0.919 \\
Residual & & 20 & 0.521 & 0.0261 & & \\
Total & 29 & 0.616 & & &
\end{tabular}


The differences in the mean values among the treatment groups are not great enough to exclude the possibility that the difference is due to random sampling variability; there is not a statistically significant difference $(\mathrm{P}=0.919)$.

Power of performed test with alpha $=0.050: 0.050$

The power of the performed test $(0.050)$ is below the desired power of 0.800 .

Less than desired power indicates you are less likely to detect a difference when one actually exists.

Negative results should be interpreted cautiously.

A)

\begin{tabular}{|c|c|c|c|c|c|c|c|c|c|c|c|c|}
\hline & 1 & 2 & 3 & 4 & 5 & 6 & 7 & 8 & 9 & 10 & 11 & 12 \\
\hline \multirow{2}{*}{ A } & 0.043 & 0.04 & 0.038 & 0.038 & 0.04 & 0.043 & 0.038 & 0.039 & 0.044 & 0.046 & 0.037 & 0.055 \\
\hline & 0.042 & 0.038 & 0.038 & 0.038 & 0.039 & 0.04 & 0.037 & 0.038 & 0.038 & 0.043 & 0.037 & 0.055 \\
\hline \multirow{2}{*}{ B } & 0.039 & 0.623 & 0.926 & 0.673 & 0.589 & 0.676 & 0.573 & 0.696 & 0.599 & 0.543 & 0.486 & 0.039 \\
\hline & 0.038 & 0.162 & 0.249 & 0.17 & 0.158 & 0.175 & 0.158 & 0.203 & 0.159 & 0.138 & 0.131 & 0.038 \\
\hline \multirow{2}{*}{ C } & 0.039 & 0.68 & 0.662 & 0.65 & 0.61 & 0.638 & 0.532 & 0.529 & 0.554 & 0.588 & 0.487 & 0.04 \\
\hline & 0.038 & 0.168 & 0.165 & 0.181 & 0.153 & 0.161 & 0.14 & 0.142 & 0.181 & 0.156 & 0.131 & 0.039 \\
\hline \multirow{2}{*}{ D } & 0.04 & 0.7 & 0.746 & 0.679 & 0.545 & 0.707 & 0.575 & 0.728 & 0.538 & 0.518 & 0.516 & 0.038 \\
\hline & 0.039 & 0.173 & 0.17 & 0.2 & 0.136 & 0.166 & 0.175 & 0.176 & 0.145 & 0.137 & 0.137 & 0.037 \\
\hline \multirow{2}{*}{$E$} & 0.039 & 0.679 & 0.632 & 0.636 & 0.807 & 0.629 & 0.558 & 0.663 & 0.625 & 0.547 & 0.577 & 0.038 \\
\hline & 0.038 & 0.169 & 0.176 & 0.185 & 0.203 & 0.183 & 0.149 & 0.179 & 0.164 & 0.139 & 0.144 & 0.038 \\
\hline \multirow{2}{*}{$\mathrm{F}$} & 0.043 & 0.658 & 0.646 & 0.649 & 0.779 & 0.565 & 0.567 & 0.625 & 0.612 & 0.556 & 0.674 & 0.038 \\
\hline & 0.044 & 0.17 & 0.155 & 0.161 & 0.18 & 0.138 & 0.147 & 0.159 & 0.16 & 0.139 & 0.175 & 0.038 \\
\hline \multirow{2}{*}{ G } & 0.043 & 0.7 & 0.709 & 0.855 & 0.588 & 0.812 & 0.547 & 0.63 & 0.6 & 0.677 & 0.639 & 0.039 \\
\hline & 0.042 & 0.191 & 0.173 & 0.19 & 0.145 & 0.189 & 0.143 & 0.162 & 0.149 & 0.167 & 0.161 & 0.038 \\
\hline \multirow{2}{*}{$\mathrm{H}$} & 0.05 & 0.039 & 0.04 & 0.039 & 0.043 & 0.04 & 0.041 & 0.048 & 0.039 & 0.04 & 0.04 & 0.037 \\
\hline & 0.05 & 0.039 & 0.039 & 0.039 & 0.041 & 0.04 & 0.041 & 0.047 & 0.038 & 0.041 & 0.04 & 0.036 \\
\hline
\end{tabular}

B)

\begin{tabular}{|c|c|c|c|c|c|c|c|c|c|c|c|c|c|}
\hline & 1 & 2 & 3 & 4 & 5 & 6 & 7 & 8 & 9 & 10 & 11 & 12 & \\
\hline \multirow{2}{*}{ A } & 0.084 & 0.085 & 0.089 & 0.094 & 0.089 & 0.089 & 0.091 & 0.09 & 0.089 & 0.092 & 0.088 & 0.09 & 570 \\
\hline & 0.083 & 0.083 & 0.087 & 0.092 & 0.088 & 0.09 & 0.091 & 0.089 & 0.089 & 0.091 & 0.086 & 0.092 & 630 \\
\hline \multirow{2}{*}{ B } & 0.086 & 0.116 & 0.179 & 0.162 & 0.144 & 0.17 & 0.125 & 0.154 & 0.139 & 0.124 & 0.15 & 0.098 & 570 \\
\hline & 0.084 & 0.094 & 0.124 & 0.114 & 0.109 & 0.117 & 0.108 & 0.108 & 0.108 & 0.103 & 0.111 & 0.1 & 630 \\
\hline \multirow{2}{*}{ C } & 0.084 & 0.152 & 0.169 & 0.145 & 0.132 & 0.169 & 0.13 & 0.17 & 0.123 & 0.119 & 0.168 & 0.092 & 570 \\
\hline & 0.083 & 0.128 & 0.116 & 0.106 & 0.103 & 0.111 & 0.101 & 0.116 & 0.097 & 0.098 & 0.122 & 0.093 & 630 \\
\hline \multirow{2}{*}{ D } & 0.084 & 0.172 & 0.206 & 0.399 & 0.715 & 0.399 & 0.159 & 0.192 & 0.159 & 0.168 & 0.486 & 0.114 & 570 \\
\hline & 0.084 & 0.134 & 0.143 & 0.305 & 0.516 & 0.286 & 0.126 & 0.134 & 0.113 & 0.125 & 0.368 & 0.111 & 630 \\
\hline \multirow{2}{*}{$E$} & 0.082 & 0.131 & 0.17 & 0.143 & 0.144 & 0.161 & 0.153 & 0.155 & 0.15 & 0.142 & 0.154 & 0.093 & 570 \\
\hline & 0.083 & 0.102 & 0.128 & 0.113 & 0.11 & 0.109 & 0.107 & 0.109 & 0.114 & 0.105 & 0.125 & 0.093 & 630 \\
\hline \multirow{2}{*}{$\mathrm{F}$} & 0.083 & 0.145 & 0.196 & 0.131 & 0.151 & 0.288 & 0.146 & 0.166 & 0.167 & 0.136 & 0.232 & 0.088 & 570 \\
\hline & 0.084 & 0.102 & 0.134 & 0.103 & 0.107 & 0.212 & 0.108 & 0.151 & 0.122 & 0.109 & 0.171 & 0.087 & 630 \\
\hline \multirow{2}{*}{ G } & 0.082 & 0.149 & 0.193 & 0.135 & 0.211 & 0.785 & 0.14 & 0.166 & 0.159 & 0.143 & 0.185 & 0.083 & 570 \\
\hline & 0.082 & 0.116 & 0.132 & 0.105 & 0.161 & 0.594 & 0.112 & 0.144 & 0.116 & 0.118 & 0.141 & 0.082 & 630 \\
\hline \multirow{2}{*}{$\mathrm{H}$} & 0.083 & 0.085 & 0.093 & 0.094 & 0.092 & 0.092 & 0.094 & 0.096 & 0.095 & 0.101 & 0.087 & 0.102 & 570 \\
\hline & 0.081 & 0.085 & 0.094 & 0.094 & 0.092 & 0.092 & 0.092 & 0.095 & 0.094 & 0.101 & 0.085 & 0.1 & 630 \\
\hline
\end{tabular}


C)

\begin{tabular}{|c|c|c|c|c|c|c|c|c|c|c|c|c|c|}
\hline & 1 & 2 & 3 & 4 & 5 & 6 & 7 & 8 & 9 & 10 & 11 & 12 & \\
\hline \multirow{2}{*}{ A } & 0.039 & 0.039 & 0.038 & 0.039 & 0.039 & 0.038 & 0.038 & 0.037 & 0.089 & 0.038 & 0.043 & 0.04 & 570 \\
\hline & 0.039 & 0.039 & 0.037 & 0.038 & 0.038 & 0.038 & 0.037 & 0.037 & 0.085 & 0.037 & 0.043 & 0.04 & 630 \\
\hline \multirow{2}{*}{ B } & 0.043 & 1.005 & 0.973 & 0.943 & 0.941 & 0.974 & 0.919 & 0.897 & 0.94 & 0.94 & 0.95 & 0.039 & 570 \\
\hline & 0.042 & 0.333 & 0.315 & 0.304 & 0.304 & 0.338 & 0.311 & 0.304 & 0.315 & 0.31 & 0.31 & 0.039 & 630 \\
\hline \multirow{2}{*}{ C } & 0.038 & 1.107 & 0.946 & 0.928 & 0.945 & 0.94 & 0.981 & 0.853 & 0.956 & 1.009 & 1.022 & 0.04 & 570 \\
\hline & 0.038 & 0.389 & 0.304 & 0.301 & 0.306 & 0.327 & 0.325 & 0.282 & 0.324 & 0.327 & 0.342 & 0.039 & 630 \\
\hline \multirow{2}{*}{ D } & 0.039 & 1.055 & 0.953 & 0.962 & 0.975 & 0.949 & 0.951 & 0.955 & 1.037 & 1.014 & 0.974 & 0.04 & 570 \\
\hline & 0.038 & 0.395 & 0.34 & 0.35 & 0.349 & 0.342 & 0.339 & 0.34 & 0.368 & 0.359 & 0.324 & 0.039 & 630 \\
\hline \multirow{2}{*}{$E$} & 0.04 & 1.064 & 1.006 & 0.989 & 1.013 & 0.978 & 0.969 & 0.984 & 0.957 & 0.995 & 0.964 & 0.04 & 570 \\
\hline & 0.039 & 0.407 & 0.365 & 0.341 & 0.365 & 0.341 & 0.336 & 0.34 & 0.353 & 0.33 & 0.315 & 0.039 & 630 \\
\hline \multirow{2}{*}{$F$} & 0.038 & 1.035 & 1.006 & 0.986 & 1.091 & 1.003 & 0.952 & 0.958 & 0.959 & 0.99 & 0.981 & 0.044 & 570 \\
\hline & 0.038 & 0.473 & 0.457 & 0.357 & 0.483 & 0.379 & 0.356 & 0.354 & 0.38 & 0.345 & 0.325 & 0.043 & 630 \\
\hline \multirow{2}{*}{ G } & 0.039 & 1.036 & 0.962 & 0.932 & 1.015 & 0.96 & 0.931 & 1.004 & 0.967 & 0.946 & 0.996 & 0.041 & 570 \\
\hline & 0.038 & 0.453 & 0.379 & 0.324 & 0.466 & 0.34 & 0.348 & 0.416 & 0.408 & 0.344 & 0.327 & 0.04 & 630 \\
\hline \multirow{2}{*}{$\mathrm{H}$} & 0.04 & 0.038 & 0.041 & 0.038 & 0.038 & 0.037 & 0.038 & 0.039 & 0.04 & 0.045 & 0.038 & 0.04 & 570 \\
\hline & 0.04 & 0.037 & 0.041 & 0.037 & 0.037 & 0.036 & 0.038 & 0.039 & 0.039 & 0.044 & 0.037 & 0.039 & 630 \\
\hline
\end{tabular}

Data Analysis for MTT analysis for Neurons at low power treatments:

\section{NEURON 1}

$30 \mathrm{sec}$

\section{One Way Analysis of Variance}

Wednesday, April 13, 2016, 12:57:56 PM

Data source: Excel1 in Notebook1

Normality Test (Shapiro-Wilk) Failed $\quad(\mathrm{P}<0.050)$

Equal Variance Test: $\quad$ Passed $\quad(P=0.736)$

\begin{tabular}{lccccc} 
Group Name & N & Missing & Mean & Std Dev & SEM \\
Column A & 3 & 0 & 1.000 & 0.000 & 0.000 \\
Column B & 3 & 0 & 1.649 & 0.776 & 0.448 \\
Column C & 3 & 0 & 1.408 & 0.674 & 0.389 \\
Column D & 3 & 0 & 1.158 & 0.375 & 0.217 \\
Column E & 3 & 0 & 1.481 & 0.807 & 0.466 \\
Column F & 3 & 0 & 0.859 & 0.0750 & 0.0433 \\
Column G & 3 & 0 & 1.348 & 0.650 & 0.376 \\
Column H & 3 & 0 & 1.098 & 0.270 & 0.156 \\
Column I & 3 & 0 & 0.924 & 0.0399 & 0.0230 \\
Column J & 3 & 0 & 1.165 & 0.534 & 0.308 \\
\multicolumn{1}{l}{ Source of Variation } & DF & SS & MS & F & P \\
Between Groups & 9 & 1.773 & 0.197 & 0.747 & 0.664 \\
Residual & & 20 & 5.274 & 0.264 &
\end{tabular}

The differences in the mean values among the treatment groups are not great enough to exclude the possibility that the difference is due to random sampling variability; there is not a statistically significant difference $(\mathrm{P}=0.664)$. 
Power of performed test with alpha $=0.050: 0.050$

The power of the performed test $(0.050)$ is below the desired power of 0.800 .

Less than desired power indicates you are less likely to detect a difference when one actually exists.

Negative results should be interpreted cautiously.

$60 \mathrm{sec}$

One Way Analysis of Variance

Wednesday, April 13, 2016, 12:59:57 PM

Normality Test (Shapiro-Wilk) Failed $\quad(\mathrm{P}<0.050)$

Equal Variance Test: $\quad$ Passed $\quad(P=0.866)$

$\begin{array}{lccccc}\text { Group Name } & \text { N } & \text { Missing } & \text { Mean } & \text { Std Dev } & \text { SEM } \\ \text { Column L } & 3 & 0 & 1.000 & 0.000 & 0.000 \\ \text { Column M } & 3 & 0 & 1.358 & 0.738 & 0.426 \\ \text { Column N } & 3 & 0 & 1.138 & 0.422 & 0.244 \\ \text { Column O } & 3 & 0 & 0.997 & 0.183 & 0.106 \\ \text { Column P } & 3 & 0 & 1.401 & 0.881 & 0.508 \\ \text { Column Q } & 3 & 0 & 0.963 & 0.225 & 0.130 \\ \text { Column R } & 3 & 0 & 1.267 & 0.851 & 0.492 \\ \text { Column S } & 3 & 0 & 0.897 & 0.178 & 0.103 \\ \text { Column T } & 3 & 0 & 0.890 & 0.0545 & 0.0315 \\ \text { Column U } & 3 & 0 & 1.186 & 0.645 & 0.372 \\ & & & & & \\ \text { Source of Variation } & \text { DF } & \text { SS } & \text { MS } & \text { F } & \text { P } \\ \text { Between Groups } & 9 & 0.953 & 0.106 & 0.384 & 0.929 \\ \text { Residual } & 20 & 5.516 & 0.276 & & \\ \text { Total } & 29 & 6.469 & & \end{array}$

The differences in the mean values among the treatment groups are not great enough to exclude the possibility that the difference is due to random sampling variability; there is not a statistically significant difference $(\mathrm{P}=0.929)$.

Power of performed test with alpha $=0.050: 0.050$

The power of the performed test (0.050) is below the desired power of 0.800 .

Less than desired power indicates you are less likely to detect a difference when one actually exists.

Negative results should be interpreted cautiously.

$90 \mathrm{sec}$

One Way Analysis of Variance

Wednesday, April 13, 2016, 1:00:56 PM

Normality Test (Shapiro-Wilk) Failed $\quad(\mathrm{P}<0.050)$

Equal Variance Test: $\quad$ Passed $\quad(P=0.707)$

$\begin{array}{lccccc}\text { Group Name } & \text { N } & \text { Missing } & \text { Mean } & \text { Std Dev } & \text { SEM } \\ \text { Column W } & 3 & 0 & 1.000 & 0.000 & 0.000 \\ \text { Column X } & 3 & 0 & 1.227 & 0.382 & 0.221 \\ \text { Column Y } & 3 & 0 & 1.497 & 0.849 & 0.490 \\ \text { Column Z } & 3 & 0 & 2.320 & 2.527 & 1.459 \\ \text { Column AA } & 3 & 0 & 1.640 & 1.156 & 0.668\end{array}$




$\begin{array}{lllllll}\text { Column AB } & 3 & 0 & 0.852 & 0.0854 & 0.0493 & \\ \text { Column AC } & 3 & 0 & 1.169 & 0.315 & 0.182 & \\ \text { Column AD } & 3 & 0 & 0.990 & 0.233 & 0.135 & \\ \text { Column AE } & 3 & 0 & 0.949 & 0.208 & 0.120 & \\ \text { Column AF } & 3 & 0 & 1.603 & 1.308 & 0.755 & \\ & & & & & & \\ \text { Source of Variation } & \text { DF } & \text { SS } & \text { MS } & \text { F } & \text { P } \\ \text { Between Groups } & 9 & 5.444 & 0.605 & 0.576 & 0.801 \\ \text { Residual } & 20 & 21.011 & 1.051 & & \\ \text { Total } & 29 & 26.455 & & & \\ & & & & & & \end{array}$

The differences in the mean values among the treatment groups are not great enough to exclude the possibility that the difference is due to random sampling variability; there is not a statistically significant difference $(\mathrm{P}=0.801)$.

Power of performed test with alpha $=0.050: 0.050$

The power of the performed test $(0.050)$ is below the desired power of 0.800 .

Less than desired power indicates you are less likely to detect a difference when one actually exists.

Negative results should be interpreted cautiously.

$120 \mathrm{sec}$

One Way Analysis of Variance

Wednesday, April 13, 2016, 1:01:48 PM

Normality Test (Shapiro-Wilk) $\quad$ Failed $\quad(\mathrm{P}<0.050)$

Equal Variance Test: $\quad$ Passed $\quad(\mathrm{P}=0.805)$

$\begin{array}{lccccl}\text { Group Name } & \text { N } & \text { Missing } & \text { Mean } & \text { Std Dev } & \text { SEM } \\ \text { Column AH } & 3 & 0 & 1.000 & 0.000 & 0.000 \\ \text { Column AI } & 3 & 0 & 1.106 & 0.299 & 0.173 \\ \text { Column AJ } & 3 & 0 & 0.979 & 0.0596 & 0.0344 \\ \text { Column AK } & 3 & 0 & 1.114 & 0.111 & 0.0641 \\ \text { Column AL } & 3 & 0 & 1.212 & 0.505 & 0.292 \\ \text { Column AM } & 3 & 0 & 1.117 & 0.414 & 0.239 \\ \text { Column AN } & 3 & 0 & 1.172 & 0.359 & 0.207 \\ \text { Column AO } & 3 & 0 & 1.022 & 0.191 & 0.110 \\ \text { Column AP } & 3 & 0 & 1.029 & 0.238 & 0.138 \\ \text { Column AQ } & 3 & 0 & 0.946 & 0.0839 & 0.0484\end{array}$

$\begin{array}{lrcccc}\text { Source of Variation } & \text { DF } & \text { SS } & \text { MS } & \text { F } & \text { P } \\ \text { Between Groups } & 9 & 0.206 & 0.0229 & 0.301 & 0.966 \\ \text { Residual } & 20 & 1.523 & 0.0761 & & \\ \text { Total } & 29 & 1.729 & & & \end{array}$

The differences in the mean values among the treatment groups are not great enough to exclude the possibility that the difference is due to random sampling variability; there is not a statistically significant difference $(\mathrm{P}=0.966)$.

Power of performed test with alpha $=0.050: 0.050$

The power of the performed test $(0.050)$ is below the desired power of 0.800 . 
Less than desired power indicates you are less likely to detect a difference when one actually exists.

Negative results should be interpreted cautiously.

$150 \mathrm{sec}$

One Way Analysis of Variance

Wednesday, April 13, 2016, 1:02:35 PM

Normality Test (Shapiro-Wilk) Passed $\quad(\mathrm{P}=0.970)$

Equal Variance Test: $\quad$ Passed $\quad(P=0.676)$

$\begin{array}{lcccccc}\text { Group Name } & \text { N } & \text { Missing } & \text { Mean } & \text { Std Dev } & \text { SEM } & \\ \text { Column AS } & 3 & 0 & 1.000 & 0.000 & 0.000 & \\ \text { Column AT } & 3 & 0 & 1.142 & 0.260 & 0.150 & \\ \text { Column AU } & 3 & 0 & 0.954 & 0.262 & 0.152 & \\ \text { Column AV } & 3 & 0 & 1.111 & 0.105 & 0.0607 & \\ \text { Column AW } & 3 & 0 & 1.251 & 0.463 & 0.267 & \\ \text { Column AX } & 3 & 0 & 0.935 & 0.109 & 0.0631 & \\ \text { Column AY } & 3 & 0 & 0.793 & 0.389 & 0.225 & \\ \text { Column AZ } & 3 & 0 & 1.001 & 0.0653 & 0.0377 & \\ \text { Column BA } & 3 & 0 & 0.877 & 0.261 & 0.150 & \\ \text { Column BB } & 3 & 0 & 1.203 & 0.200 & 0.116 & \\ & & & & & & \\ \text { Source of Variation } & \text { DF } & \text { SS } & \text { MS } & \text { F } & \text { P } \\ \text { Between Groups } & 9 & 0.582 & 0.0646 & 1.014 & 0.462 \\ \text { Residual } & 20 & 1.275 & 0.0637 & & \\ \text { Total } & 29 & 1.856 & & & \end{array}$

The differences in the mean values among the treatment groups are not great enough to exclude the possibility that the difference is due to random sampling variability; there is not a statistically significant difference $(\mathrm{P}=0.462)$.

Power of performed test with alpha $=0.050: 0.053$

The power of the performed test $(0.053)$ is below the desired power of 0.800 .

Less than desired power indicates you are less likely to detect a difference when one actually exists.

Negative results should be interpreted cautiously.

$180 \mathrm{sec}$

One Way Analysis of Variance

Normality Test (Shapiro-Wilk) Failed $\quad(\mathrm{P}<0.050)$

Equal Variance Test: $\quad$ Passed $\quad(\mathrm{P}=0.531)$

$\begin{array}{lccccl}\text { Group Name } & \text { N } & \text { Missing } & \text { Mean } & \text { Std Dev } & \text { SEM } \\ \text { Column BD } & 3 & 0 & 1.000 & 0.000 & 0.000 \\ \text { Column BE } & 3 & 0 & 1.301 & 0.475 & 0.274 \\ \text { Column BF } & 3 & 0 & 0.956 & 0.0753 & 0.0435 \\ \text { Column BG } & 3 & 0 & 1.109 & 0.353 & 0.204 \\ \text { Column BH } & 3 & 0 & 2.692 & 2.683 & 1.549 \\ \text { Column BI } & 3 & 0 & 0.881 & 0.107 & 0.0617 \\ \text { Column BJ } & 3 & 0 & 0.865 & 0.177 & 0.102 \\ \text { Column BK } & 3 & 0 & 1.049 & 0.223 & 0.129 \\ \text { Column BL } & 3 & 0 & 0.931 & 0.151 & 0.0870\end{array}$




$\begin{array}{lrrrrc}\text { Column BM } 3 & 0 & 1.140 & 0.197 & 0.114 & \\ & & & & & \\ \text { Source of Variation } & \text { DF } & \text { SS } & \text { MS } & \text { F } & \text { P } \\ \text { Between Groups } & 9 & 7.967 & 0.885 & 1.149 & 0.377 \\ \text { Residual } & 20 & 15.413 & 0.771 & & \\ \text { Total } & 29 & 23.380 & & & \end{array}$

The differences in the mean values among the treatment groups are not great enough to exclude the possibility that the difference is due to random sampling variability; there is not a statistically significant difference $(\mathrm{P}=0.377)$.

Power of performed test with alpha $=0.050: 0.082$

The power of the performed test (0.082) is below the desired power of 0.800 .

Less than desired power indicates you are less likely to detect a difference when one actually exists.

Negative results should be interpreted cautiously.

A)

\begin{tabular}{|l|r|r|r|r|r|r|r|r|r|r|r|r|} 
& $0 \mathrm{~mW}$ & $10 \mathrm{~mW}$ & $30 \mathrm{~mW}$ & $45 \mathrm{~mW}$ & $60 \mathrm{~mW}$ & $75 \mathrm{~mW}$ & $90 \mathrm{~mW}$ & $120 \mathrm{~mW}$ & $150 \mathrm{~mW}$ & $180 \mathrm{~mW}$ \\
\hline $30 \mathrm{sec}$ & 9138 & 8566 & 8844 & 7988 & 10724 & 9456 & 9356 & 8678 & 8968 & 8142 \\
\hline $60 \mathrm{sec}$ & 9516 & 9490 & 8776 & 10188 & 10340 & 9250 & 9816 & 9190 & 8180 & 8978 \\
\hline $90 \mathrm{sec}$ & 9482 & 8832 & 8432 & 8866 & 10328 & 9542 & 10210 & 8490 & 8044 & 8892 \\
\hline $120 \mathrm{sec}$ & 9004 & 9594 & 9314 & 9802 & 9594 & 9536 & 9110 & 8574 & 10870 & 8766 \\
\hline $150 \mathrm{sec}$ & 7926 & 9992 & 8686 & 8710 & 9658 & 9444 & 8618 & 7226 & 8762 & 9802 \\
\hline $180 \mathrm{sec}$ & 8010 & 9404 & 9160 & 8644 & 11574 & 10960 & 9332 & 9626 & 7626 & 8936 \\
\hline
\end{tabular}

Considered only $0 \mathrm{~mW}, 30 \mathrm{~mW}, 60 \mathrm{~mW}, 90 \mathrm{~mW}$ and $180 \mathrm{~mW}$ of power treatments.

B)

\begin{tabular}{r|r|r|r|r|}
\hline OmW & $30 \mathrm{~mW}$ & $60 \mathrm{~mW}$ & $90 \mathrm{~mW}$ & $180 \mathrm{~mW}$ \\
\hline 232 & 236 & 210 & 204 & 224 \\
\hline 234 & 266 & 206 & 216 & 278 \\
\hline 242 & 232 & 226 & 224 & 212 \\
\hline 214 & 218 & 206 & 216 & 238 \\
\hline 206 & 214 & 226 & 214 & 210 \\
\hline 216 & 230 & 218 & 214 & 222 \\
\hline
\end{tabular}


C)

\begin{tabular}{|r|r|r|r|r|}
\hline OmW & $30 \mathrm{~mW}$ & $60 \mathrm{~mW}$ & $90 \mathrm{~mW}$ & $180 \mathrm{~mW}$ \\
\hline 212 & 208 & 214 & 212 & 224 \\
\hline 214 & 204 & 212 & 198 & 202 \\
\hline 232 & 218 & 246 & 202 & 218 \\
\hline 210 & 228 & 204 & 244 & 208 \\
\hline 208 & 202 & 212 & 220 & 202 \\
\hline 196 & 218 & 212 & 220 & 216 \\
\hline
\end{tabular}

Data Analysis for Luciferase-luciferin analysis for SH-SY5Y at low power treatments (ATP-SHSY-5Y)

$30 \mathrm{sec}$

\section{One Way Analysis of Variance}

Wednesday, April 13, 2016, 1:33:48 PM

Data source: Excel2 in Notebook1

Normality Test (Shapiro-Wilk) Passed $\quad(P=0.677)$

Equal Variance Test: $\quad$ Passed $\quad(P=0.214)$

$\begin{array}{lcccccc}\text { Group Name } & \text { N } & \text { Missing } & \text { Mean } & \text { Std Dev } & \text { SEM } & \\ \text { Column A } & 3 & 0 & 1.000 & 0.000 & 0.000 & \\ \text { Column B } & 3 & 0 & 0.989 & 0.0256 & 0.0148 & \\ \text { Column C } & 3 & 0 & 1.029 & 0.135 & 0.0781 & \\ \text { Column D } & 3 & 0 & 0.968 & 0.0775 & 0.0447 & \\ \text { Column E } & 3 & 0 & 0.971 & 0.0829 & 0.0479 & \\ & & & & & & \\ \text { Source of Variation } & \text { DF } & \text { SS } & \text { MS } & \text { F } & \text { P } \\ \text { Between Groups } & 4 & 0.00750 & 0.00187 & 0.294 & 0.875 \\ \text { Residual } & & 10 & 0.0637 & 0.00637 & & \\ \text { Total } & 14 & 0.0712 & & & \end{array}$

The differences in the mean values among the treatment groups are not great enough to exclude the possibility that the difference is due to random sampling variability; there is not a statistically significant difference $(\mathrm{P}=0.875)$.

Power of performed test with alpha $=0.050: 0.050$

The power of the performed test $(0.050)$ is below the desired power of 0.800 .

Less than desired power indicates you are less likely to detect a difference when one actually exists.

Negative results should be interpreted cautiously.

$60 \mathrm{sec}$

One Way Analysis of Variance

Wednesday, April 13, 2016, 1:35:39 PM

Normality Test (Shapiro-Wilk) Passed $\quad(\mathrm{P}=0.153)$

Equal Variance Test: $\quad$ Passed $\quad(P=0.925)$ 


$\begin{array}{lcccccc}\text { Group Name } & \text { N } & \text { Missing } & \text { Mean } & \text { Std Dev } & \text { SEM } & \\ \text { Column G } & 3 & 0 & 1.000 & 0.000 & 0.000 & \\ \text { Column H } & 3 & 0 & 1.004 & 0.116 & 0.0669 & \\ \text { Column I } & 3 & 0 & 0.986 & 0.103 & 0.0596 & \\ \text { Column J } & 3 & 0 & 0.960 & 0.0620 & 0.0358 & \\ \text { Column K } & 3 & 0 & 1.025 & 0.141 & 0.0814 & \\ & & & & & & \\ \text { Source of Variation } & \text { DF } & \text { SS } & \text { MS } & \text { F } & \text { P } \\ \text { Between Groups } & 4 & 0.00699 & 0.00175 & 0.183 & 0.942 \\ \text { Residual } & 10 & 0.0957 & 0.00957 & & \\ \text { Total } & 14 & 0.103 & & & \end{array}$

The differences in the mean values among the treatment groups are not great enough to exclude the possibility that the difference is due to random sampling variability; there is not a statistically significant difference $(\mathrm{P}=0.942)$.

Power of performed test with alpha $=0.050: 0.050$

The power of the performed test $(0.050)$ is below the desired power of 0.800 .

Less than desired power indicates you are less likely to detect a difference when one actually exists.

Negative results should be interpreted cautiously.

$90 \mathrm{sec}$

One Way Analysis of Variance

Wednesday, April 13, 2016, 1:36:14 PM

Normality Test (Shapiro-Wilk) Passed $\quad(\mathrm{P}=0.687)$

Equal Variance Test: $\quad$ Passed $\quad(\mathrm{P}=0.547)$

$\begin{array}{lcccccc}\text { Group Name } & \text { N } & \text { Missing } & \text { Mean } & \text { Std Dev } & \text { SEM } & \\ \text { Column M } & 3 & 0 & 1.000 & 0.000 & 0.000 & \\ \text { Column N } & 3 & 0 & 0.929 & 0.0359 & 0.0207 & \\ \text { Column O } & 3 & 0 & 1.028 & 0.0826 & 0.0477 & \\ \text { Column P } & 3 & 0 & 0.958 & 0.107 & 0.0616 & \\ \text { Column Q } & 3 & 0 & 0.918 & 0.0362 & 0.0209 & \\ & & & & & & \\ \text { Source of Variation } & \text { DF } & \text { SS } & \text { MS } & \text { F } & \text { P } \\ \text { Between Groups } & 4 & 0.0262 & 0.00654 & 1.571 & 0.256 \\ \text { Residual } & & 10 & 0.0416 & 0.00416 & & \\ \text { Total } & 14 & 0.0678 & & & \end{array}$

The differences in the mean values among the treatment groups are not great enough to exclude the possibility that the difference is due to random sampling variability; there is not a statistically significant difference $(\mathrm{P}=0.256)$.

Power of performed test with alpha $=0.050: 0.136$

The power of the performed test (0.136) is below the desired power of 0.800 .

Less than desired power indicates you are less likely to detect a difference when one actually exists.

Negative results should be interpreted cautiously.

$120 \mathrm{sec}$ 
One Way Analysis of Variance

Normality Test (Shapiro-Wilk) Failed $\quad(\mathrm{P}<0.050)$

Equal Variance Test: $\quad$ Passed $\quad(P=0.929)$

$\begin{array}{lcccccc}\text { Group Name } & \text { N } & \text { Missing } & \text { Mean } & \text { Std Dev } & \text { SEM } & \\ \text { Column S } & 3 & 0 & 1.000 & 0.000 & 0.000 & \\ \text { Column T } & 3 & 0 & 1.046 & 0.0350 & 0.0202 & \\ \text { Column U } & 3 & 0 & 1.000 & 0.0570 & 0.0329 & \\ \text { Column V } & 3 & 0 & 1.061 & 0.0874 & 0.0505 & \\ \text { Column W } & 3 & 0 & 1.025 & 0.0756 & 0.0436 & \\ & & & & & & \\ \text { Source of Variation } & \text { DF } & \text { SS } & \text { MS } & \text { F } & \text { P } \\ \text { Between Groups } & 4 & 0.00899 & 0.00225 & 0.630 & 0.652 \\ \text { Residual } & 10 & 0.0357 & 0.00357 & & \\ \text { Total } & 14 & 0.0447 & & & \end{array}$

The differences in the mean values among the treatment groups are not great enough to exclude the possibility that the difference is due to random sampling variability; there is not a statistically significant difference $(\mathrm{P}=0.652)$.

Power of performed test with alpha $=0.050: 0.050$

The power of the performed test $(0.050)$ is below the desired power of 0.800 .

Less than desired power indicates you are less likely to detect a difference when one actually exists.

Negative results should be interpreted cautiously.

$150 \mathrm{sec}$

One Way Analysis of Variance

Wednesday, April 13, 2016, 1:37:28 PM

Normality Test (Shapiro-Wilk) Passed $\quad(\mathrm{P}=0.311)$

Equal Variance Test: $\quad$ Passed $\quad(P=0.432)$

$\begin{array}{lcccccc}\text { Group Name } & \text { N } & \text { Missing } & \text { Mean } & \text { Std Dev } & \text { SEM } & \\ \text { Column Y } & 3 & 0 & 1.000 & 0.000 & 0.000 & \\ \text { Column Z } & 3 & 0 & 1.035 & 0.0624 & 0.0361 & \\ \text { Column AA } & 3 & 0 & 1.112 & 0.100 & 0.0580 & \\ \text { Column AB } & 3 & 0 & 1.061 & 0.0244 & 0.0141 & \\ \text { Column AC } & 3 & 0 & 1.076 & 0.141 & 0.0817 & \\ \text { Source of Variation } & \text { DF } & \text { SS } & \text { MS } & \text { F } & \text { P } \\ \text { Between Groups } & 4 & 0.0212 & 0.00530 & 0.767 & 0.571 \\ \text { Residual } & 10 & 0.0692 & 0.00692 & & \\ \text { Total } & 14 & 0.0904 & & & \end{array}$

The differences in the mean values among the treatment groups are not great enough to exclude the possibility that the difference is due to random sampling variability; there is not a statistically significant difference $(\mathrm{P}=0.571)$.

Power of performed test with alpha $=0.050: 0.050$

The power of the performed test $(0.050)$ is below the desired power of 0.800 . 
Less than desired power indicates you are less likely to detect a difference when one actually exists. Negative results should be interpreted cautiously.

$180 \mathrm{sec}$

One Way Analysis of Variance

Wednesday, April 13, 2016, 1:38:03 PM

Normality Test (Shapiro-Wilk) Passed $\quad(\mathrm{P}=0.059)$

Equal Variance Test: $\quad$ Passed $\quad(P=0.431)$

$\begin{array}{lcccccc}\text { Group Name } & \text { N } & \text { Missing } & \text { Mean } & \text { Std Dev } & \text { SEM } & \\ \text { Column AE } & 3 & 0 & 1.000 & 0.000 & 0.000 & \\ \text { Column AF } & 3 & 0 & 1.107 & 0.0397 & 0.0229 & \\ \text { Column AG } & 3 & 0 & 1.179 & 0.233 & 0.135 & \\ \text { Column AH } & 3 & 0 & 1.093 & 0.0909 & 0.0525 & \\ \text { Column AI } & 3 & 0 & 1.082 & 0.0473 & 0.0273 & \\ & & & & & & \\ \text { Source of Variation } & \text { DF } & \text { SS } & \text { MS } & \text { F } & \text { P } \\ \text { Between Groups } & 4 & 0.0489 & 0.0122 & 0.918 & 0.491 \\ \text { Residual } & 10 & 0.133 & 0.0133 & & \\ \text { Total } & 14 & 0.182 & & & \end{array}$

The differences in the mean values among the treatment groups are not great enough to exclude the possibility that the difference is due to random sampling variability; there is not a statistically significant difference $(\mathrm{P}=0.491)$.

Power of performed test with alpha $=0.050: 0.050$

The power of the performed test $(0.050)$ is below the desired power of 0.800 .

Less than desired power indicates you are less likely to detect a difference when one actually exists.

Negative results should be interpreted cautiously.

Raw Data for Luciferase- luciferin analysis for neurons at low- high power treatments (ATP analysis)

\begin{tabular}{|r|r|r|r|r|r|}
\hline OmW & 250 & & 437.5 & & 500 \\
\hline 2824 & 1992 & 1550 & 1132 & 4280 & 4084 \\
\hline 1066 & 912 & 646 & 1148 & 824 & 892 \\
\hline 822 & 912 & 734 & 2430 & 2426 & 5470 \\
\hline 812 & 1486 & 1692 & 1830 & 1862 & 3878 \\
\hline 774 & 634 & 820 & 990 & 952 & 1316 \\
\hline
\end{tabular}

\begin{tabular}{r|r|r|r|r|}
\hline OmW & 362.5 & & 725 & \\
\hline 1806 & 1470 & 2498 & 1314 & 1496 \\
\hline 974 & 1268 & 1114 & 946 & 1656 \\
\hline 1190 & 1108 & 1188 & 1876 & 1536 \\
\hline
\end{tabular}


Data Analysis for Luciferase- luciferin analysis for neurons at low- high power treatments (ATP analysis)

One Way Analysis of Variance

Wednesday, April 13, 2016, 1:46:15 PM

Data source: Excel3 in Notebook1

Normality Test (Shapiro-Wilk) Failed $\quad(\mathrm{P}<0.050)$

Equal Variance Test: $\quad$ Failed $\quad(\mathrm{P}<0.050)$

$\begin{array}{lcccccc}\text { Group Name } & \text { N } & \text { Missing } & \text { Mean } & \text { Std Dev } & \text { SEM } & \\ \text { Column A } & 6 & 0 & 1.000 & 0.000 & 0.000 & \\ \text { Column B } & 6 & 0 & 1.305 & 0.520 & 0.212 & \\ \text { Column C } & 6 & 0 & 1.095 & 0.221 & 0.0901 & \\ \text { Column D } & 6 & 0 & 2.208 & 0.702 & 0.287 & \\ \text { Column E } & 3 & 0 & 4.377 & 2.501 & 1.444 & \\ \text { Column F } & 6 & 0 & 1.182 & 0.403 & 0.165 & \\ & & & & & & \\ \text { Source of Variation } & \text { DF } & \text { SS } & \text { MS } & \text { F } & \text { P } \\ \text { Between Groups } & 5 & 30.573 & 6.115 & 9.497 & <0.001 \\ \text { Residual } & 27 & 17.383 & 0.644 & & \\ \text { Total } & 32 & 47.956 & & & \end{array}$

The differences in the mean values among the treatment groups are greater than would be expected by chance; there is a statistically significant difference $(\mathrm{P}=<0.001)$.

Power of performed test with alpha $=0.050: 0.999$

Multiple Comparisons versus Control Group (Dunnett's Method) :

Comparisons for factor:

Comparison

Column A vs. Column E

Column A vs. Column D

Column A vs. Column B

Column A vs. Column F

Column A vs. Column C

Diff of Means
3.377
1.208
0.305
0.182
0.0954

\begin{tabular}{cc}
$\mathbf{q}^{\mathbf{}}$ & \multicolumn{1}{c}{$\mathbf{P}$} \\
5.952 & $<0.001$ \\
2.608 & 0.059 \\
0.659 & 0.948 \\
0.394 & 0.994 \\
0.206 & 1.000
\end{tabular}
$\mathbf{P}<\mathbf{0 . 0 5 0}$
Yes
No
Do Not Test
Do Not Test
Do Not Test

A result of "Do Not Test" occurs for a comparison when no significant difference is found between two means that enclose that comparison. For example, if you had four means sorted in order, and found no difference between means 4 vs. 2, then you would not test 4 vs. 3 and 3 vs. 2, but still test 4 vs. 1 and 3 vs. 1 ( 4 vs. 3 and 3 vs. 2 are enclosed by 4 vs. $2: 432$ 1). Note that not testing the enclosed means is a procedural rule, and a result of Do Not Test should be treated as if there is no significant difference between the means, even though one may appear to exist. 


\section{REFERENCES}

[1] Brunet, A., Monson, E., Liu, A., \& Fikretoglu, D. (2015). Trauma exposure and posttraumatic stress disorder in the canadian military. The Canadian journal of psychiatry, 60(11), 488-496.

[2] Erickson, J., Kinley, D. J., Bolton, J. M., Zamorski, M. A., Enns, M. W., \& Sareen, J. (2014). A sex-specific comparison of major depressive disorder symptomatology in the canadian forces and the general population. The Canadian journal of psychiatry, 59(7), 393-398.

[3] Veteran affairs canada, mental health supports and services and veterans affairs research (Veterans affairs, facts and figures book), Internet: http://www.veterans.gc.ca/eng/about-us/departmentofficials/minister/briefing/mentalhealth, March 2015

[4] Kessler, R.C., Sonnega, A., Bromet, E. Hughes, M., \& Nelson, C.B. (1995). Posttraumatic stress disorder in the national comorbidity survey. Archives of general psychiatry, 52(12), 1048-1060.

[5] Kulka, R.A., Schlenger, W.A., Fairbanks, J.A., Hough, R.L., Jordan, B.K., Marmar, C.R., ... Cranston, A.S. (1990). Trauma and the vietnam war generation: report of findings from the national vietnam veterans readjustment study. New york: Brunner/Mazel

[6] Tania Kohut,"8 deaths so far in 2016: Canada's first responder PTSD crisis" national online journalist global news (February 5,2016) Internet :http://globalnews.ca/news/2498974/he-was-so-desperate-for-help-canadas-firstresponder-ptsd-crisis/

[7] American psychiatric association. (1987). Diagnostic and statistical manual of mental disorders, (Revised 3rd ed.). Washington, DC: Author

[8] American psychiatric association. (2013). Diagnostic and statistical manual of mental disorders, (5th ed.). Washington, DC: Author.

[9] American psychiatric association. (2000). Diagnostic and statistical manual of mental disorders, (Revised 4th ed.). Washington, DC: Author.

[10] U.S. department of veterans affairs, PTSD : national centre for PTSD (Public: $\begin{array}{lll}\text { Treatment } & \text { Pf 14,2015. }\end{array}$ Internet:http://www.ptsd.va.gov/public/treatment/therapy-med/treatment-ptsd.asp

[11] Marks, I., Lovell, K., Noshirvani, H., Livanou, M., \& Thrasher, S. (1998). Treatment of posttraumatic stress disorder by exposure and/or cognitive restructuring: A controlled study. Archives of general psychiatry, 55(4), 317-325.

[12] Korn, D. L., \& Leeds, A. M. (2002). Preliminary evidence of efficacy for EMDR 
resource development and installation in the stabilization phase of treatment of complex posttraumatic stress disorder. Journal of clinical psychology, 58(12), 1465-1487.Chicago

[13] Foa, E. B., Keane, T. M., Friedman, M. J., \& Cohen, J. A. (Eds.). (2000). Effective treatments for PTSD: practice guidelines from the international society for traumatic stress studies. Guilford press. [Online-Guidelines 4,5,8,11,12,14,18] http://www.istss.org/treating-trauma/effective-treatments-for-ptsd,-2nd-edition.aspx

[14] U.S. department of veterans affairs, PTSD : National centre for PTSD (Public: PTSD Coach Online), Aug 14,2015. Internet: http://www.ptsd.va.gov/public/treatment/cope/index.asp

[15] Yehuda, R., \& Bierer, L. M. (2008). Transgenerational transmission of cortisol and PTSD risk. Progress in brain research, 167, 121-135. doi: 10.1016/S0079-6123(07)670095

[16] Jeffreys M., U.S. department of veteran's affairs, PTSD: National centre for PTSD (Professional: clinician's guide to medications for PTSD), Aug 14,2015. Internet: http://www.ptsd.va.gov/professional/treatment/overview/clinicians-guide-to-medicationsfor-ptsd.asp

[17] Lanius, R. A., Vermetten, E., Loewenstein, R. J., Brand, B., Schmahl, C., Bremner, J. D., \& Spiegel, D. (2010). Emotion modulation in PTSD: Clinical and neurobiological evidence for a dissociative subtype. American journal of psychiatry, 167, 640-647. doi: 10.1176/appi.ajp.2009.09081168

[18] Felmingham, K., Williams, L. M., Whitford, T. J., Falconer, E., Kemp, A. H., Peduto, A., \& Bryant, R. A. (2009). Duration of posttraumatic stress disorder predicts hippocampal grey matter loss. Neuroreport, 20(16), 1402-1406.

[19] Broekman, B. F., Olff, M., \& Boer, F. (2007). The genetic background to PTSD. Neuroscience \& biobehavioral reviews, 31(3), 348-362.

[20] Oliveira, S. C. B., Santarino, I. B., Enache, T. A., Nunes, C., Laranjinha, J., Barbosa, R. M., \& Oliveira-Brett, A. M. (2013). Human colon adenocarcinoma HT-29 cell: electrochemistry and nicotine stimulation. Bioelectrochemistry, 94, 30-38.

[21] Michael, A. F., Drummond, K. N., Doeden, D., Anderson, J. A., \& Good, R. A. (1964). Tryptophan metabolism in man. Journal of clinical investigation, 43(9), 1730.

[22] Roelandts, R. (2007). History of human photobiology. Basic and clinical dermatology, 38,1 .

[23] Leviton, R. (1992). The Healing Energies of Color. Yoga Journal,pp. 47. Online: https://books.google.ca/books?id=TOkDAAAAMBAJ\&pg=PA47\&lpg=PA47\&dq=stimu lation+of+the+nervous + system + and + the + secretory+glands-

Augustus+Pleasanton\&source=bl\&ots=yIdVPoYLr9\&sig=F3lujmruLH52YSFPL1DhibKtFs\&hl=en\&sa=X\&ved=0ahUKEwi018315YDMAhVFvYMKHdmZDWMQ6AE 
IJzAC\#v=onepage \&q=stimulation $\% 20$ of $\% 20$ the $\% 20$ nervous $\% 20$ system $\% 20$ and $\% 20$ the $\% 20$ secretory\%20glands-Augustus\%20Pleasanton\&f=false

[24] Azeemi, S. T. Y., \& Raza, M. (2005). A critical analysis of chromotherapy and its scientific evolution. Evidence-based complementary and alternative medicine, 2(4), 481488.

[25] Gøtzsche, P. C. (2011). Niels Finsen's treatment for lupus vulgaris. Journal of the royal society of medicine, 104(1), 41-42.

[26] Wolbarsht,M.L. (1991). Laser Applications in Medicine and Biology. Volume 5,pp.13

Available:

https://books.google.ca/books?id=a8Rwp27VV00C\&pg=PA2\&lpg=PA2\&dq=contempor ary+phototherapy-

+ NR+Finsen\&source $=$ bl\&ots=vCPHFd0OcG\&sig=ZRehkmuK zxC7 6QfvaLzAh z04 \&hl $=$ en $\&$ sa $=X \& v e d=0$ ahUKEwj-

O6h8IHMAhXpwYMKHXfvAy4Q6AEIIjAB\#v=onepage\&q=contemporary\%20photot herapy- $\% 20 \mathrm{NR} \% 20$ Finsen $\& \mathrm{f}=$ false

[27] Gottlieb, R. L. (2010, February). Syntonic phototherapy. In BiOS (pp. 75520N$75520 \mathrm{~N})$. International Society for optics and photonics.

[28] Lee, G., Ikeda, R. M., Dwyer, R. M., Hussein, H., Dietrich, P., \& Mason, D. T. (1982). Feasibility of intravascular laser irradiation for in vivo visualization and therapy of cardiocirculatory diseases. American heart journal, 103(6), 1076.

[29] Rebbeck, E. The Knott technic of ultraviolet blood irradiation as a control of infection in peritonitis. Amer J Gastroenterol 1943; 10:1-26

[30] Goldman, L., \& Dreffer, R. (1977). Laser treatment of extensive mixed cavernous and port-wine stains. Archives of dermatology, 113(4), 504-505.

[31] Lyons, R. F., Abergel, R. P., White, R. A., Dwyer, R. M., Castel, J. C., \& Uitto, J. (1987). Biostimulation of wound healing in vivo by a helium-neon laser. Annals of plastic surgery, 18(1), 47-50.

[32] Whelan, H. T., Smits Jr, R. L., Buchman, E. V., Whelan, N. T., Turner, S. G., Margolis, D. A., ... \& Cwiklinski, J. (2001). Effect of NASA light-emitting diode irradiation on wound healing. Journal of clinical laser medicine \& surgery, 19(6), 305-314.

[33] Conlan, M. J., Rapley, J. W., \& Cobb, C. M. (1996). Biostimulation of wound healing by low-energy laser irradiation A review. Journal of clinical periodontology, 23(5), 492496.

[34] Alió, J. L., Pérez-Santonja, J. J., Tervo, T., Tabbara, K. F., Vesaluoma, M., Smith, R. J., ... \& Maloney, R. K. (2000). Postoperative inflammation, microbial complications, and wound healing following laser in situ keratomileusis. Journal of refractive surgery, 16(5), 523-538. 
[35] Malm, M., \& Lundeberg, T. (1991). Effect of low power gallium arsenide laser on healing of venous ulcers. Scandinavian journal of plastic and reconstructive surgery and hand surgery, 25(3), 249-251.

[36] Ortiz, A. E., \& Zachary, C. B. (2011). Laser therapy for Hailey-Hailey disease: review of the literature and a case report. Dermatology reports, 3(2).

[37] Gold, M. H. (2008). Therapeutic and aesthetic uses of photodynamic therapy part two of a five-part series: lasers and light treatments for acne vulgaris promising therapies. The Journal of clinical and aesthetic dermatology, 1(3), 28.

[38] Ohshiro, T., \& Calderhead, R. G. (1988). Low level laser therapy: a practical introduction. John Wiley \& Sons.

[39] Chen, A. C., Arany, P. R., Huang, Y. Y., Tomkinson, E. M., Sharma, S. K., Kharkwal, G. B., ... \& Hamblin, M. R. (2011). Low-level laser therapy activates NF-kB via generation of reactive oxygen species in mouse embryonic fibroblasts. PloS one, 6(7), e22453.

[40] Hawkins, D. H., \& Abrahamse, H. (2006). The role of laser fluence in cell viability, proliferation, and membrane integrity of wounded human skin fibroblasts following helium-neon laser irradiation. Lasers in surgery and medicine, 38(1), 74-83.

[41] Brosseau, L., Welch, V., Wells, G., Tugwell, P., De Bie, R., Gam, A., ... \& Morin, M. (2000). Low level laser therapy for osteoarthritis and rheumatoid arthritis: a metaanalysis. The Journal of rheumatology, 27(8), 1961-1969.

[42] Soriano, F., \& Ríos, R. (1998). Gallium arsenide laser treatment of chronic low back pain: a prospective, randomized and double blind study. Laser therapy, 10(4), 175-180.

[43] Stergioulas, A. (2008). Low-power laser treatment in patients with frozen shoulder: preliminary results. Photomedicine and laser surgery, 26(2), 99-105.

[44] Lui, J., Corbet, E. F., \& Jin, L. (2011). Combined photodynamic and low-level laser therapies as an adjunct to nonsurgical treatment of chronic periodontitis. Journal of periodontal research, 46(1), 89-96.

[45] Takasaki, A. A., Aoki, A., Mizutani, K., Schwarz, F., Sculean, A., Wang, C. Y., ... \& Izumi, Y. (2009). Application of antimicrobial photodynamic therapy in periodontal and peri-implant diseases. Periodontology 2000, 51(1), 109-140.

[46] Joensen, J., Øvsthus, K., Reed, R. K., Hummelsund, S., Iversen, V. V., Lopes-Martins, R. Á. B., \& Bjordal, J. M. (2012). Skin penetration time-profiles for continuous $810 \mathrm{~nm}$ and Superpulsed $904 \mathrm{~nm}$ lasers in a rat model. Photomedicine and laser surgery, 30(12), 688-694.

[47] Rangwala, S., \& Rashid, R. M. (2012). Alopecia: a review of laser and light therapies. Dermatology online journal, 18(2).

[48] Baxter, G. D., Bleakley, C., \& McDonough, S. (2008). Clinical effectiveness of laser 
acupuncture: a systematic review. Journal of acupuncture and meridian studies, 1(2), 6582.

[49] DeTaboada, L., Ilic, S., Leichliter-Martha, S., Oron, U., Oron, A., \& Streeter, J. (2006). Transcranial application of low-energy laser irradiation improves neurological deficits in rats following acute stroke. Lasers in surgery and medicine, 38(1), 70-73.

[50] Hamblin, M. R., \& Demidova, T. N. (2006, February). Mechanisms of low level light therapy. In Biomedical optics 2006 (pp. 614001-614001). International society for optics and photonics.

[51] Manji, H., Kato, T., Di Prospero, N. A., Ness, S., Beal, M. F., Krams, M., \& Chen, G. (2012). Impaired mitochondrial function in psychiatric disorders. Nature reviews neuroscience, 13(5), 293-307.

[52] Shao, L., Martin, M. V., Watson, S. J., Schatzberg, A., Akil, H., Myers, R. M., ... \& Vawter, M. P. (2008). Mitochondrial involvement in psychiatric disorders. Annals of medicine, 40(4), 281-295.

[53] Adapted from BIOM5311F (Fall 2015), Lecture 2- The Cell, slide 13

[54] Miles B.,"The Electron Transport Chain". Internet: https://www.tamu.edu/faculty/bmiles/lectures/electrontrans.pdf, 2003

[55] Fvasconcellos (2207), Wikimedia commons - File: Mitochondrial electron transport chain - Etc4.svg, Internet: https://commons.wikimedia.org/wiki/File:Mitochondrial_electron_transport_chain $\% \mathrm{E} \%$ $80 \% 94$ Etc4.svg

[56] Karu, T. (1999). Primary and secondary mechanisms of action of visible to near-IR radiation on cells. Journal of photochemistry and photobiology B: biology, 49(1), 1-17. Chicago

[57] Karu, T. I. (1987). Photobiological fundamentals of low-power laser therapy. Quantum Electronics, IEEE Journal of, 23(10), 1703-1717.

[58] Katz, L. C., \& Shatz, C. J. (1996). Synaptic activity and the construction of cortical circuits. Science, 274(5290), 1133-1138.Chicago

[59] Sadun, A. A., Schaechter, J. D., \& Smith, L. E. (1984). A retinohypothalamic pathway in man: light mediation of circadian rhythms. Brain research, 302(2), 371-377.Chicago

[60] Skorkovská, K. (2014). [Intrinsically Photosensitive Retinal Ganglion Cells]. Ceska a slovenska oftalmologie: casopis Ceske oftalmologicke spolecnosti a Slovenske oftalmologicke spolecnosti, 71(3), 144-149.Chicago

[61] Do, M. T. H., \& Yau, K. W. (2010). Intrinsically photosensitive retinal ganglion cells. Physiological reviews, 90(4), 1547-1581. 
[62] Naeser, M. A., Saltmarche, A., Krengel, M. H., Hamblin, M. R., \& Knight, J. A. (2011). Improved cognitive function after transcranial, light-emitting diode treatments in chronic, traumatic brain injury: two case reports. Photomedicine and laser surgery, 29(5), 351-358. Chicago

[63] Khedr, E. M., Ahmed, M. A., Fathy, N., \& Rothwell, J. C. (2005). Therapeutic trial of repetitive transcranial magnetic stimulation after acute ischemic stroke. Neurology, 65(3), 466-468.

[64] Karu, T., Tiphlova, O., Esenaliev, R., \& Letokhov, V. (1994). Two different mechanisms of low-intensity laser photobiological effects on Escherichia coli. Journal of photochemistry and photobiology B: Biology, 24(3), 155-161.

[65] McCullough et al. (1977). Optical radiation sin Medicine. Aapm Report 3. American association of physicists in medicine

[66] Hashmi, J. T., Huang, Y. Y., Sharma, S. K., Kurup, D. B., De Taboada, L., Carroll, J. D., \& Hamblin, M. R. (2010). Effect of pulsing in low-level light therapy. Lasers in surgery and medicine, 42(6), 450-466.

[67] Mantineo, M., Pinheiro, J. P., \& Morgado, A. M. (2014). Low-level laser therapy on skeletal muscle inflammation: evaluation of irradiation parameters. Journal of biomedical optics, 19(9), 098002-098002.

[68] Mantineo, M., Pinheiro, J. P., \& Morgado, A. M. (2014, February). Evaluation of low level laser therapy irradiation parameters on rat muscle inflammation through systemic blood cytokines. In SPIE BiOS (pp. 89320M-89320M). International society for optics and photonics.

[69] Mester, E., Szende, B., \& Gärtner, P. (1967). [The effect of laser beams on the growth of hair in mice]. Radiobiologia, radiotherapia, 9(5), 621-626.

[70] Mester, E., Spiry, T., Szende, B., \& Tota, J. G. (1971). Effect of laser rays on wound healing. The American journal of surgery, 122(4), 532-535.

[71] Mester, E., Szende, B., Spiry, T., \& Scher, A. (1971). Stimulation of wound healing by laser rays. Acta chirurgica academiae scientiarum hungaricae, 13(3), 315-324.

[72] Weintraub, M. I. (1997). Noninvasive laser neurolysis in carpal tunnel syndrome. Muscle \& nerve, 20(8), 1029-1031.

[73] Michael M Barbour, Microlight Corporation of America (2002). 510(k) Summary as required by section 807.92 (c), http://www.laserhealing.com/pdf/ml830 fda.pdf

[74] Stemer, A. B., Huisa, B. N., \& Zivin, J. A. (2010). The evolution of transcranial laser therapy for acute ischemic stroke, including a pooled analysis of NEST-1 and NEST-2. Current cardiology reports, 12(1), 29-33.

[75] Lampl, Y., Zivin, J. A., Fisher, M., Lew, R., Welin, L., Dahlof, B., ... \& Ilic, S. (2007). 
Infrared laser therapy for ischemic stroke: a new treatment strategy results of the neurothera effectiveness and safety trial-1 (NEST-1). Stroke, 38(6), 1843-1849.

[76] Lapchak, P. A., Han, M. K., Salgado, K. F., Streeter, J., \& Zivin, J. A. (2008). Safety profile of transcranial near-infrared laser therapy administered in combination with thrombolytic therapy to embolized rabbits. Stroke, 39(11), 3073-3078.

[77] Oron, A., Oron, U., Streeter, J., Taboada, L. D., Alexandrovich, A., Trembovler, V., \& Shohami, E. (2007). Low-level laser therapy applied transcranially to mice following traumatic brain injury significantly reduces long-term neurological deficits. Journal of neurotrauma, 24(4), 651-656.

[78] Moreira, M. S., Velasco, I. T., Ferreira, L. S., Ariga, S. K. K., Barbeiro, D. F., Meneguzzo, D. T., ... \& Marques, M. M. (2009). Effect of phototherapy with low intensity laser on local and systemic immunomodulation following focal brain damage in rat. Journal of photochemistry and photobiology B: biology, 97(3), 145-151.

[79] Wu, Q., Huang, Y. Y., Dhital, S., Sharma, S. K., Chen, A. C. H., Whalen, M. J., \& Hamblin, M. R. (2010, February). Low level laser therapy for traumatic brain injury. In BiOS (pp. 755206-755206). International society for optics and photonics.

[80] Schiffer, F., Johnston, A. L., Ravichandran, C., Polcari, A., Teicher, M. H., Webb, R. H., \& Hamblin, M. R. (2009). Psychological benefits 2 and 4 weeks after a single treatment with near infrared light to the forehead: a pilot study of 10 patients with major depression and anxiety. Behavioral and brain functions, 5(1), 1.

[81] Naeser, M. A., Zafonte, R., Krengel, M. H., Martin, P. I., Frazier, J., Hamblin, M. R., Knight, J.A., Meehan III \& Baker, E. H. (2014). Significant improvements in cognitive performance post-transcranial, red/near-infrared light-emitting diode treatments in chronic, mild traumatic brain injury: open-protocol study. Journal of neurotrauma, 31(11), 10081017.

[82] Naeser, M. A., Martin, P. I., Ho, M. D., Krengel, M. H., Bogdanova, Y., Knight, J. A., ... \& Koo, B. B. (2015, May). Red/near-infrared light-emitting diode therapy for traumatic brain injury. In SPIE defense+ security (pp. 94670M-94670M). International society for optics and photonics.

[83] Salgado, S. I. A., Parreira, R. B., Ceci, L. A., de Oliveira, L. V. F., \& Zangaro, R. A. (2015). Transcranial light emitting diode therapy (TCLT) and its effects on neurological disorders. Journal of bioengineering \& biomedical sciences, 5(1), 1.

[84] Moges, H., Vasconcelos, O. M., Campbell, W. W., Borke, R. C., McCoy, J. A., Kaczmarczyk, L., Feng, J. \& Anders, J. J. (2009). Light therapy and supplementary riboflavin in the SOD1 transgenic mouse model of familial amyotrophic lateral sclerosis (FALS). Lasers in surgery and medicine, 41(1), 52-59. 
[85] Trimmer, P. A., Schwartz, K. M., Borland, M. K., De Taboada, L., Streeter, J., \& Oron, U. (2009). Reduced axonal transport in Parkinson's disease cybrid neurites is restored by light therapy. Molecular neurodegeneration, 4(1), 1-11.

[86] Ying, R., Liang, H. L., Whelan, H. T., Eells, J. T., \& Wong-Riley, M. T. (2008). Pretreatment with near-infrared light via light-emitting diode provides added benefit against rotenone-and MPP+-induced neurotoxicity. Brain research, 1243, 167-173.

[87] Zhang, L., Xing, D., Zhu, D., \& Chen, Q. (2008). Low-power laser irradiation inhibiting A $325-35$-induced PC12 cell apoptosis via PKC activation. Cellular physiology and biochemistry, 22(1-4), 215-222.

[88] Byrnes, K. R., Waynant, R. W., Ilev, I. K., Wu, X., Barna, L., Smith, K., ... \& Anders, J. J. (2005). Light promotes regeneration and functional recovery and alters the immune response after spinal cord injury. Lasers in surgery and medicine, 36(3), 171-185.

[89] Gigo-Benato, D., Geuna, S., de Castro Rodrigues, A., Tos, P., Fornaro, M., Boux, E., Battiston, B. \& Giacobini-Robecchi, M. G. (2004). Low-power laser biostimulation enhances nerve repair after end-to-side neurorrhaphy: a double-blind randomized study in the rat median nerve model. Lasers in medical science, 19(1), 57-65.

[90] Barbosa, R. I., Marcolino, A. M., de Jesus Guirro, R. R., Mazzer, N., Barbieri, C. H., \& Fonseca, M. D. C. R. (2010). Comparative effects of wavelengths of low-power laser in regeneration of sciatic nerve in rats following crushing lesion. Lasers in medical science, 25(3), 423-430.

[91] Gür, A., Karakoc, M., Nas, K., Cevik, R., Sarac, J., \& Demir, E. (2002). Efficacy of low power laser therapy in fibromyalgia: a single-blind, placebo-controlled trial. Lasers in medical science, 17(1), 57-61.

[92] Gur, A., Karakoc, M., Cevik, R., Nas, K., Sarac, A. J., \& Karakoc, M. (2003). Efficacy of low power laser therapy and exercise on pain and functions in chronic low back pain. Lasers in surgery and medicine, 32(3), 233-238.

[93] Gur, A., Cosut, A., Jale Sarac, A., Cevik, R., Nas, K., \& Uyar, A. (2003). Efficacy of different therapy regimes of low-power laser in painful osteoarthritis of the knee: A doubleblind and randomized-controlled trial. Lasers in surgery and medicine, 33(5), 330-338.

[94]Yurtkuran, M., Alp, A., Konur, S., Özçakir, S., \& Bingol, U. (2007). Laser acupuncture in knee osteoarthritis: a double-blind, randomized controlled study. Photomedicine and laser therapy, 25(1), 14-20.

[95] Chow, R. T., Johnson, M. I., Lopes-Martins, R. A., \& Bjordal, J. M. (2009). Efficacy of low-level laser therapy in the management of neck pain: a systematic review and meta- 
analysis of randomised placebo or active-treatment controlled trials. The Lancet, 374(9705), 1897-1908.

[96] Baxter, G. D., Bleakley, C., \& McDonough, S. (2008). Clinical effectiveness of laser acupuncture: a systematic review. Journal of acupuncture and meridian studies, 1(2), 6582.

[97] de Paula Eduardo, C., \& Gouw-Soares, S. (2001). The use of lasers for endodontic applicationsin dentistry. Medical laser application, 16(3), 231-243.

[98] Apfelberg D 1992 Laser-assisted liposuction may benefit surgeons and subjects. Clinical laser monthly 10:259

[99] Sandra Tagliolatto, Vanessa Barcellos Medeiros, Oriette Gerin Leite (2012) Laserlipolysis: update and literature review-review article. Surg cosmet dermatol, 4(2), $164-74$.

[100] Rojas, J. C., \& Gonzalez-Lima, F. (2011). Low-level light therapy of the eye and brain. Eye Brain, 3, 49-67.

[101] Kara, T. (1999). Primary and secondary mechanisms of action of visible to near-IR radiations on cells. Journal of photochemistry and photobiology B: biology, 49, 1-17.

[102] Passarella, S., Casamassima, E., Molinari, S., Pastore, D., Quagliariello, E., Catalano, I. M., \& Cingolani, A. (1984). Increase of proton electrochemical potential and ATP synthesis in rat liver mitochondria irradiated in vitro by helium-neon laser. FEBS letters, 175(1), 95-99.

[103] Karu, T., Pyatibrat, L., \& Kalendo, G. (1995). Irradiation with He-Ne laser increases ATP level in cells cultivated in vitro. Journal of photochemistry and photobiology B: biology, 27(3), 219-223.

[104] Mochizuki-Oda, N., Kataoka, Y., Cui, Y., Yamada, H., Heya, M., \& Awazu, K. (2002). Effects of near-infra-red laser irradiation on adenosine triphosphate and adenosine diphosphate contents of rat brain tissue. Neuroscience letters, 323(3), 207-210.

[105] Amat, A., Rigau, J., Nicolau, R., Aalders, M., Fenoll, M. R., van Gemert, M., \& Tomàs, J. (2004). Effect of red and near-infrared laser light on adenosine triphosphate (ATP) in the luciferin-luciferase reaction. Journal of photochemistry and photobiology A: chemistry, 168(1), 59-65.

[106] Benedicenti, S., Pepe, I. M., Angiero, F., \& Benedicenti, A. (2008). Intracellular ATP level increases in lymphocytes irradiated with infrared laser light of wavelength $904 \mathrm{~nm}$. Photomedicine and laser surgery, 26(5), 451-453. 
[107] Lapchak, P. A., \& De Taboada, L. (2010). Transcranial near infrared laser treatment (NILT) increases cortical adenosine-5'-triphosphate (ATP) content following embolic strokes in rabbits. Brain research, 1306, 100-105.

[108] Oron, U., Ilic, S., De Taboada, L., \& Streeter, J. (2007). Ga-As (808 nm) laser irradiation enhances ATP production in human neuronal cells in culture. Photomedicine and laser surgery, 25(3), 180-182.

[109] Kujawa, J., Zavodnik, L., Zavodnik, I., Buko, V., Lapshyna, A., \& Bryszewska, M. (2004). Effect of low-intensity $(3.75-25 \mathrm{~J} / \mathrm{cm} 2)$ near-infrared $(810 \mathrm{~nm})$ laser radiation on red blood cell ATPase activities and membrane structure. Journal of clinical laser medicine \& surgery, 22(2), 111-117.

[110] Peplow, P. V., Chung, T. Y., Ryan, B., \& Baxter, G. D. (2011). Laser photobiomodulation of gene expression and release of growth factors and cytokines from cells in culture: a review of human and animal studies. Photomedicine and laser surgery, 29(5), 285-304.

[111] Masha, R. T., Houreld, N. N., \& Abrahamse, H. (2013). Low-intensity laser irradiation at $660 \mathrm{~nm}$ stimulates transcription of genes involved in the electron transport chain. Photomedicine and laser surgery, 31(2), 47-53.

[112] Wagner, V. P., Curra, M., Webber, L. P., Nör, C., Matte, U., Meurer, L., \& Martins, M. D. (2016). Photobiomodulation regulates cytokine release and new blood vessel formation during oral wound healing in rats. Lasers in medical science, 1-7.

[113] Wagner, V. P., Meurer, L., Martins, M. A. T., Danilevicz, C. K., Magnusson, A. S., Marques, M. M., ... \& Martins, M. D. (2013). Influence of different energy densities of laser phototherapy on oral wound healing. Journal of biomedical optics, 18(12), 128002.

[114] Poyton, R. O., \& Ball, K. A. (2011). Therapeutic photobiomodulation: nitric oxide and a novel function of mitochondrial cytochrome c oxidase. Discovery medicine, 11(57), 154-159.

[115] Gagliardi, S., Atlante, A., \& Passarella, S. (1997). A novel property of adenine nucleotides: Sensitivity to helium-neon laser in mitochondrial reactions. IUBMB Life, 41(3), 449-460.

[116] Karu, T. (2010). Mitochondrial mechanisms of photobiomodulation in context of new data about multiple roles of ATP. Photomedicine and laser surgery, 28(2), 159-160.

[117] Jacques, S. L. (2013). Optical properties of biological tissues: a review. Physics in medicine and biology, 58(11), R37. 
[118] Hawkins, D., \& Abrahamse, H. (2007). How long after laser irradiation should cellular responses be measured to determine the laser effect? Journal of laser applications, 19(2), 74-83.

[119] Su, Y. A., Wu, J., Zhang, L., Zhang, Q., Su, D. M., He, P., Wang, B.D., Li, H., Webster, M.J., Rennert, O.M. \& Ursano, R. J. (2008). Dysregulated mitochondrial genes and networks with drug targets in postmortem brain of patients with posttraumatic stress disorder (PTSD) revealed by human mitochondria-focused cDNA microarrays. International journal of biological sciences, 4(4), 223.

[120] Hayworth, C. R., Rojas, J. C., Padilla, E., Holmes, G. M., Sheridan, E. C., \& Gonzalez-Lima, F. (2010). In Vivo low-level light therapy increases cytochrome oxidase in skeletal muscle. Photochemistry and photobiology, 86(3), 673-680.

[121] Huang, Y. Z., Sommer, M., Thickbroom, G., Hamada, M., Pascual-Leonne, A., Paulus, W., Classen, J., Peterchev, A.V., Zangen, A. \& Ugawa, Y. (2009). Consensus: New methodologies for brain stimulation. Brain stimulation, 2(1), 2-13.

[122] McKinley, R. A., Bridges, N., Walters, C. M., \& Nelson, J. (2012). Modulating the brain at work using noninvasive transcranial stimulation. Neuroimage, 59(1), 129-137.

[123] Cassano, P., Cusin, C., Mischoulon, D., Hamblin, M. R., De Taboada, L., Pisoni, A., Chang, T., Yeung, A., Ionescu, D.F., Petrie, S.R. \& Nierenberg, A. A. (2015). Nearinfrared transcranial radiation for major depressive disorder: proof of concept study. Psychiatry journal, 2015.

[124] Sauleau, P., Lapouble, E., Val-Laillet, D., \& Malbert, C. H. (2009). The pig model in brain imaging and neurosurgery. Animal, 3 (08), 1138-1151.

[125] Lind, N. M., Moustgaard, A., Jelsing, J., Vajta, G., Cumming, P., \& Hansen, A. K. (2007). The use of pigs in neuroscience: modeling brain disorders. Neuroscience \& bio behavioral reviews, 31(5), 728-751.

[126] Bayés, À., Collins, M. O., Croning, M. D., van de Lagemaat, L. N., Choudhary, J. S., \& Grant, S. G. (2012). Comparative study of human and mouse postsynaptic proteomes finds high compositional conservation and abundance differences for key synaptic proteins. PloS one, 7(10), e46683.

[127] Vandal, M., Alata, W., Tremblay, C., Rioux-Perreault, C., Salem, N., Calon, F., \& Plourde, M. (2014). Reduction in DHA transport to the brain of mice expressing human APOE4 compared to APOE2. Journal of neurochemistry, 129(3), 516-526.

[128] Patergnani, S., Baldassari, F., De Marchi, E., Karkucinska-Wieckowska, A., Wieckowski, M. R., \& Pinton, P. (2014). Methods to monitor and compare mitochondrial and glycolytic ATP production. Methods in enzymology, 542, 313-332. 
[129] Tiina Karu (2007) Ten lectures on basic science of laser phototherapy, Prima book publications

[130] Mahinda, H. A. M., \& Murty, O. P. (2009). Variability in thickness of human skull bones and sternum-An autopsy experience. Journal of forensic medicine and toxicology, 26(2), 26-31.

[131] Huang, H., Zhang, J., Wakana, S., Zhang, W., Ren, T., Richards, L. J., ... \& Mori, S. (2006). White and gray matter development in human fetal, newborn and pediatric brains. Neuroimage, 33(1), 27-38.

[132] Smith, A. M., Mancini, M. C., \& Nie, S. (2009). Second window for in vivo imaging. Nature nanotechnology, 4(11), 710.

[133] Aulakh, K., Zakaib, S., Willmore, W. G., \& Winnie, N. Y. (2016, March). Transcranial light-tissue interaction analysis. In SPIE BiOS (pp. 97061B-97061B). International society for optics and photonics.

[134] Ugryumova, N., Matcher, S. J., \& Attenburrow, D. P. (2004). Measurement of bone mineral density via light scattering. Physics in medicine and biology, 49(3), 469.

[135] Salomatina, E., Jiang, B., Novak, J., \& Yaroslavsky, A. N. (2006). Optical properties of normal and cancerous human skin in the visible and near-infrared spectral range. Journal of biomedical optics, 11(6), 064026-064026.

[136] Neira, R., Arroyave, J., Ramirez, H., Ortiz, C. L., Solarte, E., Sequeda, F., ... \& Chao, J. J. (2002). Fat liquefaction: effect of low-level laser energy on adipose tissue. Plastic and reconstructive surgery, 110(3), 912-922.

[137] Anderson, R. R., \& Parrish, J. A. (1982). Optical properties of human skin. In The science of photomedicine (pp. 147-194). Springer US.

[138] Karu, T. I. (2008). Mitochondrial signaling in mammalian cells activated by red and near-IR radiation. Photochemistry and photobiology, 84(5), 1091-1099.

[139] Lusardi, T. A. (2009). Adenosine neuromodulation and traumatic brain injury. Current neuropharmacology, 7(3), 228-237. 
